PALEO

Revue d'archéologie préhistorique

15 | 2003

Varia

\title{
Le mobilier funéraire de la Dame de Saint-Germain- la-Rivière (Gironde) et l'origine paléolithique des inégalités
}

Grave goods associated to the Saint-Germain-la-Rivière burial and the

Palaeolithic origin of social inequality

Marian Vanhaeren et Francesco d'Errico

\section{OpenEdition}

Journals

Édition électronique

URL : http://journals.openedition.org/paleo/1293

DOI : $10.4000 /$ paleo.1293

ISSN : 2101-0420

Éditeur

SAMRA

Édition imprimée

Date de publication : 1 décembre 2003

Pagination : 195-238

ISSN : $1145-3370$

Référence électronique

Marian Vanhaeren et Francesco d'Errico, « Le mobilier funéraire de la Dame de Saint-Germain-laRivière (Gironde) et l'origine paléolithique des inégalités », PALEO [En ligne], 15 | 2003, mis en ligne le 03 août 2010, consulté le 07 juillet 2020. URL : http://journals.openedition.org/paleo/1293 ; DOI : https://doi.org/10.4000/paleo.1293

Ce document a été généré automatiquement le 7 juillet 2020

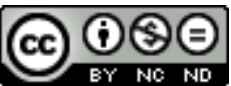

PALEO est mis à disposition selon les termes de la licence Creative Commons Attribution - Pas d'Utilisation Commerciale - Pas de Modification 4.0 International. 


\title{
Le mobilier funéraire de la Dame de Saint-Germain-la-Rivière (Gironde) et l'origine paléolithique des inégalités
}

\author{
Grave goods associated to the Saint-Germain-la-Rivière burial and the \\ Palaeolithic origin of social inequality
}

Marian Vanhaeren et Francesco d'Errico

\section{Introduction}

1 Jusqu'à la moitié du XXème siècle, la stratification sociale des sociétés du Paléolithique supérieur n'était pas considérée comme un sujet de recherche à aborder par l'étude des collections archéologiques car l'ethnographie des peuples chasseurs-cueilleurs donnait déjà toutes les réponses. Bon nombre d'ethnologues et de préhistoriens ont pendant longtemps soutenu que les sociétés de chasseurs-cueilleurs étaient par définition égalitaires et caractérisées par l'absence d'une division de travail marquée, d'un artisanat spécialisé, de richesses, d'institutions religieuses et d'une stratification sociale hormis celle imposée par les inégalités " naturelles " (c'est-à-dire l'âge et le sexe biologiques) entre individus et par la nomination temporaire d'un chef informel (Lips 1947 ; Steward 1955 ; Service 1962, 1966, Rogers 1965 ; Slobodin 1969 ; Williams 1974 et Nooter 1979).

2 Les études ethnographiques menées depuis ont cependant montré qu'il existe une forte variabilité dans l'organisation sociale de ces sociétés et que des groupes sociaux autres que biologiques et basés, selon les cas, sur la division du travail, la richesse, le pouvoir religieux ou politique - ne sont pas exclusifs des sociétés de production (Lee et DeVore 1968, Testart 1981, 1982a-b, Koyama et Thomas 1981, Price et Brown 1985, Kelly 1995, Price et Feinman 1995 et Arnold 1996). Si par exemple il est établi que toutes les 
sociétés font une distinction entre les sexes et que dans la majorité des cas cette distinction correspond à l'appartenance biologique des individus et va de pair avec des tâches sociales spécifiques (Mead 1948, McClormack et Strathern 1980, Ortner et Whitehead 1981, Caplan 1987, Mathieu 1991), l'ethnographie nous apprend aussi que dans certaines sociétés il peut y avoir divergence entre le " sexe biologique " et le " sexe social " (ou genre) et qu'il existe des sociétés avec un " troisième sexe " ou genre mixte auquel sont attribués des pouvoirs particuliers, notamment chamaniques (Désy 1978, Whitehead 1981). Selon Price (1991), ces différences de sexe ou de genre se reflètent constamment dans la parure. Mais le sexe et l'âge ne sont pas les seuls fondements de division dans ces sociétés. Certaines tribus de chasseurs-cueilleurs de la côte nord-ouest de l'Amérique du Nord présentent une hiérarchie en trois classes : les " esclaves ", les " gens du commun " et les " honorables" (Testart 1981, Donald 1997), la primauté de ces derniers se fondant sur leur munificence ostentatoire (le " potlatch ") envers les autres membres de la tribu.

3 Aujourd'hui, on admet qu'il est dangereux de faire des généralisations sur l'organisation sociale des sociétés de chasseurs-cueilleurs et que les archéologues doivent élaborer des hypothèses explicites concernant l'organisation de ces sociétés et vérifier ces dernières par l'analyse des données archéologiques. Cela n'est pas toujours aisé et, par exemple, le débat sur l'interprétation chamanique de l'art des grottes ornées en témoigne (Lewis-Williams et Dowson 1988, Parkington 1989, Clottes et LewisWilliams 1996, de Beaune 1998, Bahn 2001).

4 La distribution spatiale des vestiges découverts in situ dans des sites d'occupations tels que Pincevent (Leroi-Gourhan et Brézillon 1966, 1972, Julien et al., 1988, Julien et Rieu 1999, Bodu 1993, Taborin 1994), Gönnersdorf (Bosinski et al., 2002), Les Eglises (Delpech et Villa 1993), Meer (Cahen et Van Noten 1980) et Etiolles (Pigeot et al., 1991) a permis d'obtenir des informations sur l'organisation de l'espace domestique et proposer des hypothèses sur l'apprentissage et la division du travail. Les objets d'art mobilier ont été utilisés pour différencier les sites d'agrégation des sites d'habitat temporaire (Conkey 1984, 1987, 1992). L'étude des compétences techniques nécessaires à la réalisation de l'outillage lithique (Pigeot et al., 1991), des œuvres d'art (Vialou 1987, Lorblanchet 1995, 1997, Fritz 1999) et de la parure (Fritz et Simonnet 1996) semble indiquer l'existence dans les sociétés du Paléolithique supérieur d'artisans spécialisés consacrant sans doute une partie non négligeable de leur temps à l'apprentissage et à l'entretien de leur compétences. Une prédominance d'adolescents et adultes masculins dans les sépultures gravettiennes d'Italie a été évoquée pour proposer que les chasseurs constituaient un groupe privilégié au sein de ces sociétés (Mussi et al., 1989) mais l'attribution au sexe masculin de ces sépultures est remise en cause (Henry-Gambier 2001). Malgré l'apport de ces études, force est d'admettre que l'on sait encore relativement peu de chose sur l'organisation des sociétés de cette période.

5 L'étude des objets de parure associés à des sépultures peut contribuer à combler ce vide. A l'intérieur d'une société, la parure a souvent la fonction de marquer l'appartenance d'un individu à un ou à plusieurs groupes sociaux (Roach et Eicher 1965, Strathern et Strathern 1971, Faris 1972, Kuper 1973, Ray 1975, Tainter 1978, Corwell et Schwarz 1979, Brain 1979, Hodder 1979, 1991, Turner 1980, O'Shea 1984, Wiessner 1984, Carey 1986, 1991, Dubin 1987, Taborin 1993, Preston-Whyte 1994, Sciama et Eicher 1998, O'Hear 1998, Meisch 1998 et Vanhaeren 2002). Selon les sociétés, les groupes sociaux sont déterminés par le sexe de l'individu, par son âge (enfance, adolescence, maturité, 
vieillesse) et/ou par le franchissement, au cours de sa vie, de certaines étapes biologiques (puberté, ménopause) et relationnelles (célibat, mariage, veuvage). A cette fonction de base de la parure, commune à la plupart des sociétés traditionnelles, se superpose celle d'identifier des groupes composés par des individus partageant des liens de parenté biologiques et/ou culturels plus ou moins stricts (lignage, clan, caste, etc.) ou appartenant à la même classe sociale (hommes libres, esclaves, guerriers, aristocrates, etc.). La parure peut aussi avoir la fonction de mettre en exergue des individus ayant acquis ou hérité un statut social exclusif (chamane, chef, pape, roi, etc.).

6 Mais l'ethnographie montre également que d'une part, les objets de parure peuvent avoir un grand nombre de fonctions en dehors de celle de marqueurs sociaux et que, d'autre part, les membres d'un groupe peuvent ainsi porter des objets de parure de type différent en fonction du contexte d'utilisation (guerre, fête, rituel, funérailles, événement d'agrégation, etc.). Ces études indiquent par ailleurs que c'est souvent la combinaison et l'arrangement d'objets différents sur le corps qui sont utilisés pour communiquer ces identités. Perdue pour la plupart de ces objets, trouvés au cours de fouilles dans des sites d'habitat, cette dimension est partiellement préservée pour les parures associées à des contextes archéologiques tels que des dépôts intentionnels (cachettes, offrandes, sépultures primaires) ou accidentels mais conservant l'unité de la parure d'origine (p. ex. perte de colliers entiers). Pour extraire ces informations il est nécessaire d'organiser les données archéologiques concernant l'acquisition, la production, le port et l'abandon des parures dans un réseau d'inférences qui peut permettre d'identifier leur fonction prédominante et le rôle qu'elles ont joué dans la structuration des sociétés paléolithiques (Vanhaeren et d'Errico 2001, 2003a, 2003b; d'Errico et Vanhaeren 1999, 2000, 2002 ; Vanhaeren 2002).

7 En suivant cette démarche, nous avons récemment, à travers l'étude de la parure de l'enfant de La Madeleine (Vanhaeren et d'Errico 2001), pu mettre en évidence de longues heures passées au ramassage, à la fabrication et à l'assemblage d'ornements complexes destinés à être portés par certains jeunes enfants. Cet effort, que l'on retrouve également dans la parure des enfants de Sungir (White 1999) et de la Grotte des Enfants (Vanhaeren 2002), est certainement le reflet de l'attachement des parents ou d'un groupe familial élargi à sa progéniture; mais, remis dans le contexte d'une société traditionnelle, il doit également être mis en relation avec l'attribution d'une identité sociale distincte à l'ensemble ou à une partie des membres de cette classe d'âge. L'étalage ostentatoire de centaines, voire de milliers d'objets sur des individus qui, en considérant leur âge, n'ont pas pu acquérir un statut particulier par leurs actes, suggère l'existence, au moins embryonnaire, de lignages utilisant la parure pour se reconnaitre et s'identifier au sein du groupe.

Soumis à une telle analyse, le mobilier funéraire de la Dame de Saint-Germain-laRivière offre un important potentiel d'information sur la stratification sociale des sociétés du Paléolithique supérieur. Il est en effet associé à un seul individu, daté directement par ${ }^{14} \mathrm{C}$ AMS dont l'âge et le sexe sont estimés avec un bon degré de certitude (Gambier et al., 2000, 2002). Ce mobilier funéraire inclut la plus grande collection connue de craches de cerf associées à une inhumation individuelle et cela à une époque où cette espèce était extrêmement rare dans la région (Delpech 1983). De plus, ce mobilier provient d'un site ayant livré des couches d'occupation contemporaines de la sépulture et riches en objets de parure dont deux lots de dents 
percées, découverts groupés. La comparaison du mobilier de la sépulture avec celui découvert dans le site met en exergue le caractère exceptionnel du premier et permet de discuter la question du rôle social de l'inhumée et, de manière plus générale, le degré de complexité des sociétés du Paléolithique supérieur.

\section{Le site de Saint-Germain-la-Rivière}

9 Le site de Saint-Germain-la-Rivière est situé au lieu-dit " Pille-Bourse " sur la commune éponyme à mi-chemin entre Libourne et Saint-André-de-Cubzac en Gironde. Il se trouve en pied de falaise, face au sud, sur la rive droite de la Dordogne, qui coule actuellement 1200 mètres plus loin et 35 mètres en contrebas. Le site a été découvert en 1929 par Henri Mirande et René Lépront, membres de la Société d'Etudes Préhistoriques de Libourne, qui venait d'être créée une année auparavant (Lépront et Mirande 1933). Les deux abris adjacents, le talus intermédiaire et le talus situé à l'avant des zones abritées ont fait l'objet de plusieurs fouilles menées par Mirande et Lépront entre 1929 et 1933 (Garde 1934, 1969), par Blanchard entre 1933 et 1934 (Blanchard et al., 1972), par Trécolle entre 1963 et 1968 (Lenoir 1983 ; Lenoir et al., 1991, 1994, 1995) et par Lenoir en 1996 (1997) (fig. 1). Les fouilleurs ont mis en évidence une séquence composée de trois unités archéostratigraphiques relevant du Magdalénien (tab. 1), une frise gravée, les restes d'au moins douze individus, dont deux certainement inhumés, et deux lots d'objets de parure appelés les " colliers" Mirande. Bien que les informations publiées par les premiers fouilleurs du site soient souvent lacunaires, celles fournies par les derniers répondent aux impératifs de la recherche archéologique actuelle. 
Figure 1 - Haut : Plan du site de Saint-Germain-la-Rivière avec localisation approximative des zones fouillées, des sépultures et des restes humains isolés. Bas : Vue prise de l'ouest (à gauche) et coupe selon l'axe Nord-Sud (à droite) du grand abri.

Figure 1 - Top: Plan of the Saint-Germain-la-Rivière site with approximate location of the excavated areas, burials and isolated human remains. Bottom: View taken form the West (left) and North-South section (right) of the main shelter.
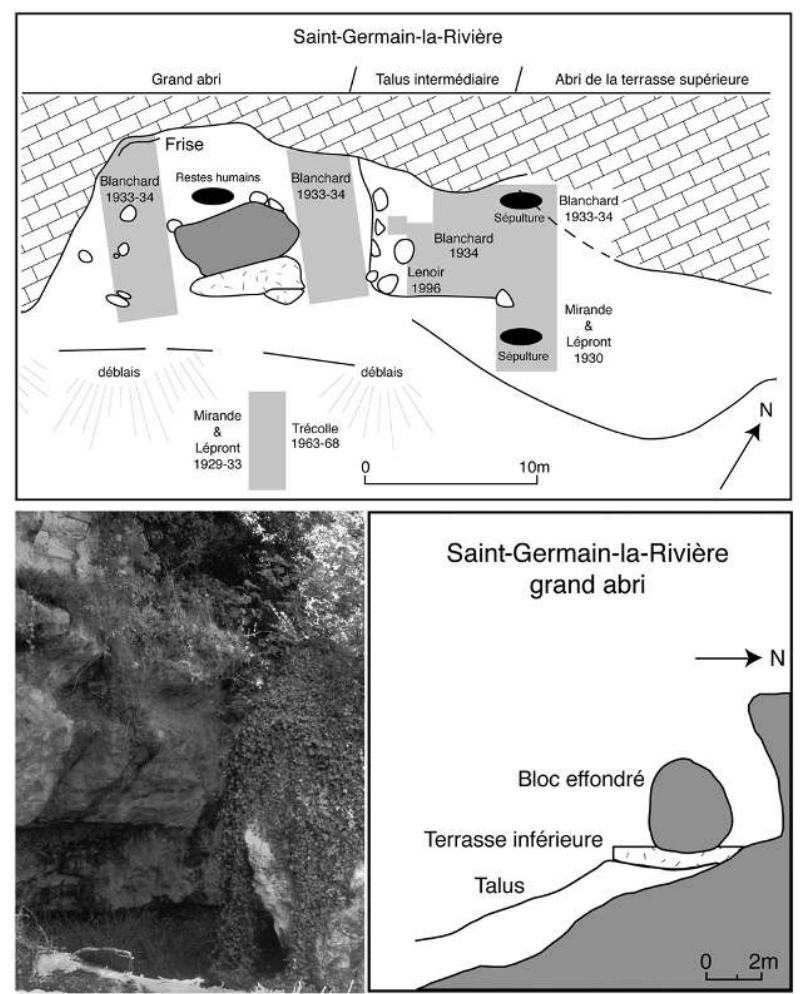

Tableau 1- Corrélation entre dates ${ }^{14} \mathrm{C}$, couches archéologiques et attributions culturelles à SaintGermain-la-Rivière

Table 1 - Correlation between ${ }^{14} \mathrm{C}$ dates, archaeological layers and their cultural attributions at the SaintGermain-la-Rivière site

\begin{tabular}{|c|c|c|c|c|}
\hline \multicolumn{3}{|c|}{ Stratigraphie } & \multirow{2}{*}{$\begin{array}{c}\text { Dates } 14 \mathrm{C} \text { BP } \\
\text { talus devant le grand abri } \\
\text { (Trécolle) }\end{array}$} & \multirow[b]{2}{*}{$\begin{array}{l}\text { Attribution } \\
\text { culturelle }\end{array}$} \\
\hline $\begin{array}{l}\text { abri de la terrasse supérieure } \\
\text { (Mirande et Blanchard) }\end{array}$ & $\begin{array}{c}\text { grand abri } \\
\text { (Blanchard) }\end{array}$ & $\begin{array}{l}\text { talus devant le grand abri } \\
\text { (Trécolle) }\end{array}$ & & \\
\hline$?$ & & & \multirow{5}{*}{$\begin{array}{l}14100 \pm 160 \text { BP (Gif 6037) } \\
15330 \pm 150 \text { BP (Gif 7345) } \\
15300 \pm 410 \text { BP (Gif 5479) }\end{array}$} & $\begin{array}{l}\text { Magdalénien } \\
\text { supérieur? }\end{array}$ \\
\hline $\begin{array}{l}\text { couche } \\
\text { unique }\end{array}$ & $\begin{array}{c}\text { couche } \\
\text { supérieure }\end{array}$ & & & \multirow[t]{2}{*}{$\begin{array}{l}\text { Magdalénien } \\
\text { moyen }\end{array}$} \\
\hline \multirow[b]{2}{*}{ ? } & stérile & & & \\
\hline & $\begin{array}{l}\text { couche } \\
\text { inférieure }\end{array}$ & $\begin{array}{c}\mathrm{C} \\
\mathrm{C} 1\end{array}$ & & $\begin{array}{l}\text { Magdalénien } \\
\text { moyen }\end{array}$ \\
\hline \multirow[t]{4}{*}{ substar } & substrat: & $\mathrm{C} 2$ & & mélange \\
\hline & & C3 & \multirow{3}{*}{$\begin{array}{l}16200 \pm 600 \text { BP (Gif 5478) } \\
16890 \pm 130 \text { BP (GifA 7260) }\end{array}$} & \multirow{3}{*}{$\begin{array}{l}\text { Magdalénien } \\
\text { ancien }\end{array}$} \\
\hline & & $\mathrm{C} 4$ & & \\
\hline & & substrat & & \\
\hline
\end{tabular}

\section{Séquence archéostratigraphique}

\section{Les occupations du Magdalénien ancien}

Un Magdalénien ancien, daté entre 17000 et 16000 BP (tab. 1) est identifié dans la tranchée Trécolle creusée dans le talus à l'avant du grand abri (couches C3-C4). L'industrie lithique est " peu laminaire mais lamellaire, riche en lamelles à dos " et en éclats (Lenoir et al., 1994 : 67). L'industrie osseuse comprend des aiguilles, des sagaies entières et fragmentées, un fragment de bâton percé, une baguette et des fragment de 
bois de renne portant des traces de sciage. Certains de ces objets portent des incisions ou des rainures (Lenoir et al., 1994). L'Antilope saïga domine l'assemblage faunique qui se complète par le Renne, le Cheval et les Bovinés (Ouzrit 1986; Costamagno 1999, 2001). La couche qui surmonte cet ensemble (couche $\mathrm{C} 2$ ) résulte d'après les fouilleurs d'un mélange entre les couches sous- et sus-jacentes.

\section{Les occupations du Magdalénien moyen}

11 Un premier ensemble de Magdalénien moyen, daté entre 16500 et 14000 BP (tab. 1) est observé dans la tranchée Trécolle (couches $\mathrm{C} 1-\mathrm{C}$ ) et dans le grand abri (couche inférieure). L'industrie lithique, laminaire, comprend des grattoirs, des grattoirsburins, des burins, des perçoirs, des pointes à cran atypiques, des lames courtes souvent larges et épaisses, des lamelles à dos, des lamelles à dos denticulées et des triangles scalènes (Blanchard et al., 1972; Lenoir 1983 ; Lenoir et al., 1991, 1994, 1995). L'industrie osseuse se compose d'aiguilles, de sagaies et fragments de sagaies (dont certaines à section ovale, biseau double et une de forme biconique), de baguettes, d'une spatule et d'os portant des incisions, rainures ou polis (Blanchard et al. op. cit.; Lenoir et al., 1994). L'art mobilier comprend un renne stylisé gravé sur un fragment de bois de renne (Dubourg 1997). La faune est semblable à celle du Magdalénien ancien. Un possible mur, des blocs calcaires avec anneaux et cuvettes, un galet utilisé, des oxydes de manganèse, des ocres jaunes et rouges et un morceau de résine sont inventoriés par Blanchard (Blanchard et al. op. cit.). Un deuxième ensemble de Magdalénien moyen est reconnu par Blanchard dans le grand abri et l'abri de la terrasse supérieure. L'industrie lithique se distingue du premier ensemble par la rareté des grattoirs et des lamelles denticulées et la plus grande variété de burins (Blanchard et al. op. cit.; de SonnevilleBordes 1960; Lenoir 1983). L'industrie osseuse est plus riche et comprend des baguettes, poinçons, aiguilles, ciseaux, sagaies à biseau simple et double, un tube en os, un bâton percé et des outils divers en os et en bois de renne (Blanchard et al., 1972). L'art mobilier se compose d'un avant-train de bouquetin sculpté sur un bâton percé et de divers objets en os présentant des décors en forme de cannelures profondes, croix, triangles, ovales et traits divers (Blanchard et al. op.cit.; de Sonneville-Bordes 1960; Lenoir 1983 ; Dubourg 1997). Des blocs calcaires à cupules et deux galets présentant une surface plane proviennent également de cet ensemble. Les deux ensembles du Magdalénien sont séparés sous le grand abri par une couche stérile.

\section{Les occupations du Magdalénien supérieur ou de l'Azilien}

12 La découverte d'un harpon à double rang de barbelures (Blanchard et al. op. cit.) et d'un assemblage faunique dominé par le Cheval et comportant aussi du Cerf et du Sanglier (Blanchard et al. op. cit.; Garde 1946) suggère une occupation du Magdalénien supérieur ou de l'Azilien en sommet de séquence dans l'abri de la terrasse supérieure.

\section{Le talus intermédiaire}

13 Les dépôts situés dans le talus entre les deux abris se composent d'un amoncellement de fragments de crâne et d'os longs, parfois en connexion anatomique, de Cheval, de Bœuf et de Cerf ainsi que de restes de Rongeurs (Blanchard et al., 1972). Le talus est interprété par Blanchard comme " une réserve de viande " (Blanchard et al. op. cit. : 42). En 1997, Lenoir identifie également de gros ossements dans le talus qu'il interprète en 
revanche comme provenant soit de fouilles anciennes, soit du secteur situé au-dessus du gisement qui a été exploité comme carrière.

\section{L'art rupestre}

14 La frise gravée (Courty 1957; Leroi-Gourhan 1965; Breuil dans Blanchard et al., 1972 : 32-33; Bouvier et Trécolle 1966 ; Dubourg 1997) a été découverte sous les éboulis, sur la paroi dans la zone ouest du grand abri lors de la campagne de fouille menée par Blanchard (fig. 1). L'abbé Breuil repérait parmi les traits un arrière-train de cheval acéphale et un animal indéterminable. Bouvier et Trécolle identifient par contre ce dernier comme un anthropomorphe et les traits restant comme appartenant à l'arrièretrain d'un autre animal acéphale, peut-être un Bovidé, associés à des signes.

\section{Vestiges humains}

15 Un premier squelette a été découvert devant l'abri de la terrasse supérieure (fig. 1) en 1930 par Mirande et Lépront (Garde 1934, 1969). Ce squelette en position repliée était très mal conservé et seuls quelques restes fragmentaires de la calotte crânienne et de la mandibule ont été récupérés. L'étude de Vallois montre qu'ils appartiennent à un homme de 40-50 ans (Blanchard et al., 1972). La deuxième sépulture, connue sous le nom de Dame de Saint-Germain-la-Rivière a été découverte en 1934 par Blanchard à l'aplomb de la voûte de l'abri de la terrasse supérieure (fig. 1), une dizaine de mètres plus au nord de la première (Blanchard s.d., 1935 ; Garde 1969, Blanchard et al., 1972). Le squelette a été attribué à une jeune femme adulte (Riquet 1959; Blanchard et al., 1972), ce qui a été confirmé par une étude récente (Gambier et al., 2002). Des fragments de crânes et de mandibules appartenant à un homme, à une jeune femme et à trois enfants de 6 à 8 ans proviennent de la couche supérieure du secteur (fig. 1) laissé comme témoin par Blanchard entre le gros bloc et la paroi du grand abri (Blanchard et al., 1972 : annexe). Un inventaire plus récent de l'ensemble des restes humains (Gambier et Lenoir 1991) dénombre les restes d'au moins douze individus dont six adultes et six enfants.

\section{Les " colliers" Mirande}

Deux ensembles d'objets de parure, l'un composé de " 22 craches de cerf biforées " et l'autre de " 55 incisives de renne perforées d'un trou " (Garde 1946), font partie de la collection Mirande conservée au Musée de la Société Historique et Archéologique de Libourne. La provenance stratigraphique de ces ensembles est inconnue. Selon Garde, membre de cette société, les colliers auraient été découverts dans le grand abri, en dessous du grand rocher (Garde 1946: 72). Cette zone était inaccessible avant les fouilles effectuées par Blanchard. Les " colliers " proviendraient donc de fouilles menées après 1934. Un autre mystère qui entoure la découverte de ce matériel concerne la date d'entrée de ces " colliers" au Musée. Quand en 1937, Mirande fait don de ses collections au Musée, ces “ colliers ” n'en font pas partie. Ce n'est qu'en 1945 que Mirande fait, au cours d'une réunion de la Société, une communication les concernant, relatée par Garde (1945). Ils sont inscrits dans l'inventaire du Musée en 1946 (Garde 1946) sans que l'on sache précisément de quelle façon et à quelle date ils ont été acquis par cette institution. Nous savons, grâce au compte-rendu d'un visiteur anonyme, que 
ces colliers étaient exhibés à côté des craches de cerf de la sépulture lors de l'exposition commémorative consacrée à la découverte du gisement, organisée à Libourne en 1969 (Garde 1969).

\section{La sépulture de la dame de Saint-Germain-la-Rivière}

La fouille de cette inhumation, menée par Blanchard, Neuville et Chauveau (Blanchard et al., 1972), a mis en évidence une structure composée de quatre blocs soutenant deux dalles qui semblaient protéger la défunte (fig. 2). La plus grande dalle est pourvue d'un anneau situé à l'aplomb du crâne. La petite dalle protégeait les membres inférieurs. Deux blocs supplémentaires calent les piliers soutenant la grande dalle. Le corps reposait les membres fléchis et en décubitus latéral gauche sur le substrat rocheux, la tête, recouverte de la main droite, à l'est, les pieds à l'ouest (Blanchard et al. op. cit.). La conservation des connexions anatomiques suggère que le corps a été recouvert de sédiment avant sa décomposition (Gambier et al., 2000). Blanchard (Blanchard s.d., Blanchard et al., 1972) mentionne comme mobilier funéraire (tab. 2) " deux poignards " en bois de cervidé (fig. $3 \mathrm{a}-\mathrm{b}$ ), " une côte de Cervidé " fendue et perforée qu'il interprète comme un " passe-lien " (fig. 3 c), " des Trivia ", " une Cypraea ", " 70 canines de renne et de cerf perforées ", " des instruments en silex " (burins, grattoirs, lames, lamelles à bord abattu, etc.) et " un gros nucléus en forme lenticulaire " (fig. 4). L'emplacement exact du mobilier funéraire n'est pas connu. En 1935, Blanchard écrit que celui-ci “ dents, coquillage, armes reposait à l'aplomb de ce qui fut le ventre et les reins de l'ensevelis ". En 1972 il affirme que les outils en os auraient été " placés sur le squelette", les coquillages trouvés "à la hauteur du bassin", les dents perforées " formaient vraisemblablement un collier", et les outils lithiques semblent avoir été trouvés mélangés aux éléments du collier (Blanchard s.d., Blanchard et al., 1972). D'après l'auteur (Blanchard et al., 1972) l'ocre était omniprésente sur le squelette, sur le mobilier funéraire, sur les nombreux ossements de rongeurs découverts autour de ceux-ci et imprégnait le sédiment environnant. Blanchard relie au rite funéraire un foyer et un certain nombre de restes osseux trouvés à proximité de la sépulture (fig. 5). Le foyer s'étalait apparemment au dessus et autour de la grande dalle couvrant le squelette. Les restes osseux comprenaient " des fragments de cornes de bovidé", un frontal de bovidé muni de ses chevilles osseuses, "des massacres de chevaux, et des bois de renne". Touché par la complexité de la structure funéraire et la richesse du mobilier, Blanchard proposa que le personnage inhumé devait être "vénéré de sa tribu " (Blanchard et al. op. cit.). Une date 14C AMS effectuée sur une côte (Gambier et al., 2000), situe la mort de l'individu vers $15780 \pm 200$ BP (GifA 95456). 
Figure 2 - Plan (en haut) et squelette photographié in situ (en bas) de la sépulture de la Dame de Saint-Germain-la-Rivière (d'après Blanchard et al., 1972).

Figure 2 - Plan (top) and in situ photograph (bottom) of the Saint-Germain-la-Rivière burial (after Blanchard et al., 1972).
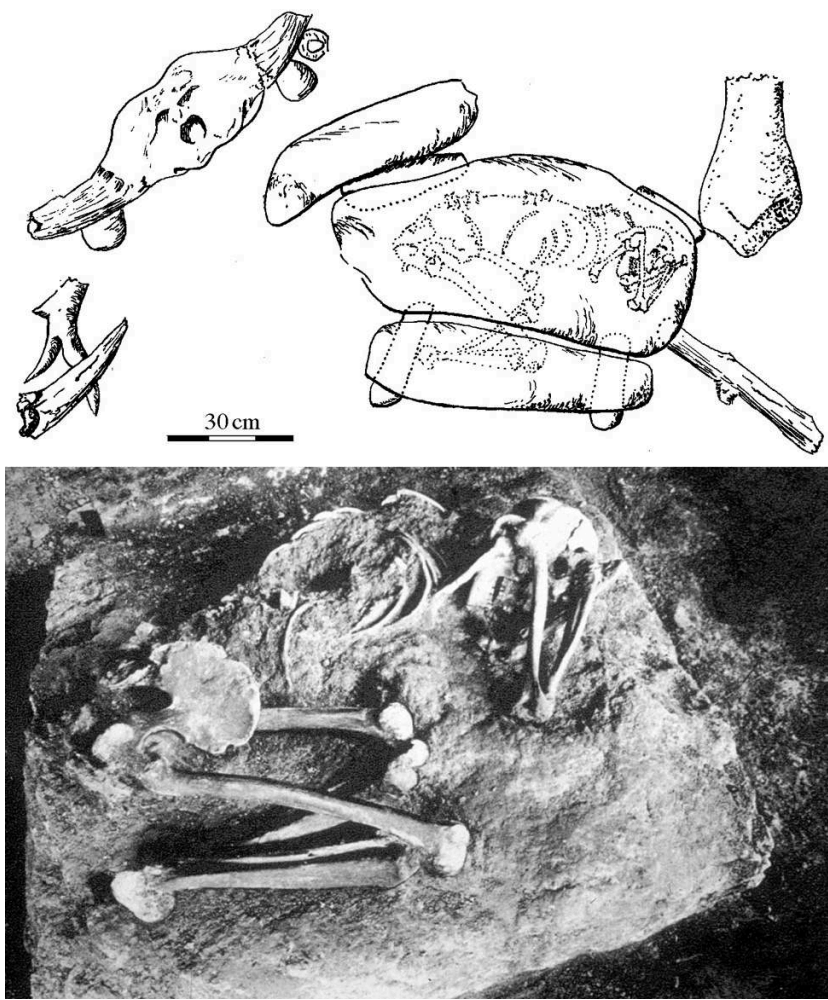
Figure 3 - Outils en os découverts près du squelette de la Dame de Saint-Germain-la-Rivière, à l'intérieur de la structure en pierre.

Figure 3 - Bone tools found near the Saint-Germain-la-Rivière skeleton, inside the stone structure.

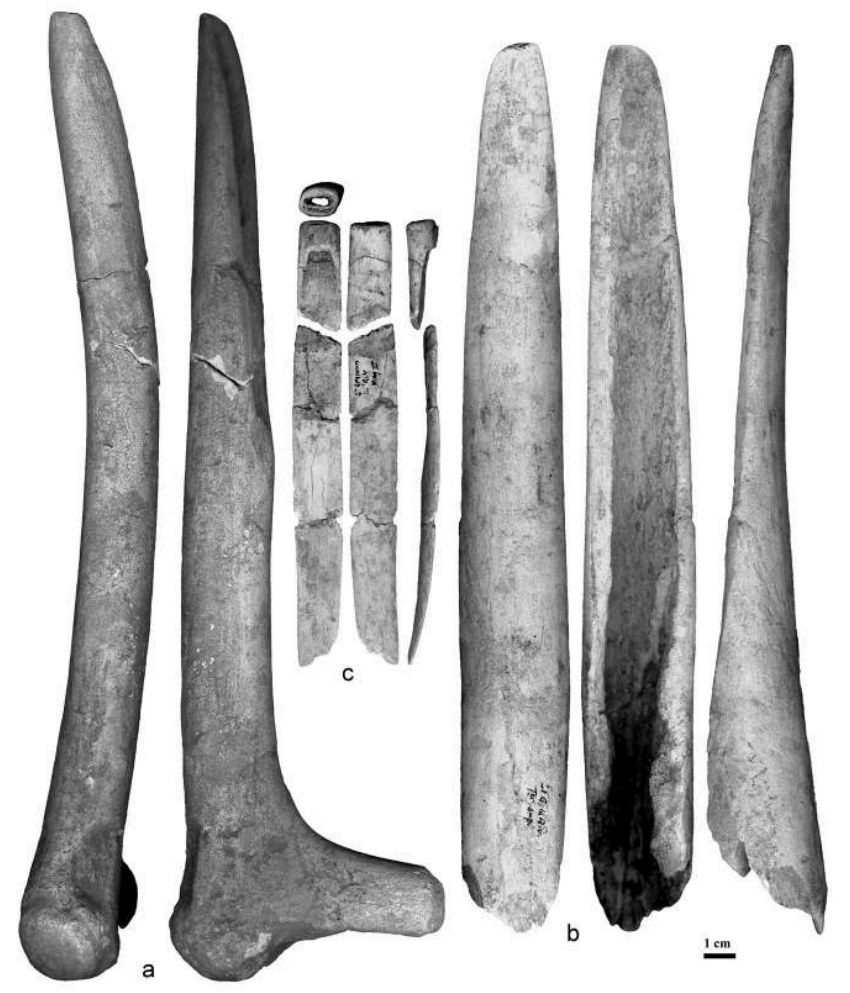

a-b : "poignards ", c : côte de cervidé $a-b$ : "daggers", c : sawn deer rib. 
Figure 4 - Outillage lithique découvert près du squelette de la Dame de Saint-Germain-la-Rivière, à l'intérieur de la structure en pierre.

Figure 4 - Stone tools found near the Saint-Germain-la-Rivière skeleton, inside the stone structure.

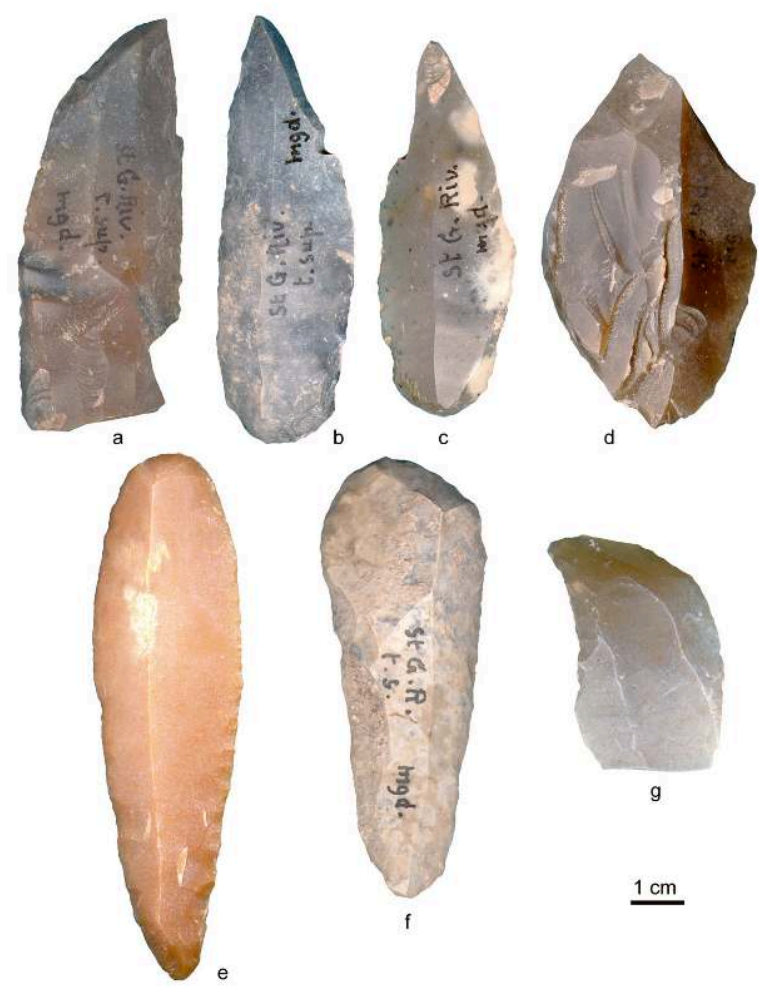

a: burin multiple, b,c: grattoir-burin, d: burin, e,f: grattoir, g: bec. a: multiple burin, b,c: scraper-burin, d: burin, e,f: scraper, g: bec 
Figure 5 - Restes osseux ocrés découverts à proximité de la sépulture de la Dame de SaintGermain-la-Rivière.

Figure 5 - Ocred faunal remains found near the Saint-Germain-la-Rivière burial.

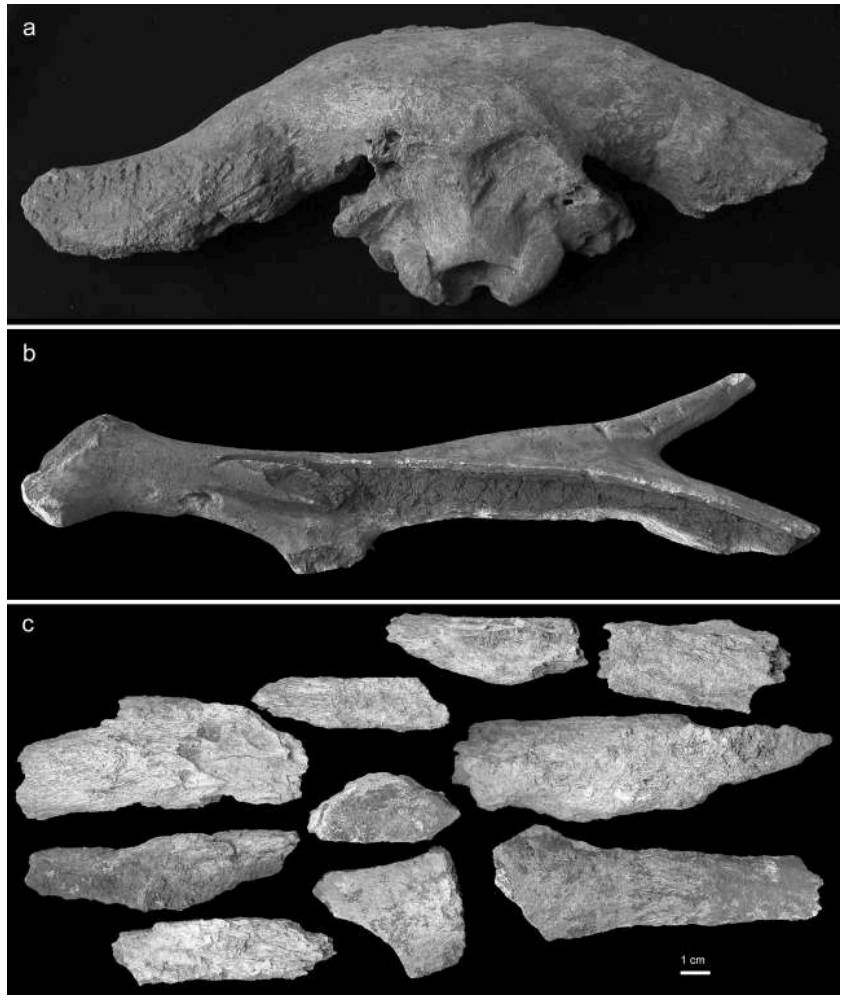

a : crâne de bison ; $b$ : bois de renne avec marques d'extraction ; $c$ : fragments de cheville osseuse. $a$ : bison skull, $b$ : split reindeer antler; $c$ : horn core fragments. 
Tableau 2 - Objets découverts à l'intérieur de la structure de pierre près du squelette de la Dame de Saint-Germain-la-Rivière $(\cdot=$ présent, $\cdot \cdot=$ nombreux $)$

Table 2 - Grave goods found inside the stone structure near the skeleton of the Saint-Germain-la-Rivière Lady $(\cdot=$ present,$\cdot=$ numerous $)$

\begin{tabular}{|c|c|c|c|c|}
\hline & Mobilier funéraire & Blanchard & Retrouvé & Manquant \\
\hline \multirow{4}{*}{ 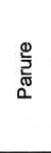 } & Trivia europea & - & 3 & _ \\
\hline & Cypraea & 1 & - & 1 \\
\hline & Perle en stéatite & - & 1 & - \\
\hline & Croche de cerf & 70 & 71 & 1 \\
\hline \multirow{2}{*}{ 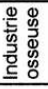 } & Côte de cervidé & 1 & 1 & - \\
\hline & Poignard en bois de cervidé & 2 & 2 & - \\
\hline \multirow{5}{*}{ 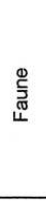 } & Métatarsien de renne & 1 & - & 1 \\
\hline & Métatarsien d'antilope saïga & 1 & - & 1 \\
\hline & Phalange d'antilope saïga & - & 1 & - \\
\hline & Mâchoire de renard & 1 & - & 1 \\
\hline & Ossements de rongeurs & - & _ & - \\
\hline \multirow{9}{*}{ 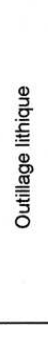 } & Lame & - & - & - \\
\hline & Lame à encoche & - & - & - \\
\hline & Lamelle à dos & _ & - & _- \\
\hline & Burin & _ & 2 & - \\
\hline & Grattoir & _ & 2 & - \\
\hline & Grattoir-burin & _ & 2 & - \\
\hline & Bec tranchant & _ & 1 & - \\
\hline & Nucléus & _ & - & _ \\
\hline & Total & $>86$ & 86 & $>9$ \\
\hline
\end{tabular}

\section{Le mobilier funéraire}

Quatre-vingt six objets provenant de cette sépulture sont conservés dans les réserves du Musée National de Préhistoire (tab. 2, fig. 6). En comparant cet inventaire à la description dressée par Blanchard (Blanchard s.d., Blanchard et al., 1972), on remarque l'absence d'une cyprée, d'un métatarsien de renne, d'une mâchoire de renard et de quatre pièces lithiques. Parmi les dents perforées, nous avons identifié exclusivement des craches de cerfs. Il est probable que les "canines de renne " citées par Blanchard ne soient pas perdues mais correspondent en réalité aux craches de biche. Cela est d'autant plus probable que le nombre de dents de la collection coïncide à peu près à celui donné par Blanchard. De plus, l'idée erronée selon laquelle seuls les cerfs mâles possèdent des craches a été très souvent répandue et même citée dans une publication en rapport direct avec cette collection (Garde, 1969). Bien que nous ayons repéré une canine de plus que le nombre indiqué par Blanchard, la comparaison entre nos craches et celles figurées dans la monographie du site révèle qu'une crache supplémentaire manque à l'appel (fig. 6 encadré). En revanche, nous avons découvert, mêlée aux craches, une perle allongée en stéatite (fig. $6 \mathrm{n}^{\circ} 72$ ). Blanchard affirme que de nombreuses Trivia se seraient "transformées en poussière" lors de la mise au jour du squelette. Nous avons cependant retrouvé trois de ces coquillages dans la collection du Musée. Une phalange d'Antilope saïga, non mentionnée par Blanchard, semble également faire partie du mobilier funéraire. 
Figure 6 - Objets de parure associés à la sépulture de la Dame de Saint-Germain-la-Rivière. Figure 6 - Personal onaments associated to the Saint-Germain-la-Rivière burial.

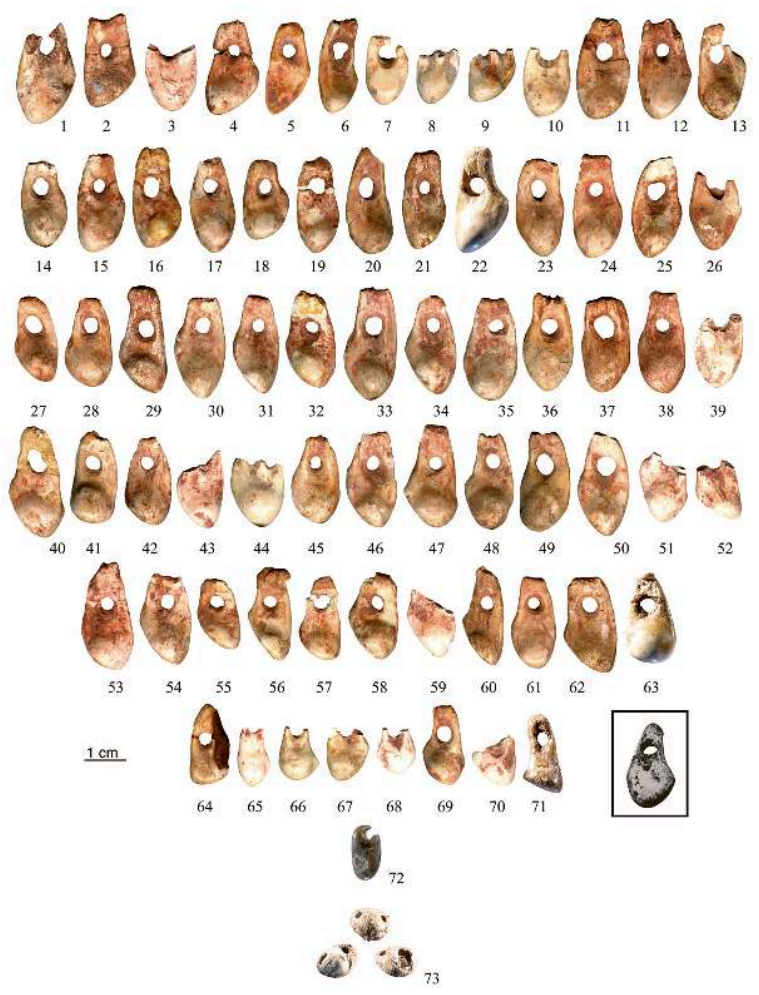

1-71: craches de cerf, 72 : perle en stéatite, 73 : Trivia europea, encadré : crache de biche figurée par Blanchard (Blanchard et al., 1972) non retrouvée dans la collection du Musée National de Préhistoire (Les Eyzies-de-Tayac). Toutes les craches sont figurées en vue vestibulaire sauf celle encadrée, présentée en vue linguale.

1-71: red deer canines, 72: steatite bead, 73: Trivia europea, framed: hind canine figured by Blanchard (Blanchard et al., 1972) not found in the collections of the Musée National de Préhistoire (Les Eyzies-deTayac). With the exception of the framed specimen, which is represented in lingual view, all the others are figured in buccal view.

\section{Les craches de cerf}

\section{Etat de conservation}

19 Dix-neuf des 71 craches manquent d'une partie $(n=3)$ ou de la totalité $(n=16)$ de la racine. Des 53 craches restantes, 18 présentent un excellent état de conservation, 10 sont entières mais avec la racine recollée et 25 présentent des petites fractures ou des écaillements. Les craches cassées ont souvent des fractures nettes, localisées au niveau de la perforation, qui rappellent celles des craches entières recollées. Ce fait et l'absence de patine sur les fractures indique qu'il s'agit de cassures postdépositionnelles récentes.

\section{Identification du sexe et latéralisation}

La totalité des craches présentent un état de conservation permettant l'indentification du sexe avec la méthode proposée par d'Errico et Vanhaeren (2002). L'application de cette méthode révèle une forte prépondérance des craches de cerfs mâles ( $88 \%$ ) (tab. 3 , fig. $6 \mathrm{n}^{\circ}$ 1-63). La crache figurée par Blanchard, manquante dans la collection du Musée, était une crache de biche. La latéralisation des dents indique, chez les deux sexes, une 
légère prédominance de craches droites. La recherche systématique d'appariements a permis d'identifier cinq paires de craches provenant chacune d'un même cerf mâle et une paire provenant d'une même biche (fig. 7). La prise en compte de ces appariements donne un nombre minimal d'individus de 58 mâles et 8 biches soit 66 individus au total. De ces derniers, $84 \%$ ne sont représentés que par leur canine gauche ou droite. Le rapport entre la largeur et l'épaisseur des racines (fig. 8) confirme l'identification du sexe fondée sur la morphologie dentaire : les trois craches de biches entières ont des racines plus étroites que celles des cerfs mâles comme ce que l'on observe systématiquement dans les populations actuelles (d'Errico et Vanhaeren op. cit.).

Tableau 3 - Composition de la collection de craches associées à la sépulture de Saint-Germain-laRivière (en haut) et du " collier" de craches de la collection Mirande (en bas). ( )= non retrouvée. Table 3 - Composition of the red deer canine collection associated to the Saint-Germain-la-Rivière burial (top) and of the red deer canine "necklace" from the Mirande collection (bottom). ( ) = not found.

\begin{tabular}{|c|c|c|c|c|c|c|}
\hline \multirow[b]{2}{*}{ Sexe } & \multirow[b]{2}{*}{ Nombre } & \multirow[b]{2}{*}{ Décorées } & \multicolumn{2}{|c|}{ Latéralisation } & \multirow[b]{2}{*}{ N. pairs } & \multirow[b]{2}{*}{ NMI } \\
\hline & & & Gauche & Droite & & \\
\hline \multicolumn{7}{|l|}{ Sépulture } \\
\hline Biche & $8+(1)$ & 3 & 4 & 5 & 1 & 8 \\
\hline Cerf mâle & 63 & 42 & 26 & 37 & 5 & 58 \\
\hline Total & 72 & 44 & 30 & 42 & 6 & 66 \\
\hline \multicolumn{7}{|c|}{ "Collier" Mirande } \\
\hline Biche & 10 & 4 & 3 & 7 & 0 & 10 \\
\hline Cerf mâle & 12 & 4 & 10 & 2 & 0 & 12 \\
\hline Total & 22 & 8 & 13 & 9 & 0 & 22 \\
\hline
\end{tabular}

Figure 7 - Craches appariées de la sépulture de Saint-Germain-la-Rivière. Figure 7 - Paired red deer canines from the Saint-Germain-la-Rivière burial.
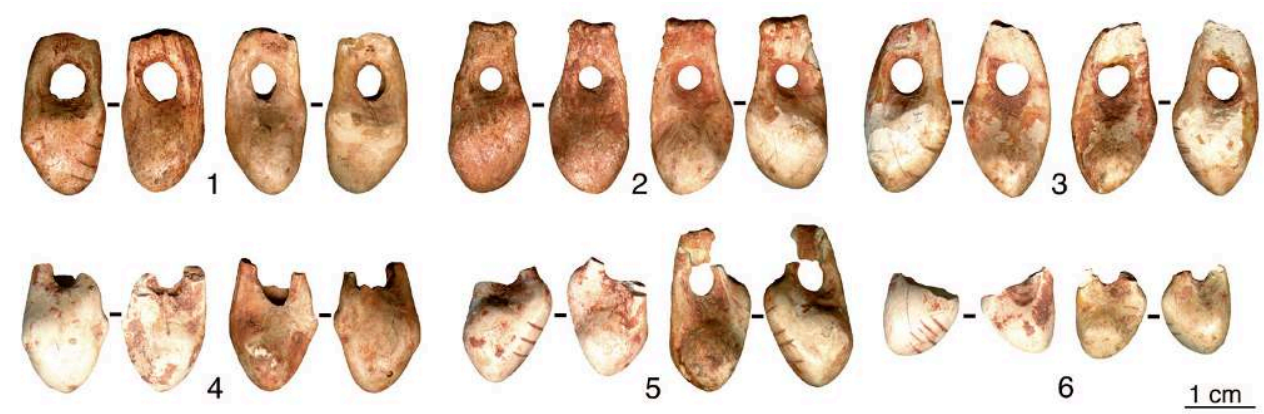

1-5: canines ayant appartenu à des cerfs mâles, 6 : paire provenant d'une biche. Chaque paire est représentée, de gauche à droite, par la face linguale et vestibulaire de la crache droite et par la face vestibulaire et linguale de la crache gauche.

7-5: stag canines, 6: pair of canines from a hind. For each pair we represent, from left to right, the lingual and buccal aspect of the right canine and the buccal and lingual aspect of the left canine. 
Figure 8 - Diagramme en nuage de points du diamètre mésio-distal sur le diamètre vestibulo-lingual des racines des craches de Saint-Germain-la-Rivière.

Figure 8 - Scattergram of root width against root thickness of the red deer canines from the SaintGermain-la-Rivière burial.

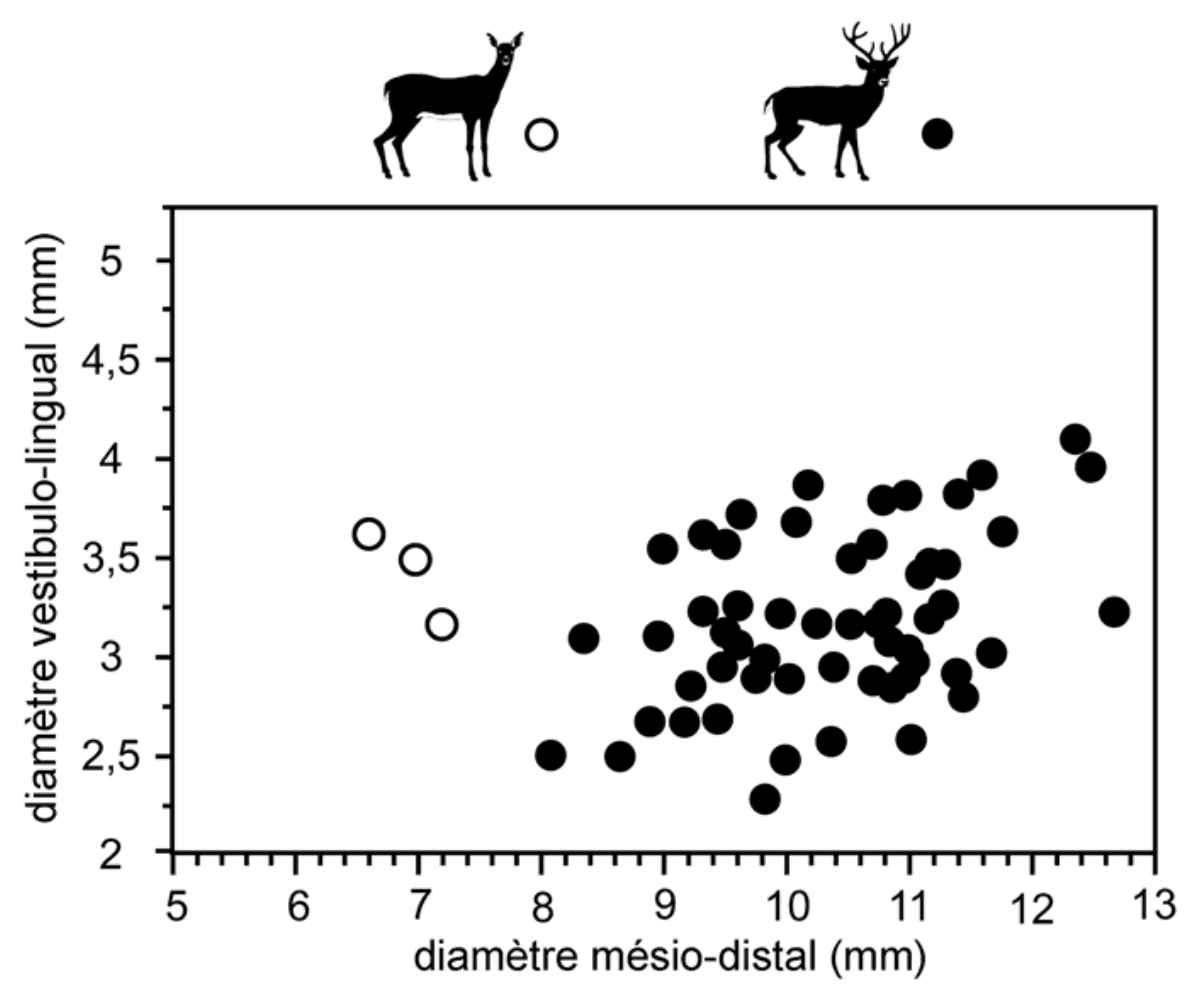

\section{Estimation de l'âge}

Deux méthodes ont été appliquées pour estimer l'âge des cerfs qui ont fourni les craches perforées ${ }^{1}$. La première, basée sur des stades d'usure de la couronne (d'Errico et Vanhaeren 2002), indique qu'un tiers environ des craches de mâle provient d'animaux dont l'âge est compris entre 2 et 4 ans (stade 1), un tiers de cerfs adultes âgés de 4-6 ans (stade 2) et un dernier tiers d'individus de 6-12 ans (stade 3), les vieux mâles (stade 4-5) étant rares (fig. 9). Cette attribution est confirmée par la méthode morphométrique, applicable aux craches avec une facette d'usure occlusale (stades d'usure 2-5), qui indique une préférence pour des mâles plus jeunes que 9 ans et surtout pour des jeunes mâles de moins de 5 ans. Quatre-vingts pour cent des craches de mâles appartiennent à des animaux de moins de 6 ans (fig. 9 e-f). Les huit craches de biche appartiennent à des individus de tous âges, indiquant que la chasse aux femelles ne se cantonnait pas exclusivement à une classe d'âge particulière. La très faible représentation de mâles âgés peut être interprétée comme la démonstration du faible rôle joué par la chasse de mâles dominants pendant ou à la fin de la période du rut, face à une chasse menée tout au long de l'année sur des mâles jeunes et moins expérimentés. L'hypothèse alternative est celle d'une sélection, dictée par une préférence culturelle pour les craches de jeunes mâles, aux couronnes non endommagées par l'usure. 
Figure 9 - Estimation de l'âge des cerfs à partir des craches de cerfs mâles (à gauche) et de biches (à droite) associées à la sépulture de Saint-Germain-la-Rivière.

Figure 9 - Age estimation of the stags (left) and hinds (right) from the canines associated to the SaintGermain-la-Rivière burial.
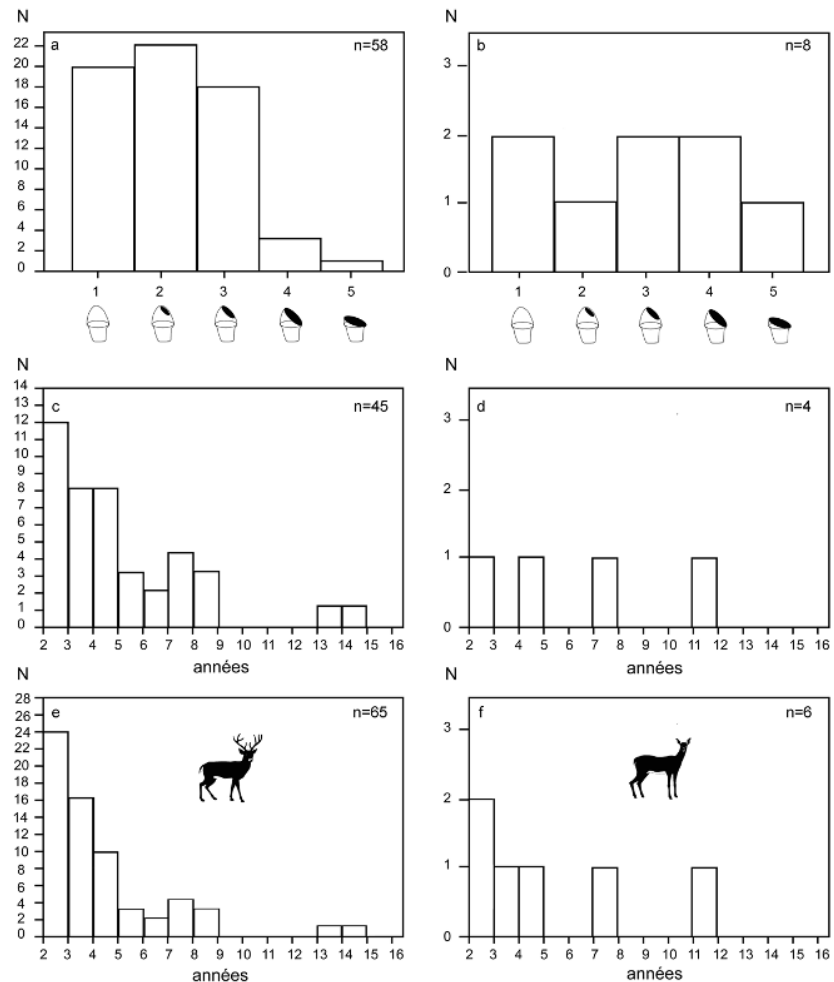

a-b: estimation de l'âge basée sur la méthode des stades d'usure (mâles: stade 1: 2-4 ans, stade 2: 4-7 ans, stade 3: 7-11 ans, stade 4: 10-13 ans, stade 5: 12-16 ans; biches: stade 1: 2-4 ans, stade 2: 4-9 ans, stade 3: 9-13 ans, stade 4: 12-14 ans, stade 5: 14-20 ans); c-d: estimation de l'âge sur la base de critères métriques, e-f: profil d'âge combinant c-d et l'estimation de l'âge des craches pour lesquelles seule la méthode morphologique a pu être appliquée.

$a-b$ : age estimation based on crown wear stages (stags: stage 1: 2-4 years, stage 2: 4-7 years, stage 3: 7-17 years, stage 4: 10-13 years, stage 5: $12-16$ years; hinds: stage 1: 2-4 years, stage 2: 4-9 years, stage 3: 9-13 years, stage 4: 12-14 years, stage 5: 14-20 years), c-d: age estimation based on metric criteria, e-f: age profile combining $(c-d)$ and the age estimates of canines to which only the method of the stages of wear can be applied.

\section{Perforations}

A l'exception de trois craches de mâles présentant une double perforation (fig. $6 \mathrm{n}^{\circ}$ 8-9 et 44 ), toutes les autres dents possèdent une perforation unique, localisée au centre de la racine. Cette perforation a été réalisée par une rotation exercée sur les faces vestibulaire et linguale de la dent à l'aide d'une pointe robuste en silex. Ce procédé a produit des perforations biconiques évasées (fig. 10). La perforation par rotation a été précédée par la gravure d'un sillon orienté dans l'axe de la racine dont les extrémités sont encore visibles sur bon nombre de craches (fig. $10 \mathrm{~b}$-d). Ces sillons ont sans doute servi à caler la pointe de l'outil à l'amorce de la rotation. Celle-ci a produit des perforations d'un diamètre supérieur à $2 \mathrm{~mm}$ et pouvant atteindre $5 \mathrm{~mm}$ (fig. 11). Il s'agit des plus grandes perforations que nous avons pu examiner jusqu'à présent sur des craches de cerf (Vanhaeren et d'Errico 2003b). Aucune différence significative ne s'observe entre les perforations réalisées sur les craches des deux sexes. Malgré la dimension réduite des perforations sur les craches biforées, la technique de perforation 
est comparable: production de deux sillons parallèles près du collet suivie d'une rotation réalisée avec une pointe en silex extrêmement fine. Les craches appariées portent des perforations presque identiques en forme et dimensions (fig. 7 et 11), indice suggérant que le même artisan a été responsable de la perforation de chaque paire (d'Errico et Vanhaeren 1999, 2002).

Figure 10 - Macrophotos des perforations sur quatre craches de la sépulture de Saint-Germain-laRivière. Echelle $=5 \mathrm{~mm}$.

Figure 10 - Macrographs of perforations on four red deer canines from the Saint-Germain-la-Rivière burial. Scale $=5 \mathrm{~mm}$.

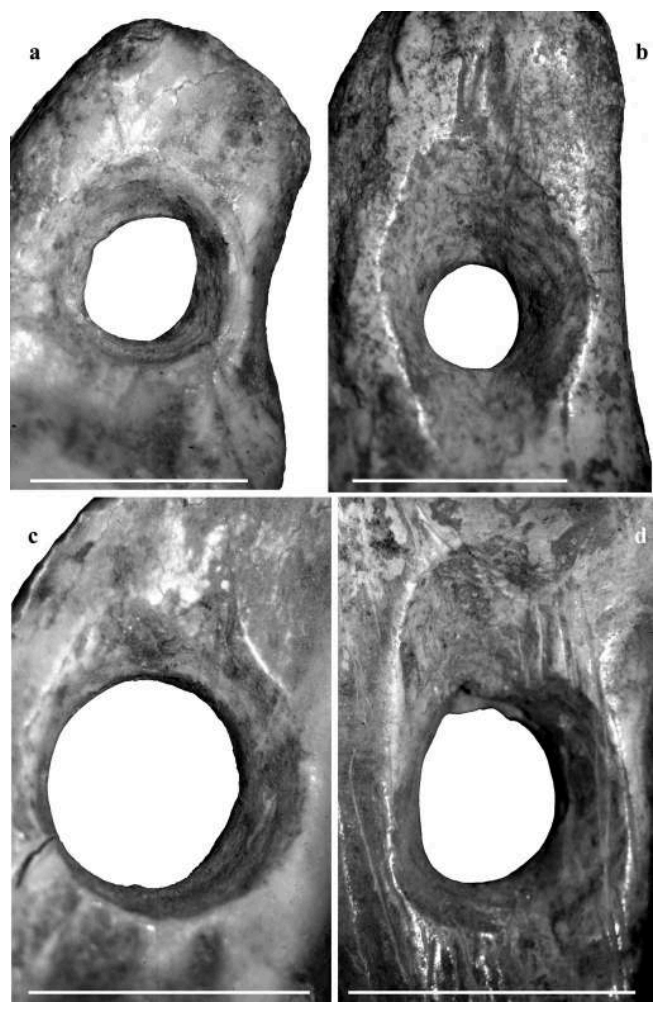


Figure 11 - Dimensions des perforations sur les craches de la sépulture.

Figure 11 - Dimension of the perforations on the red deer canines associated to the burial.

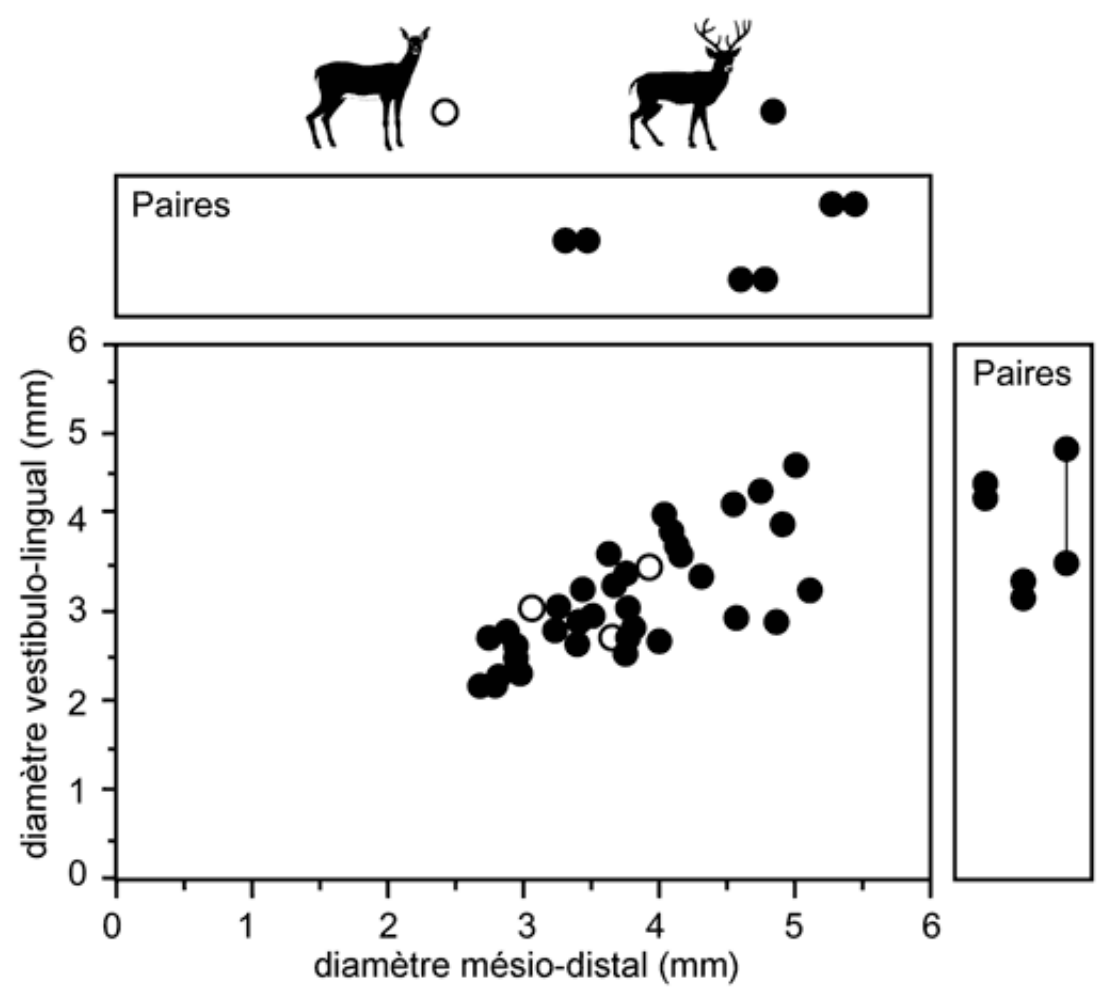

\section{Traces d'utilisation et mode d'attache}

Les quelques traces d'utilisation repérées, qui consistent dans un poli localisé de préférence à droite et/ou à gauche de la perforation, ne permettent pas une identification certaine du mode d'attache.

\section{Décor}

Deux tiers des craches de cerf mâles et un tiers des craches de biches ont été décorés (tab. 2) sur la surface occlusale (fig. $12 \mathrm{n}^{\circ} 14$ ). Le décor consiste en des séries de trois à six entailles parallèles ou des croisillons formés par deux ou trois entailles. Trois pièces associent les deux motifs (fig. $12 \mathrm{n}^{\circ}$ 7, 24, 28 et Fig. 13 c). Toutes les entailles ont été réalisées par le mouvement de va-et-vient d'un tranchant non retouché comme l'indiquent leur morphologie étroite et profonde, leur section symétrique et l'absence de “ marches" provoquées par les aspérités d'un tranchant retouché (d'Errico 1998). Sur certaines pièces, cette technique laisse des entailles nettes (fig. 13 a, e, f), sur d'autres les sorties accidentelles du tranchant ou la difficulté d'entamer le sillon sur l'émail a produit, à côté d'entailles profondes, plusieurs stries parasites parallèles ou légèrement désaxées (fig. $13 \mathrm{c}, \mathrm{d}, \mathrm{h}$ ). Quatre des six paires sont décorées et il est intéressant de remarquer que l'artisan n'a réalisé aucun décor symétrique sur les deux craches provenant du même animal. On observe même un exemple où seule une crache de la paire a été décorée. La position du décor sur la dent attire également l'attention : ces décors ne sont visibles que si la face mésiale ou vestibulaire est orientée vers l'observateur. 
Figure 12 - Vues linguales des craches décorées de la sépulture.

Figure 12 - Lingual view of the decorated red deer canines from the burial.

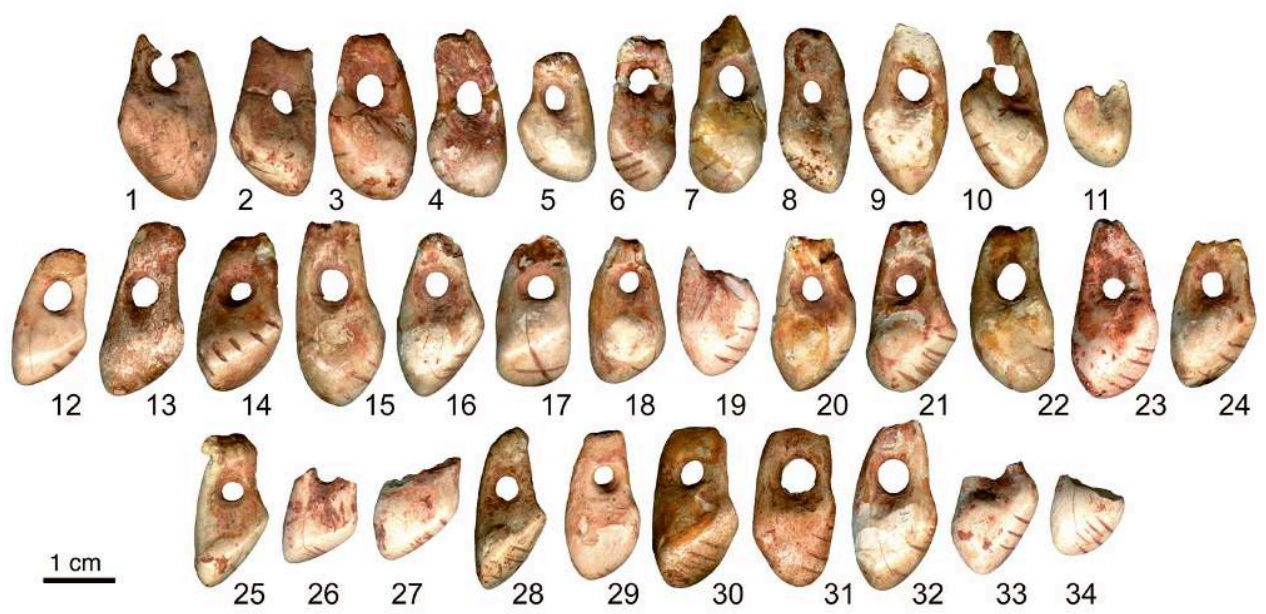

Figure 13 - Vues occlusales de dix craches décorées de la sépulture. Les deux dernières (h) sont appariées. Echelle $=5 \mathrm{~mm}$.

Figure 13 - Occlusal view of the ten decorated red deer canines from the burial. The two last canines (h) come from the same animal. Scale $=5 \mathrm{~mm}$.

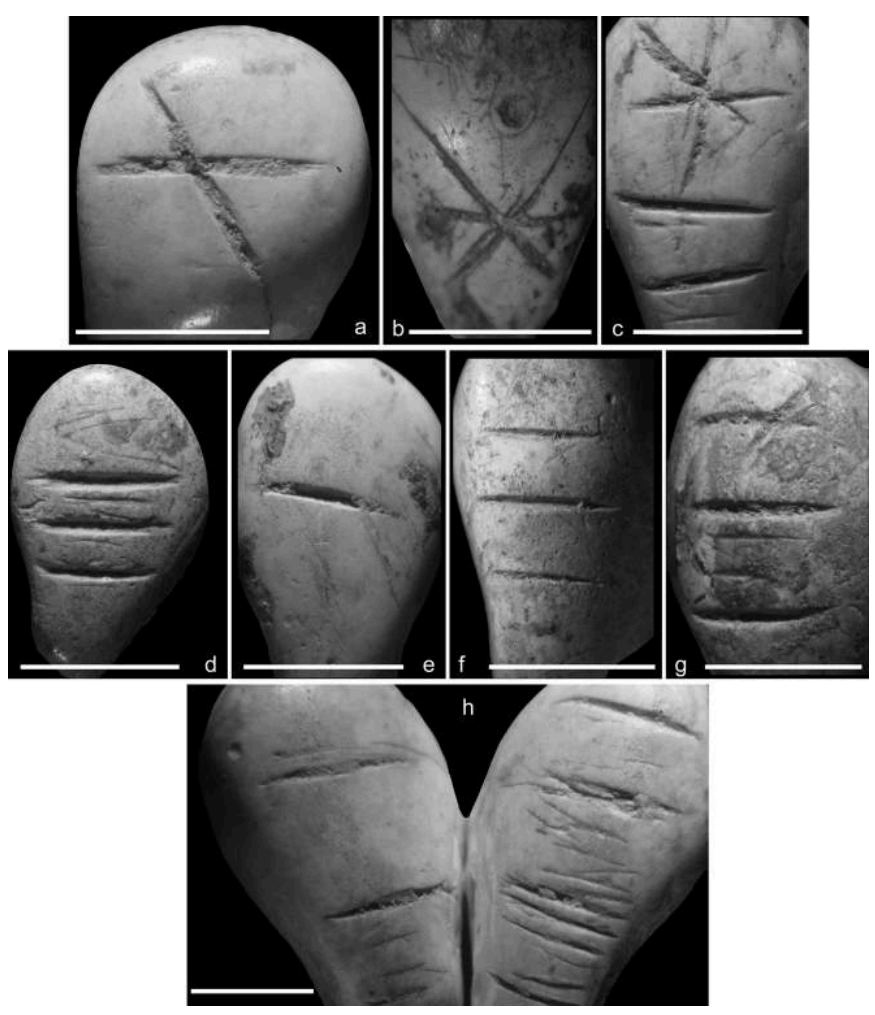


Figure 14 - " collier" de craches de cerf de la collection Mirande. Les dents sont figurées en vue vestibulaire.

Figure 14 - "necklace" of red deer canines from the Mirande collection (buccal view).

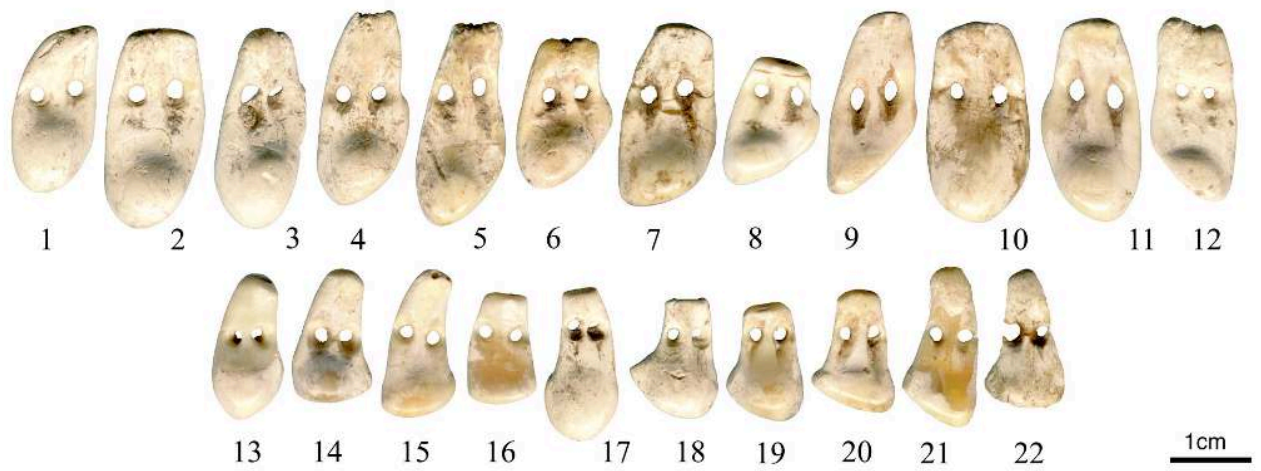

1-12: craches de cerf mâles, 13-22: craches de biches.

1-12: stag canines, 13-14: hind canines.

\section{La perle en stéatite}

La perle en stéatite, de couleur verte jaunâtre, est légèrement plus petite que les craches et présente une perforation obtenue par rotation (fig. $6 \mathrm{n}^{\circ} 72$ ). La position désaxée de cette dernière, qui devait fragiliser l'anneau, est probablement à l'origine de la fracturation de la pièce. La surface est couverte de stries larges, superficielles et sans orientation préférentielle, évoquant une abrasion effectuée par des éléments grossiers. Ces stries apparaissent émoussées par une usure due à un polissage intentionnel ou produite par le port de l'objet.

\section{Les Trivia europea}

Un seul des trois exemplaires est entier (fig. $6 \mathrm{n}^{\circ} 73$ ), les autres portent des fractures récentes. Tous sont biforés et présentent des résidus de colorants semblables à ceux observés sur les autres objets de la sépulture, ce qui semble confirmer leur appartenance à celle-ci. Dans les trois cas, les perforations ont été pratiquées sur la face convexe près des extrémités et du labre. Cette localisation suggère la présence d'un fil traversant les deux perforations et orientant l'ouverture vers l'observateur.

\section{Les « colliers » Mirande}

\section{Les craches de cerf}

\section{Etat de conservation}

Les 22 craches qui composent ce " collier " présentent un excellent état de conservation (fig. 14). Même si à première vue ces craches ne semblaient pas porter de traces d'ocre, l'analyse microscopique des perforations en révèle la présence sous forme de microrésidus. A l'inverse de celles de la sépulture, ces craches ne présentent pas d'encroûtements de sédiment. 


\section{Identification du sexe et latéralisation}

28

Cette collection est composée de 12 craches de cerf mâles et de 10 craches de biches (tab.3). Une opposition s'observe dans leur latéralisation (fig. 15) : les craches de biche sont en majorité des droites, celles de mâle presque toutes des gauches. Aucun appariement n'a pu être identifié.

Figure 15 - Latéralisation, NMI (en haut) et stades d'usure (en bas) des craches de la collection Mirande.

Figure 15 - Lateralisation, MNI (top), and wear stages (bottom) of the red deer canines from the Mirande collection.
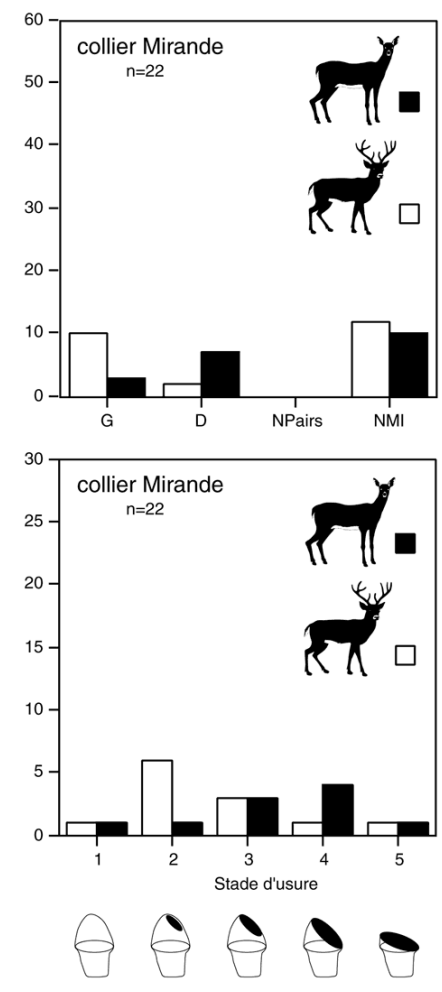

\section{Estimation de l'âge}

L'estimation de l'âge par la méthode morphométrique est rendue difficile à cause des modifications que ces craches ont subies lors de leur aménagement en objet de parure (cf. ci-dessous). Les stades d'usure révèlent que toutes les classes d'âges sont représentées aussi bien chez les mâles que chez les femelles (fig. 15). Les craches d'animaux d'âge compris entre 4 et 6 ans (stade 2) et, en moindre mesure, entre 6 et 10 ans (stade 3), constituent le groupe le plus important chez les mâles. Une préférence pour des individus plus âgés (10-16 ans, stade 3-4) s'observe chez les femelles.

\section{Façonnage}

La morphologie naturelle des craches a été modifiée intentionnellement sur toutes les dents de biche (fig. 14, $\mathrm{n}^{\circ}$ 13-22) et sur huit des douze dents de mâles (fig. 14, $\mathrm{n}^{\circ}$ 1-3, 7-11). Les racines d'au moins cinq dents, quatre appartenant à des femelles et une à un mâle (fig. $14 \mathrm{n}^{\circ} 8,14,16,18,19$ ), ont été raccourcies par sciage. Les stigmates laissés par ce procédé ont été ensuite régularisés par abrasion (fig. $16 \mathrm{a}, \mathrm{b}$, i). Les racines des autres 
pièces, qui ne semblent pas, à en juger par leur longueur, avoir été sciées, ont été néanmoins abrasées. L'abrasion a été pratiquée soit de façon à produire une facette nette, perpendiculaire à l'axe de la dent (fig. $16 \mathrm{~d}, \mathrm{e}, \mathrm{h}$ ), soit de manière à réduire l'étendue de celle-ci en réalisant des facettes convergentes de part et d'autre de la première (fig. $16 \mathrm{a}, \mathrm{b}$ ). Sur une racine la surface abrasée est arrondie, ce qui évoque un changement constant de l'orientation de l'objet au cours du travail (fig. $14 \mathrm{n}^{\circ} 13$ et fig. $16 \mathrm{c})$. Toutes ces facettes ont ensuite été soigneusement polies, processus qui a effacé les traces d'abrasion pour ne laisser que des stries microscopiques et un lustrage luisant (fig. 16 f, g). La reproduction expérimentale de ces traces (d'Errico 1993a-b) indique que le lustrage a pu être obtenu à l'aide d'une peau animale ou même en frottant les pièces entre les doigts. L'abrasion et le polissage ont sans doute également été utilisés pour modifier la morphologie de la couronne de plusieurs craches et pour leur donner un aspect luisant (fig. $14 \mathrm{n}^{\circ} 16,19,20,21$ ). Sur une crache de mâle (fig. 14 $\mathrm{n}^{\circ} 9$ ), l'abrasion a régularisé la face distale de la couronne. L'orientation des stries laissées par ce procédé indique que l'abrasion a été effectuée avec un geste parallèle à l'axe majeur de la dent (fig. 17).

Figure 16 - Traces de façonnage sur les craches de la collection Mirande (cf. texte). Echelle= $1 \mathrm{~mm}$. Figure 16 - Traces of manufacture on the red deer canines from the Mirande collection (see text). Scale = $1 \mathrm{~mm}$.

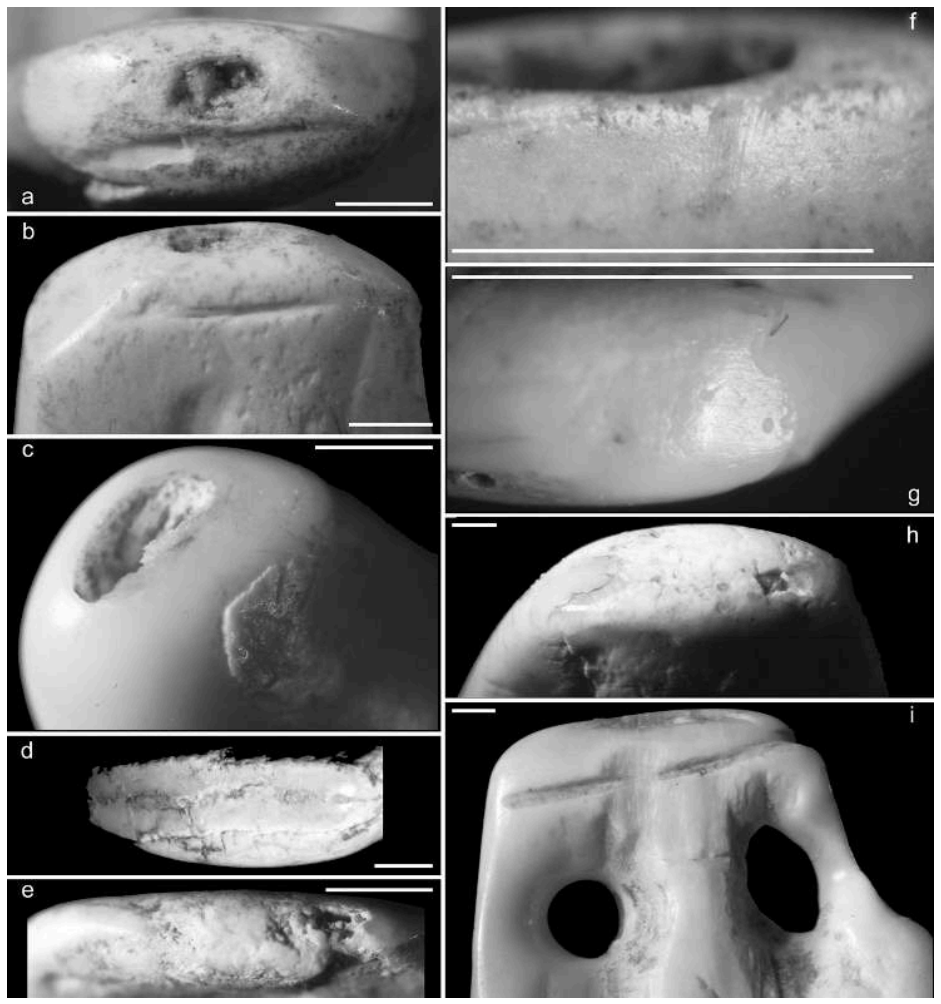


Figure 17 - Modification par abrasion de la face distale (trait blanc vertical) de la couronne d'une crache de la collection Mirande (à gauche). Cette modification produit une facette (centre) couverte de stries obliques (photo au MEB à droite) par rapport à l'axe de la dent. Echelle $=1 \mathrm{~mm}$.

Figure 17 - Traces of grinding on the distal aspect (vertical white bar) of a red deer canine from the Mirande collection (left) producing a facet (center) covered by oblique striations (SEM photo on the right). Scale $=1 \mathrm{~mm}$.

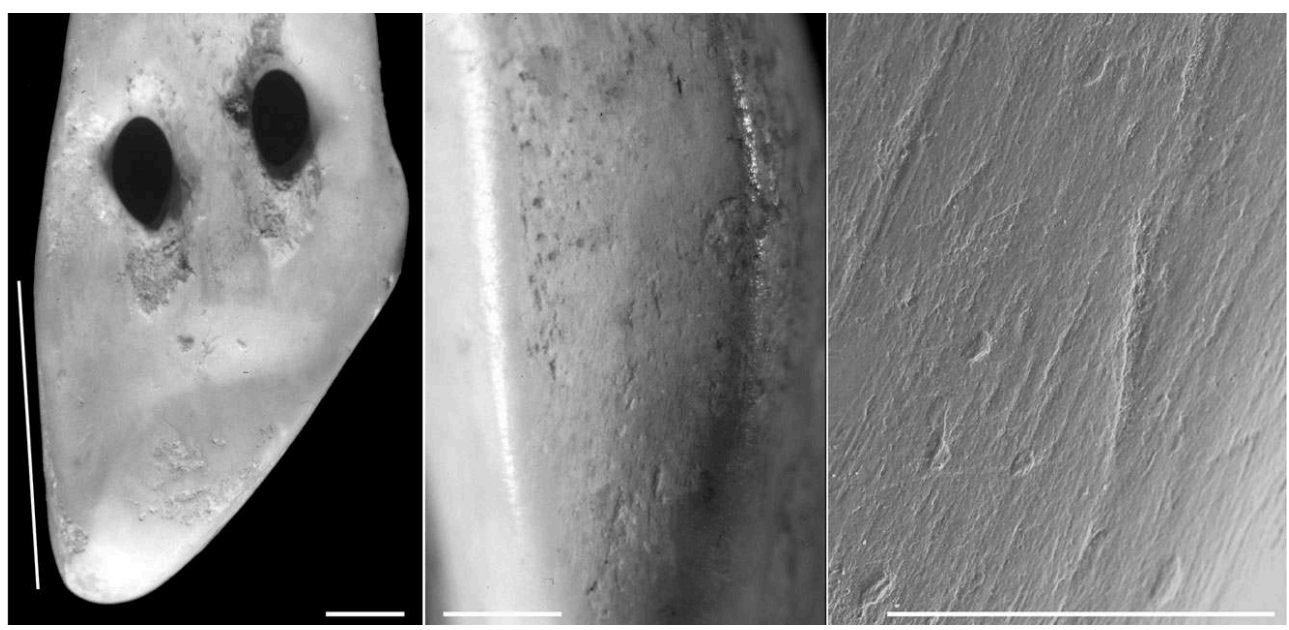

\section{Perforations}

31 Ces craches biforées ont été perforées avec la même technique que celle décrite pour les craches de la sépulture: creusement d'un fin sillon longitudinal suivi d'une perforation par rotation. Cependant, la perforation a réclamé ici l'utilisation de perçoirs fins, nécessaires à la production de petites perforations cylindriques (fig. $18 \mathrm{a}$ ). Les perforations sur les dents de biche sont systématiquement plus petites que celles sur les craches de mâle (fig. 19). L'artisan était donc conscient des contraintes imposées par la différence de taille entre les racines et utilisait des pointes différentes pour les craches des deux sexes. Si les craches de mâles et de femelles étaient intégrées dans la même parure, le lien utilisé pour les attacher devait avoir un diamètre inférieur à 1 millimètre, largeur minimale des perforations sur les craches de biche. 
Figure 18 - Photos au MEB des deux perforations (haut) sur une crache de la collection Mirande avec restes des sillons qui ont précédé la perforation par rotation. Bas : détail de la gorge creusée par le frottement du fil d'attache. Echelle $=1 \mathrm{~mm}$.

Figure 18 - SEM photos of the two perforations (top) on a red deer canine from the Mirande collection with the remains of grooves made before drilling. Bottom: indentation linking the two perforations produced by friction with a thread. Scale $=1 \mathrm{~mm}$.

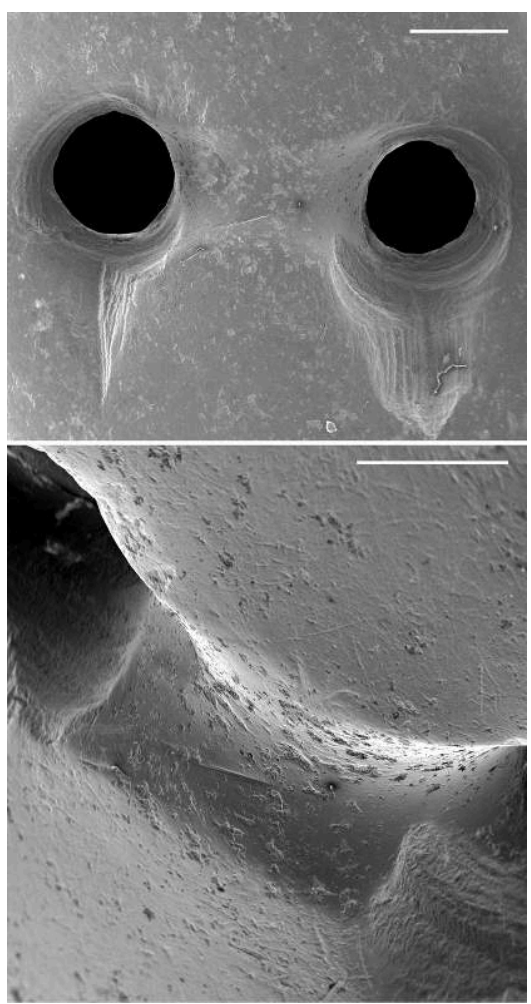


Figure 19 - Dimensions des perforations sur les craches biforées de la collection Mirande. Figure 19 - Dimension of the perforations on the red deer canines from the Mirande collection.

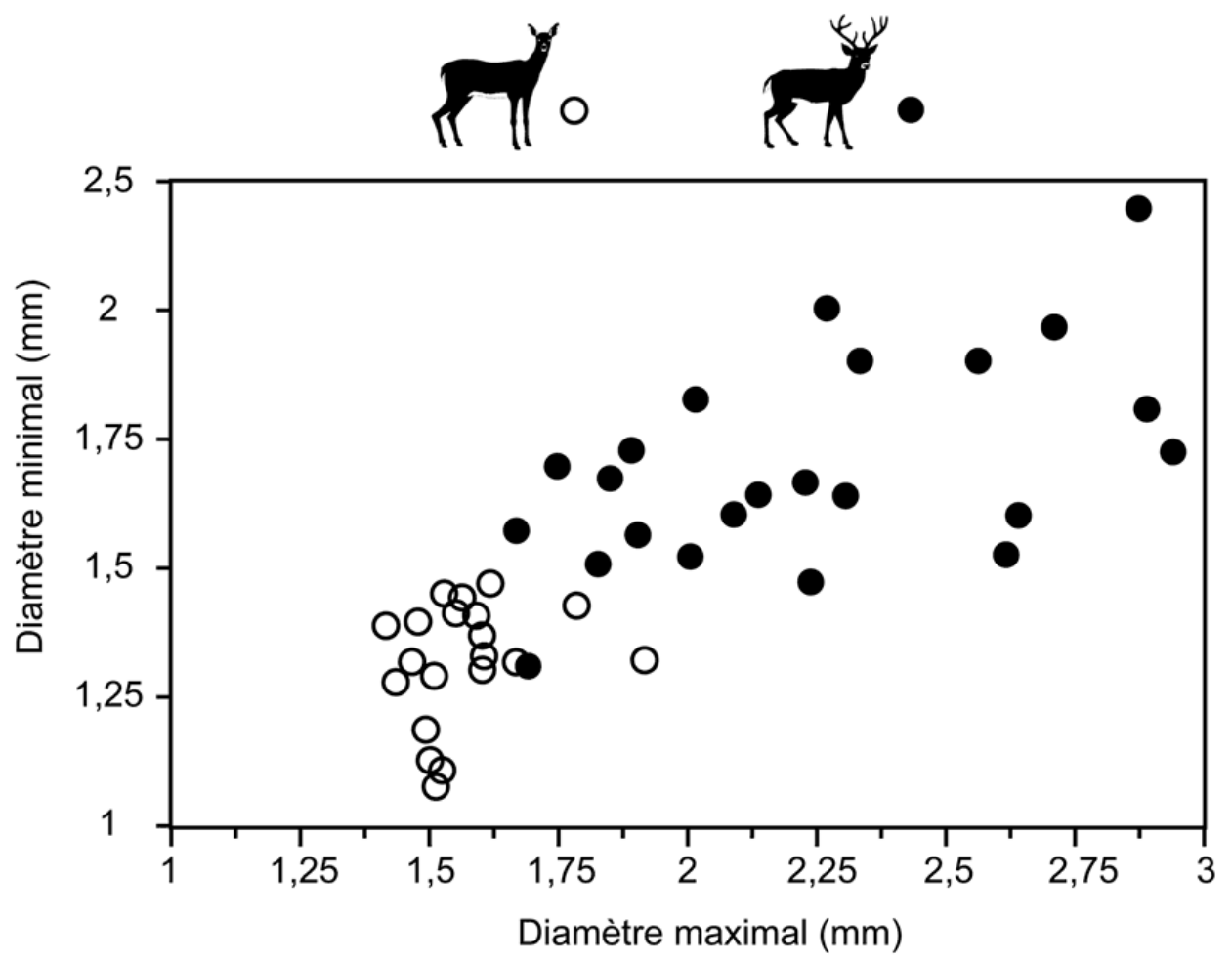

\section{Décor}

Quatre craches de mâle et quatre de biche portent un décor gravé sur la face occlusale de la dent (tab. 3). Il s'agit :

- d'entailles parallèles, présentes chez les deux sexes et réalisées, comme celles de la sépulture, par le va-et-vient de tranchants aigus, probablement non retouchés (fig. 20 a-b, e, g);

- d'entailles convergentes, réalisés avec la même technique, sur une crache de biche (fig. 20 c);

- de chevrons, gravés avec des tranchants fins sur une autre crache du même sexe (fig. 20 c, d) ;

- de "v" emboîtés, gravés sur une crache de mâle avec une pointe robuste (fig. 20 f). 
Figure 20 - Vues occlusales (a-f) et mésiale ( $g$ ) de sept craches décorées de la sépulture de SaintGermain-la-Rivière. Echelle $=1 \mathrm{~mm}$.

Figure 20 - Occlusal (a-f) and mesial ( $g$ ) views of seven decorated red deer canines from the SaintGermain-la-Rivière burial. Scale $=1 \mathrm{~mm}$.

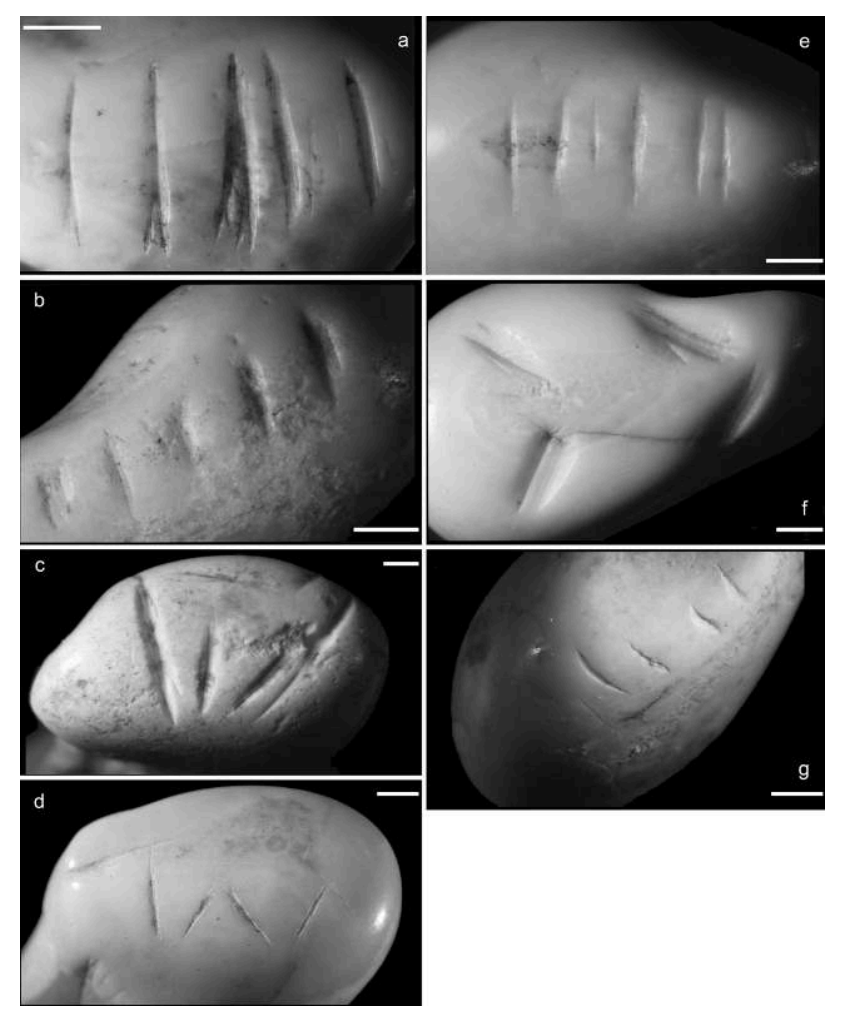

\section{Traces d'utilisation et mode d'attache}

Ces craches présentent des traces d'utilisation intenses qui permettent de reconstituer avec certitude le mode d'attache. L'usure affecte systématiquement la surface entre les deux perforations sur la face linguale et les ponts latéraux sur la face vestibulaire (fig. 21). Elle produit à ces endroits un sillon arrondi et lustré, associé à des stries perpendiculaires à l'axe de la dent, qui emporte les traces de perforation ainsi que un à deux tiers de l'épaisseur des ponts (fig. 18 b et 21). Sur deux pièces (fig. $14 \mathrm{n}^{\circ} 13$ et 17) l'usure a même sectionné le pont central ou latéral (fig. 21 b). Le fil d'attache devait donc passer entre les deux trous sur la face linguale et derrière les ponts latéraux sur la face vestibulaire. Les traces d'usure indiquent que les craches étaient enfilées plutôt que cousues individuellement. L'attache individuelle aurait en effet produit des usures sur les faces mésiales et distales, ce qui n'est pas le cas. La localisation de l'usure fait plutôt penser au passage du lien de la face vestibulaire d'une crache à la face vestibulaire de la voisine dans un collier continu. Il est probable que dans ce collier, les craches étaient attachées de manière à orienter leur face vestibulaire vers l'observateur car c'est cette position qui permet de rendre visible leur décor. En orientant ainsi les craches, le fil d'attache n'était visible que sur le pont entre les deux perforations, le reste du fil étant caché par les ponts latéraux. En jouant sur la latéralisation et sur les différences de taille et de forme, dues au sexe et à l'âge des animaux, ce collier pouvait créer un effet de symétrie et de dégradé d'impact visuel certain (fig. 22). Cette hypothèse est renforcée par le raccourcissement artificiel des racines mené 
vraisemblablement dans le but de mettre le bord des ces dernières au même niveau que celui des autres et, de ce fait, donner une homogénéité à l'ensemble.

Figure 21 - Macrophotos des perforations et des usures (flèches) sur plusieurs craches de la collection Mirande. Echelle $=1 \mathrm{~mm}$.

Figure 21 - Macrophotos of perforations and use wear (arrows) on red deer canines from the Mirande collection. Scale $=1 \mathrm{~mm}$.

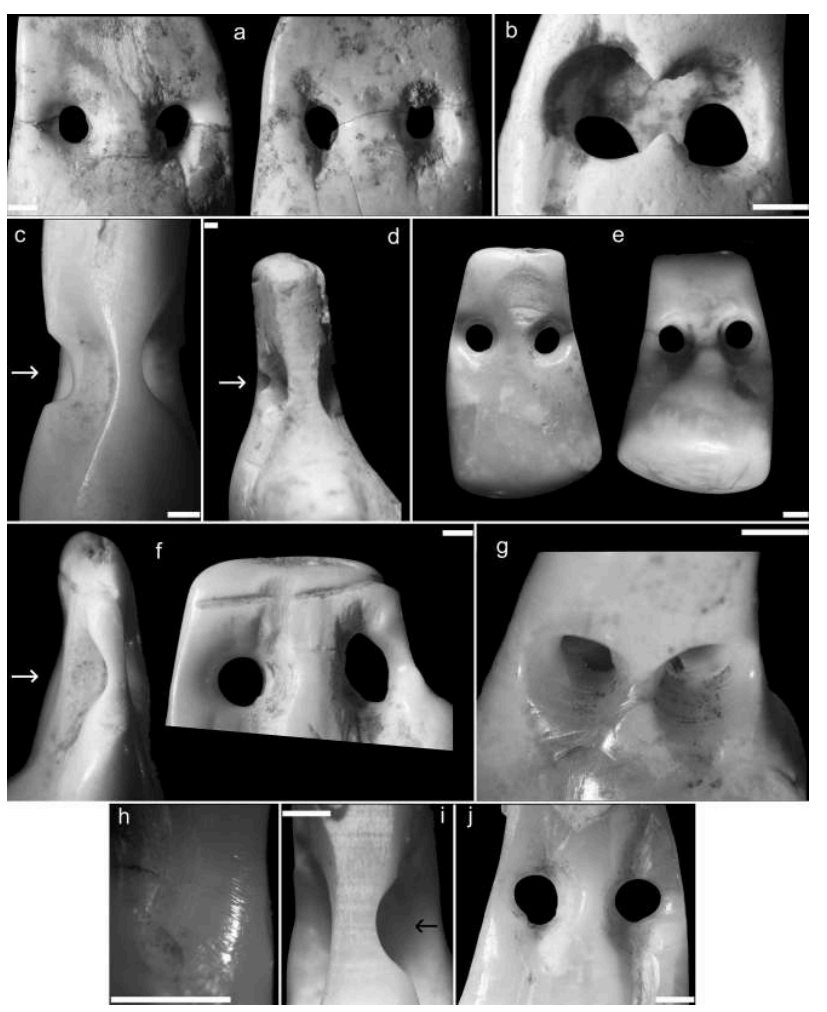

Figure 22 - Reconstitution du mode d'attache des craches de la collection Mirande. Figure 22 - Reconstitution of the red deer canine beadwork from the Mirande collection.

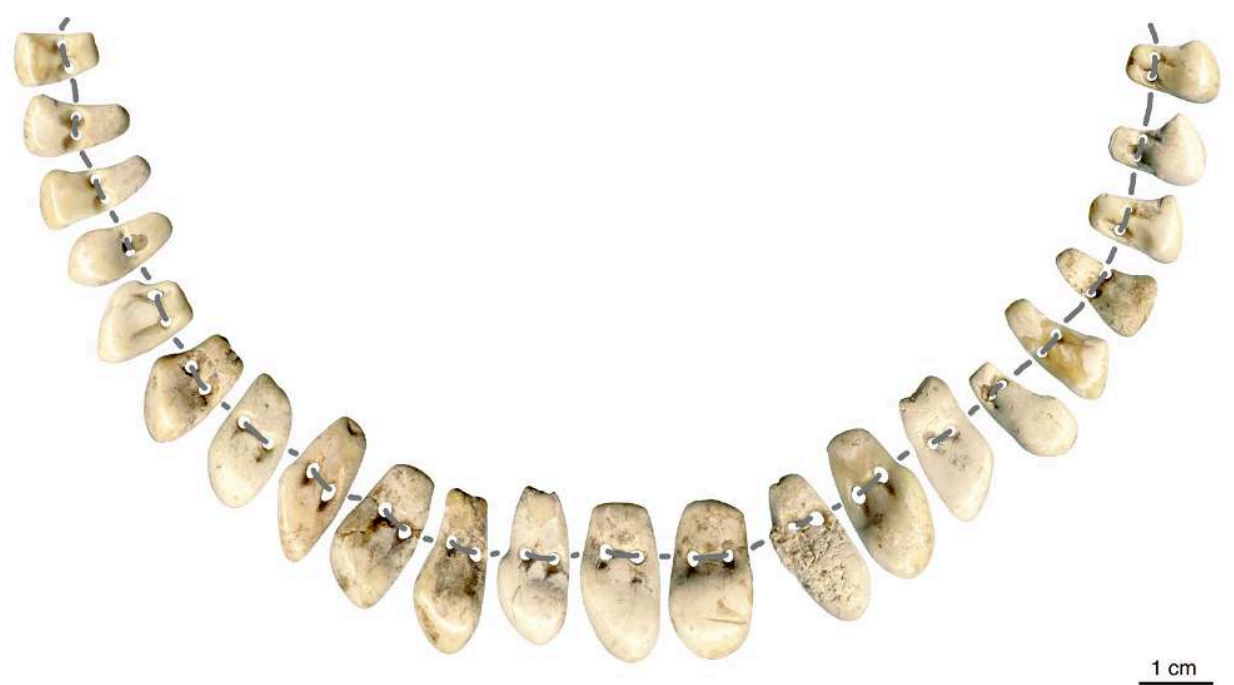




\section{Les incisives de renne}

\section{Etat de conservation} conservation, une pièce cassée et deux fragments (fig. 23), soit six spécimens en moins que le nombre indiqué par Garde lors du premier inventaire (1946).

Figure 23 - " collier" d'incisives de renne de la collection Mirande.

Figure 23 - "necklace " of reindeer incisors from the Mirande collection.
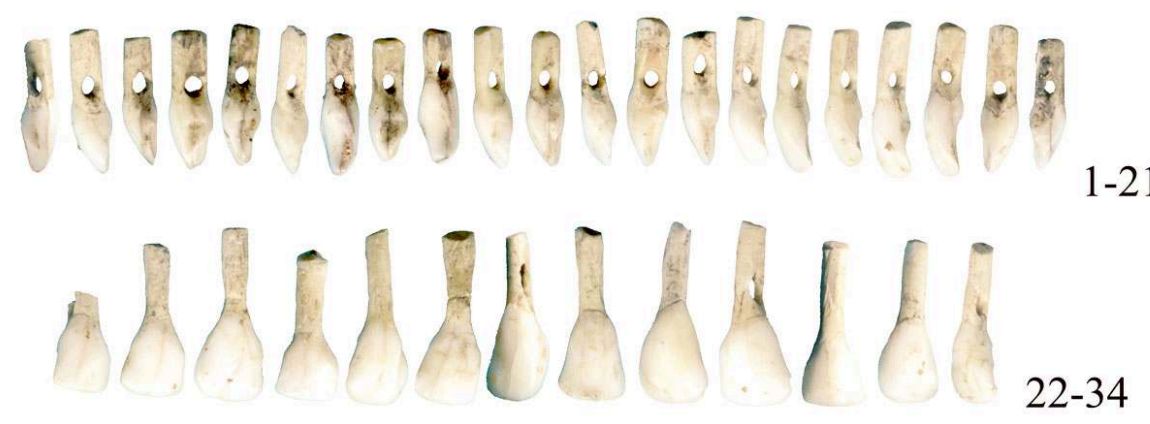

$1 \mathrm{~cm}$

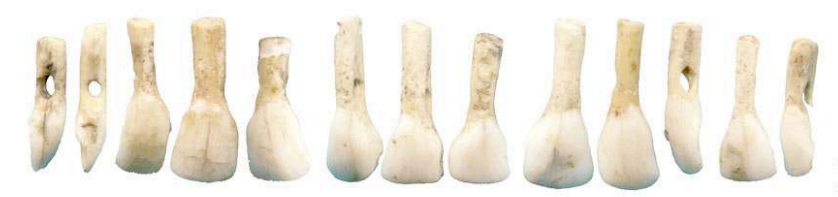

$35-47$

\section{Latéralisation, position dans la mandibule et identification de dents ayant appartenu au même animal}

Les huit incisives inférieures sont représentées dans la collection dans des proportions qui ne sont pas significativement différentes. Vingt-trois des 49 incisives étudiées sont des I1/I2 dont 13 gauches et 10 droites. Les 26 restants sont des I3/I4 dont 11 gauches et 15 droites. La comparaison systématique des stades d'usure et la recherche des facettes de contact a permis d'identifier des groupes de deux ou trois incisives ayant appartenu à quatre rennes différents. Comme on ne peut exclure, au contraire des craches de cerf, que certaines dents manquantes ne fassent pas partie de la collection, le nombre de rennes abattus pour créer cette parure ne peut être établi précisément et oscille entre 8 et 15 .

\section{Analyse technologique}

La première étape de l'aménagement des incisives a consisté dans le sciage des racines. Ce sciage a pu être effectué directement sur la mandibule, comme il a été proposé par Poplin (1983) pour les incisives de Petersfels, ou après extraction des dents. Choisir entre ces deux possibilités est problématique ici car, après sciage, les extrémités des racines ont été systématiquement régularisées par abrasion (fig. 24). Il est de ce fait difficile de savoir si la différence de hauteur que l'on observe entre les extrémités de certaines racines de dents adjacentes et provenant de la même mandibule sont dues à un sciage individuel ou à une abrasion plus intense. 
Figure 24 - Incisives de renne ayant appartenu au même animal ; au centre : vue linguale avec facettes de contact; à gauche : détail de la racine avec facettes produites par raclage; en haut : détail de l'extrémité de la racine avec facettes d'abrasion ; à droite : détail des perforations réalisées avec la même gestuelle sur les deux incisives. Echelle $=5 \mathrm{~mm}$.

Figure 24 - Reindeer incisors from the same animal; centre: lingual view of the matching teeth; left: detail of the root with elongated facets produced by scraping; top: close-up view of the root apex with facets produced by grinding; right: detail of the perforations made on both incisors with similar motions. Scale= $5 \mathrm{~mm}$.

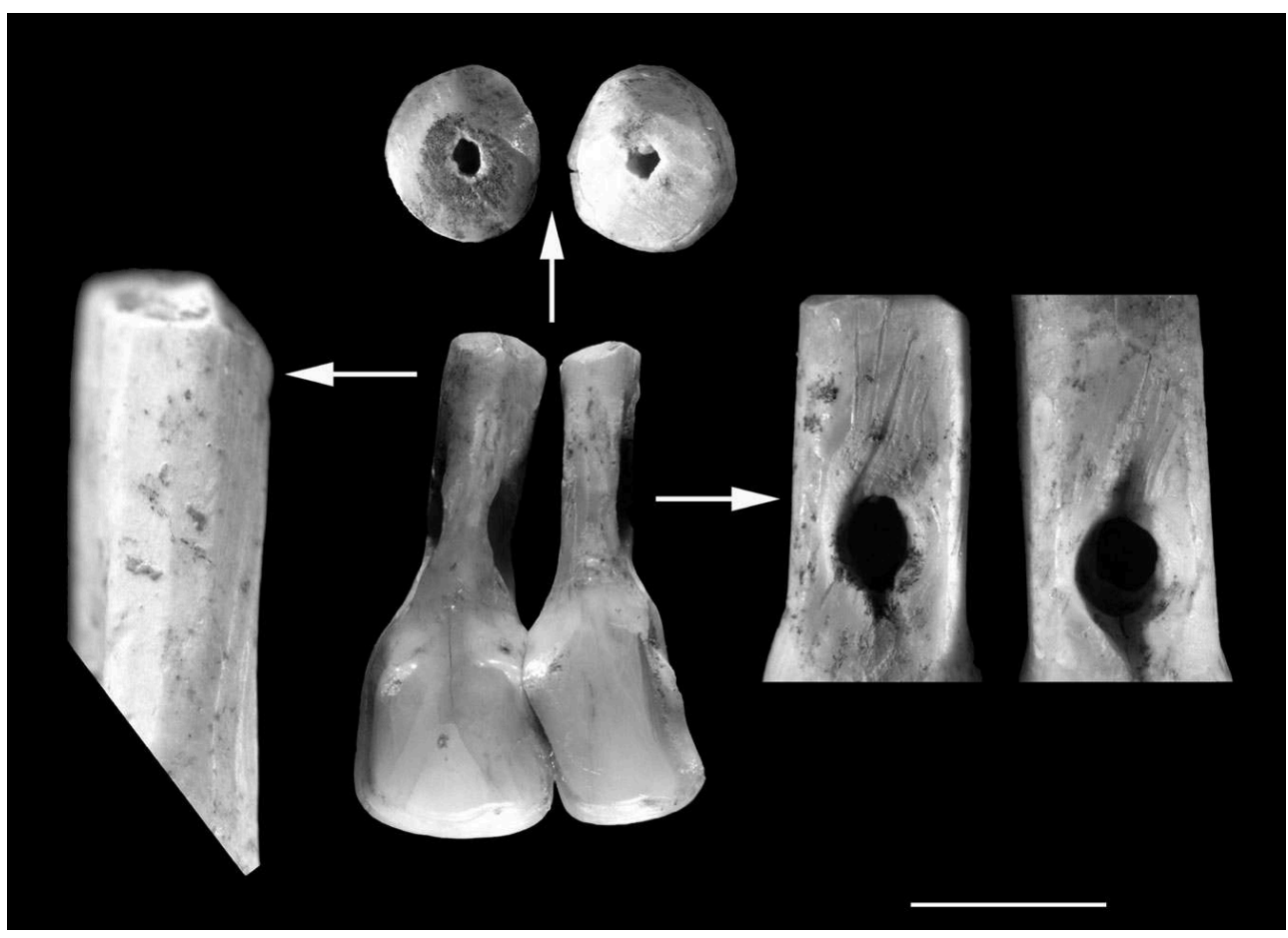

L'aménagement des incisives en objets de parure suit un procédé standardisé. La racine est raclée longitudinalement au burin, comme indiqué par la régularité des facettes et l'absence de stries sur celles-ci. L'extrémité de la racine est ensuite régularisée par abrasion en deux étapes. La première consiste à produire une facette perpendiculaire à l'axe de la dent. La deuxième à abraser les bords de celle-ci par l'intermédiaire d'une série de facettes adjacentes qui donnent à l'extrémité de la racine une morphologie caractéristique en tronc de cône. Pour perforer les racines, un sillon est gravé sur les faces mésiales et distales en partant du collet en direction de l'apex avant d'achever le travail par rotation avec une fine pointe en silex (fig. 24). La dimension minimale de ces perforations indique que le fil d'attache avait un diamètre inférieur à 1 millimètre (fig. 25). 
Figure 25 - Dimensions des perforations sur les incisives de renne de la collection Mirande. Figure 25 - Dimension of the perforations on the reindeer incisors from the Mirande collection.

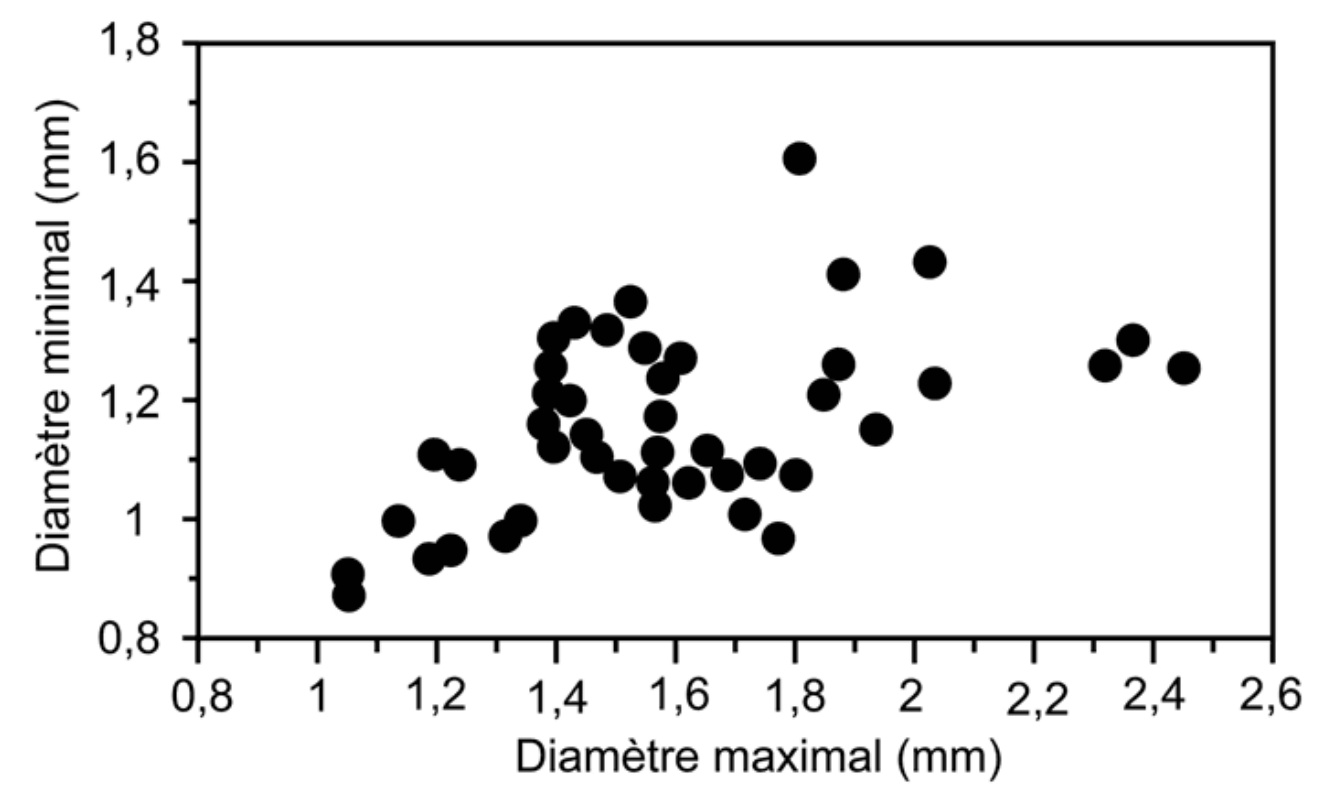

Traces d'utilisation et mode d'attache

L'usure affecte systématiquement la surface de la perforation du côté lingual en effaçant les stries concentriques laissées par la perforation et en amenuisant, dans certains cas, le pont créé par celle-ci. Cela suggère que les incisives étaient attachées individuellement par leur pont lingual mais il est difficile d'établir si elles étaient cousues sur un vêtement ou reliées les unes aux autres pour former un collier. Il est vraisemblable, comme proposé pour les craches, qu'en jouant sur les différences de taille entre incisives centrales et latérales, sur les différences de forme due à la latéralisation et sur le raccourcissement des racines, ces dents pouvaient être disposées de façon à créer un dégradé harmonieux.

\section{Les autres objets de parure découverts dans le site d'habitat}

\section{Identification spécifique et dénombrement}

La collection Mirande du Musée de Libourne comprend plusieurs objets de parure isolés. Nous ne disposons que de peu d'informations sur ce matériel. Selon Garde (1934), une dent percée aurait été découverte par Mirande dans une zone ocrée mise au jour dans la tranchée creusée par ce fouilleur en avant de l'abri supérieur. Une "crache percée d'un trou ", " un petit coquillage ", "un fragment d'os " et " une coquille Saint-Jacques" également percés, font partie de l'inventaire du Musée à partir de 1946 sans que l'on puisse établir leur provenance (Garde 1946). Ce matériel n'étant pas marqué, toute information sur sa provenance stratigraphique et spatiale semble perdue à jamais. De son côté, Blanchard ne mentionne, dans ses publications, aucun objet de parure en provenance des couches d'habitat du site. Cependant, nous avons trouvé sept objets de parure dans le matériel conservé au Musée des Eyzies, dans une boite étiquetée SaintGermain-la-Rivière " Magdalénien III ". Un certain nombre d'objets de parure provient également des fouilles Trécolle. Ils sont décrits par Lenoir et al., 1994 comme " une 
incisive de renne" (couche $\mathrm{C}$ ), " trois incisives de renne" (interface $\mathrm{C} / \mathrm{C} 1$ ), " une incisive de renne ", " une perle en stéatite ", " un oursin ", " des fragments de pecten" et " un fossile indéterminable" (couche $\mathrm{C} 1$ ); " deux perles en os" (interface $\mathrm{C} 1 / \mathrm{C} 2$ ); " une coquille de Pecten percée " et " une perle en stéatite à double perforation qui imite une incisive de renne" (couche (2), "une incisive de renne sciée " et " un fragment de Pecten paraissant perforé" pour l'interface $\mathrm{C} 2 / \mathrm{C} 3$; " un oursin" et " deux métapodes vestigiels de renne " (couche $\mathrm{C} 3$ ) ; "une canine de renard" et "un métapode vestigiel de renne portant un essai de perforation". A cette liste il faut ajouter " une deuxième prémolaire supérieure droite " humaine perforée (interface C2/C3) étudiée par Le Mort (1985).

Nous avons pu examiner au Musée de Libourne un grand pecten perforé (fig. $26 \mathrm{n}^{\circ} 1$ ), deux Nucella lapillus de taille différente (fig. $\left.26 \mathrm{n}^{\circ} 2,5\right)$, une crache droite appartenant à un jeune mâle adulte (fig. $26 \mathrm{n}^{\circ}$ ), une incisive d'antilope saïga (fig. $26 \mathrm{n}^{\circ} 4$ ) et un élément de parure en os biforé imitant une racine d'incisive (fig. $26 \mathrm{n}^{\circ} 6$ ). De la collection Blanchard conservée au Musée National de Préhistoire (fig. 27) font partie deux moulages internes d'un bivalve (fig. $27 \mathrm{n}^{\circ}$ 3) et d'un gastéropode indéterminé (fig. $27 \mathrm{n}^{\circ} 2$ ), un fragment de gastéropode, également indéterminé (fig. $27 \mathrm{n}^{\circ} 1$ ), ainsi qu'un objet tubulaire non déterminé, présentant une perforation latérale anthropique, obtenue par abrasion et rotation (fig. $27 \mathrm{n}^{\circ} 4$ ). Les deux moulages internes ne portent aucune trace anthropique et doivent de ce fait être exclus de la collection des objets de parure. A cette collection appartiennent aussi une incisive de renne percée (fig. 27 $\mathrm{n}^{\circ}$ 5), une crache droite de cerf mâle âgé (fig. $27 \mathrm{n}^{\circ}$ 6), un fossile d'oursin avec une perforation naturelle (fig. $27 \mathrm{n}^{\circ} 7$ ), trois Trivia europea dont une avec une petite perforation naturelle (fig. $27 \mathrm{n}^{\circ}$ 9) et un grand Glycymeris avec une perforation sur l'umbo (fig. $27 \mathrm{n}^{\circ} 8$ ). 
Figure 26 - Objets de parure provenant des fouilles Mirande du site d'habitat de Saint-Germain-laRivière.

Figure 26 - Personal ornaments from the Mirande excavation at Saint-Germain-la-Rivière.

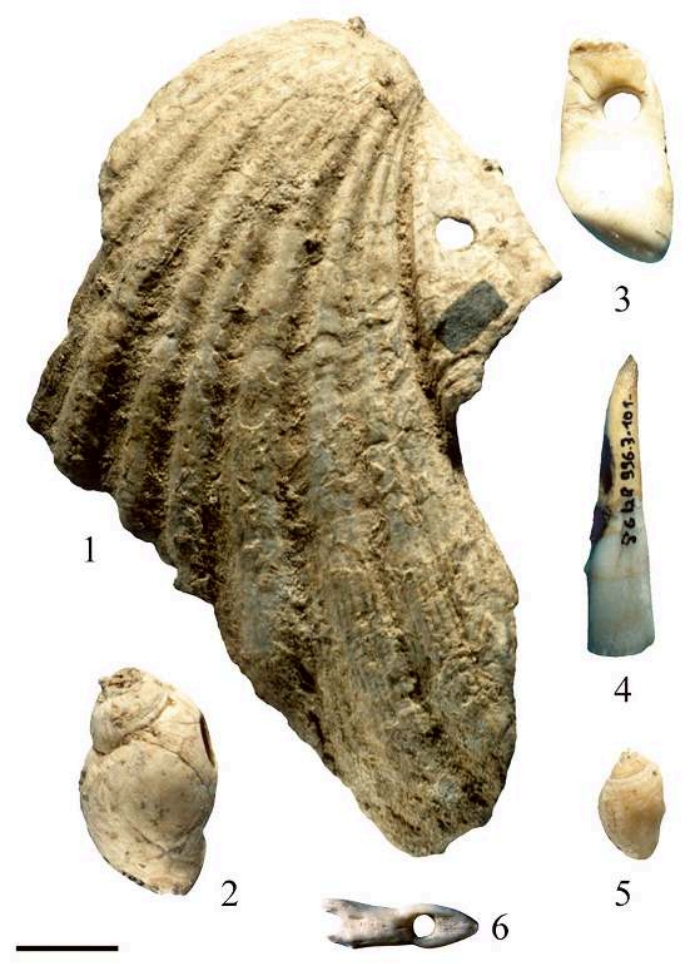

Figure 27 - Objets de parure provenant des fouilles Blanchard du site d'habitat de Saint-Germain-laRivière.

Figure 27 - Personal ornaments from the Blanchard excavation at Saint-Germain-la-Rivière.

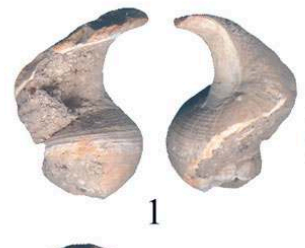

(

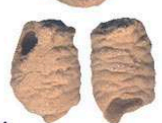

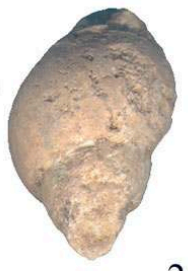

2

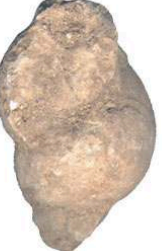

(1)

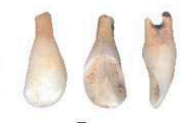

5

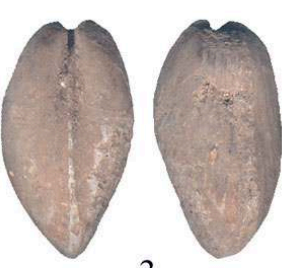

3

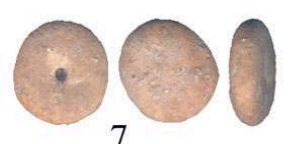

7

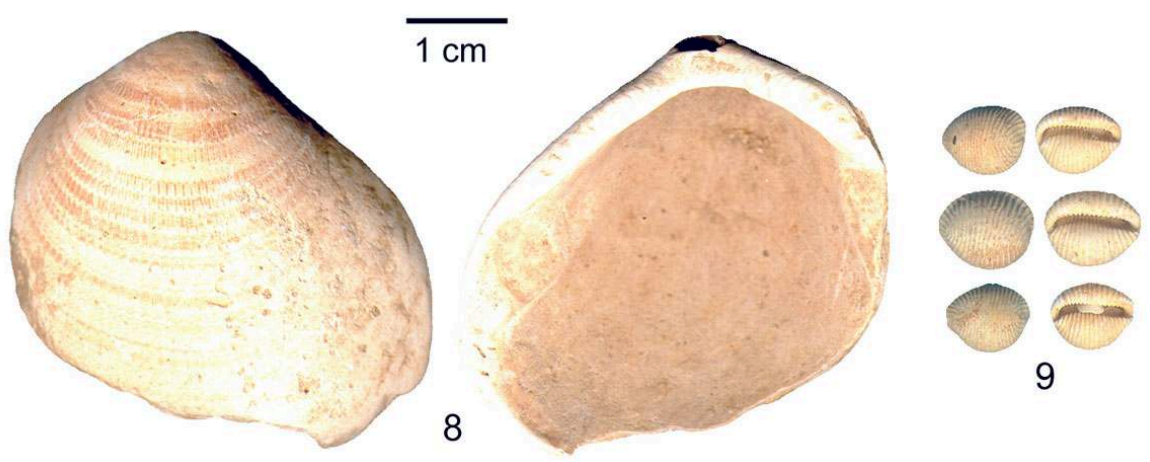


Le matériel des fouilles Trécolle, que nous avons pu examiner grâce à l'amabilité de Michel Lenoir, comprend, du haut vers le bas de la séquence stratigraphique, une incisive perforée de renne âgé (fig. $28 \mathrm{n}^{\circ} 1$ ) et un fragment d'Ostrea (fig. $28 \mathrm{n}^{\circ} 2$ ) (couche C) ; trois incisives de renne perforées, dont une cassée (fig. $28 n^{\circ} 3-5$ ), un fragment de Pecten (fig. $28 \mathrm{n}^{\circ} 6$ ) et trois fossiles d'oursins (fig. $28 \mathrm{n}^{\circ} 7-9$ ) dont un avec perforation naturelle (interface C-C1) ; une incisive de renne perforée (fig. $28 \mathrm{n}^{\circ} 10$ ), un oursin (fig. $28 \mathrm{n}^{\circ} 11$ ) et une perle ronde en stéatite (fig. $28 \mathrm{n}^{\circ} 12$ ), un grand (fig. $28 \mathrm{n}^{\circ} 13$ ) et un petit (fig. $28 \mathrm{n}^{\circ} 14$ ) fragment de Pecten et un fragment de bivalve indéterminé (fig. $28 \mathrm{n}^{\circ} 15$ ) (couche $\mathrm{C} 1$ ) ; deux pendeloques (fig. $28 \mathrm{n}^{\circ} 16-17$ ) en stéatite dont une imitant une incisive de renne, un oursin non perforé (fig. $28 \mathrm{n}^{\circ} 18$ ), un fragment d'huître (fig. 28 $n^{\circ} 19$ ) et de Pecten (fig. $28 n^{\circ} 20$ ) (interface couche C1-C2) ; une perle en stéatite biforée imitant une incisive de renne (fig. $29 \mathrm{n}^{\circ}$ 1), le moulage interne d'un fossile indéterminé (fig. $29 \mathrm{n}^{\circ}$ 2), un petit tronçon de dentale (fig. $29 \mathrm{n}^{\circ}$ 3), un fragment de Pecten avec perforation naturelle (fig. $29 \mathrm{n}^{\circ}$ 4), un autre fragment de Pecten (fig. $29 \mathrm{n}^{\circ}$ 5), un moulage interne d'un coquillage indéterminé (fig. $29 \mathrm{n}^{\circ}$ 6), une Nucella lapillus avec deux grandes perforations obtenues par rotation (fig. $29 \mathrm{n}^{\circ} 7$ ) (couche C2); une incisive de renne avec gorge près du collet (fig. $29 \mathrm{n}^{\circ} 8$ ) (interface entre les couches $\mathrm{C} 2$ et $\mathrm{C} 3$ ) ; un oursin avec perforation naturelle (fig. $29 \mathrm{n}^{\circ}$ 9), deux épiphyses de métacarpe vestigiel de renne (fig. $29 \mathrm{n}^{\circ}$ 10-11), le moulage interne d'un coquillage indéterminé (fig. 29 $\mathrm{n}^{\circ} 12$ ) et un fragment de coquillage, également indéterminé (fig. $29 \mathrm{n}^{\circ} 13$ ) (couche C3) ; une épiphyse de métacarpe vestigiel de renne sans perforation (fig. $29 \mathrm{n}^{\circ} 14$ ), une canine de renard avec perforation cassée (fig. $29 \mathrm{n}^{\circ} 15$ ) (interface couche C3-C4); une autre canine de renard avec perforation cassée (fig. $29 \mathrm{n}^{\circ} 16$ ) (couche $\mathrm{C} 4$ ). Nous n'avons pas pu analyser la prémolaire humaine (fig. 29 encadré) (interface C2-C3), qui est en cours d'étude par D. Gambier. 
Figure 28 - Objets de parure et fragments de coquillages (cf. texte) provenant des fouilles Trécolle du site d'habitat de Saint-Germain-la-Rivière. Les couches de provenance sont indiquées à droite. Figure 28 - Personal ornaments and shell fragments (cf. text) from the Trécolle excavations of the SaintGermain-la-Rivière site. The stratigraphic provenance is indicated on the right.

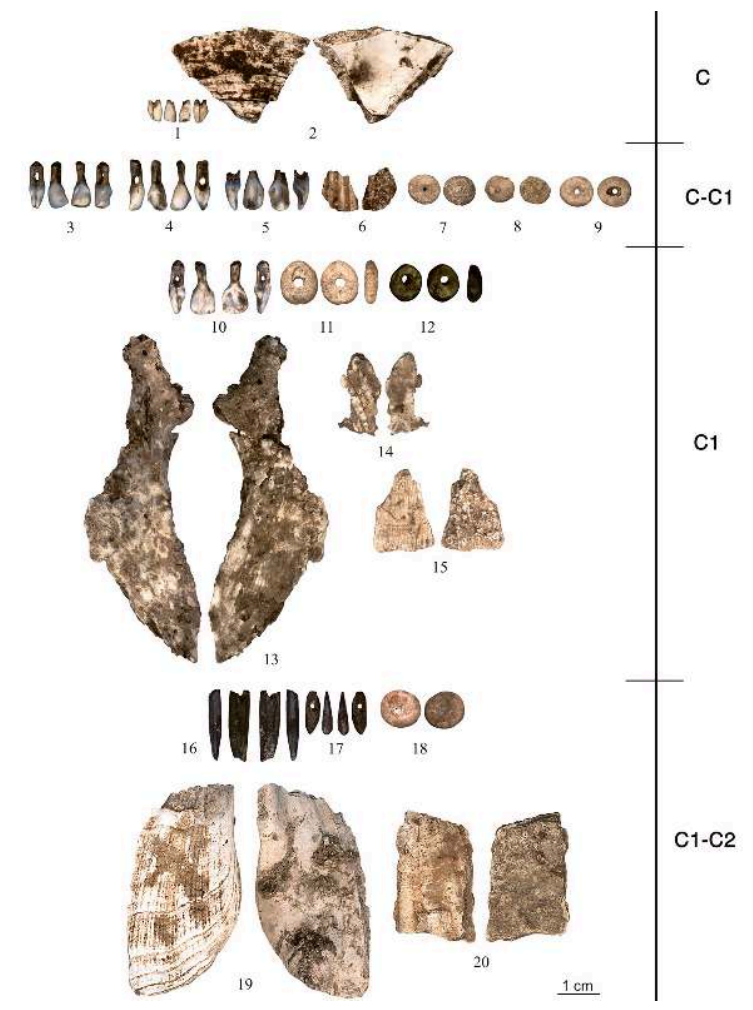


Figure 29 - Objets de parure et fragments de coquillages (cf. texte) provenant des fouilles Trécolle du site d'habitat de Saint-Germain-la-Rivière. Les couches de provenance sont indiquées à droite. Figure 29 - Personal ornaments and shell fragments (cf. text) from the Trécolle excavations of the SaintGermain-la-Rivière site. The stratigraphic provenance is indicated on the right.

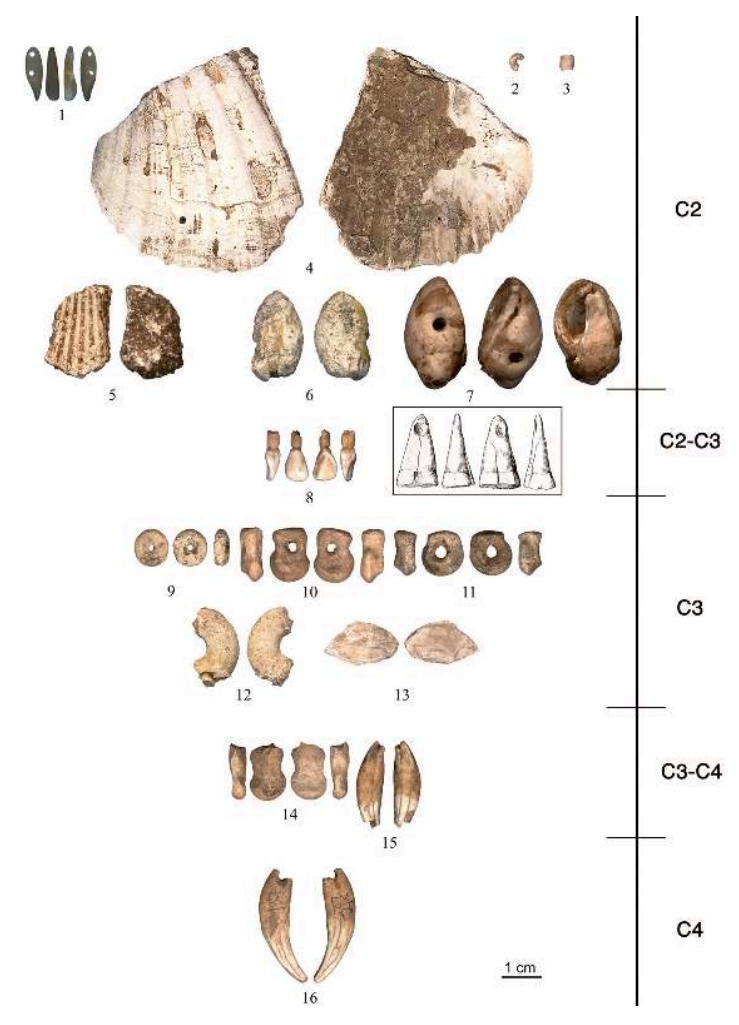

\section{Analyse technologique}

L'incisive de renne (fig. $27 \mathrm{n}^{\circ}$ 5) et la crache de cerf (fig. $27 \mathrm{n}^{\circ}$ 6) de la collection Blanchard ont été perforées avec les mêmes techniques que celles décrites précédemment pour les colliers de la collection Mirande. La localisation et la taille des perforations sont également les mêmes. La crache de la collection Mirande a été perforée avec la même technique que celle décrite sur les craches de la sépulture et présente une perforation de taille comparable (fig. $26 \mathrm{n}^{\circ} 3$ ). Cependant, elle se différencie de ces dernières par la position excentrée de la perforation, particularité jamais observée sur les craches de la sépulture. Malgré leur différence de taille, les deux Nucella lapillus de la collection Mirande (fig. $26 \mathrm{n}^{\circ} 2$, 5) présentent des grandes perforations localisées au même endroit, indice possible de leur intégration dans une même parure. Les incisives de renne provenant des couches $\mathrm{C}$ et $\mathrm{C} 1$ de la fouille Trécolle (fig. $28 n^{\circ} 1,3-5,10$ ) ont eu la racine sciée, polie et perforée en suivant le même procédé que nous avons décrit pour le collier Mirande. Des différences s'observent cependant dans la morphologie de la zone façonnée par abrasion et dans la gestuelle adoptée. Sur une pièce, cette technique est utilisée pour produire une extrémité pointue (fig. $30 \mathrm{c}$ ), sur une autre, une facette oblique (fig. $30 \mathrm{~b}$ ), sur une troisième, le plan de sciage est régularisé par simple polissage sur une surface souple (fig. 30 a). Aucune pièce du collier Mirande ne présente ces caractères. De plus quatre de ces incisives ont une couleur foncée que l'on ne retrouve pas chez les pièces de Mirande. L'incisive de renne de la couche $\mathrm{C} 2-\mathrm{C} 3$ (fig. $29 \mathrm{n}^{\circ} 8$ ) a été sciée de la même façon que toutes les autres mais le plan de sciage n'a pas été régularisé et une gorge a été 
pratiquée près du collet (fig. $30 \mathrm{~d}$ ). Des gorges d'origine naturelle, semblables à celle de la couche C2-C3, sont connues en littérature (Gauthier 1986). Cependant, dans notre cas, la présence de traces diagnostiques d'outil, résultant de la sortie accidentelle du tranchant au cours du creusement de la gorge, démontrent l'origine anthropique de celle-ci. Nous pouvons également dire que la pièce a été portée, à en juger par l'émoussé présent, à l'intérieur de la gorge.

Figure 30 - Détails des incisives de rennes des couches $\mathrm{C}$ et $\mathrm{C} 1$ de la fouille Trécolle (cf. texte). Figure 30 - Close-up view of the reindeer incisors from levels $C$ and $C 1$ of the Trécolle excavations (cf. text).

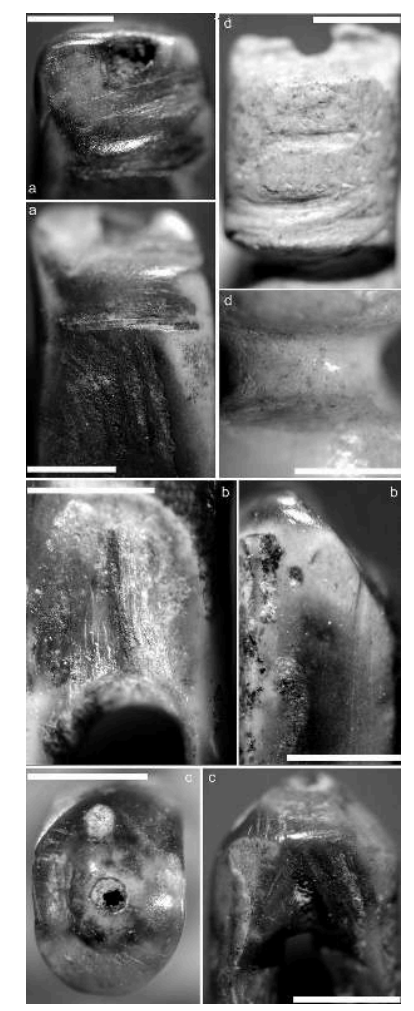

43 Aucune trace anthropique claire ne s'observe sur les six oursins fossiles issus des fouilles Trécolle et sur le spécimen des fouilles Blanchard. La présence de perforations sur plusieurs de ces pièces et leur similitude morphologique et dimensionnelle avec la perle ronde en stéatite et les deux perles façonnées sur l'épiphyse de métacarpe vestigiel de renne découvertes dans les mêmes couches, nous ont poussé à comparer les dimensions et la fréquence des perforations de notre échantillon avec ceux d'une thanatocénose d'oursins oligocènes (fig. 31). Cette comparaison révèle que les pièces archéologiques ont des diamètres proches ou dépassant la limite supérieure de l'étendue des diamètres des oursins oligocènes (fig. 32). De plus, les oursins de l'échantillon de contrôle perforés naturellement ne représentent que $1 \%$ de l'ensemble tandis que la moitié des pièces archéologiques est perforée. Ces différences peuvent refléter un choix des Paléolithiques ou être due à un processus taphonomique pre- ou post-dépositionnel qui aurait sélectionné les oursins de plus grande taille et généré un taux plus important de perforations naturelles. Les méthodes de fouille et de tamisage auraient pu par exemple entraîner un tel biais. Cependant, la moitié des oursins de la collection de comparaison a un diamètre supérieur à $5 \mathrm{~mm}$ et plusieurs objets de parure issus des fouilles Trécolle ne dépassent pas cette dimension. Nous ne pouvons donc 
attribuer la différence de taille entre les oursins du site et ceux de la collection de comparaison au mode de prélèvement. De même, il est difficile d'envisager un processus taphonomique lié au mode de formation du site (altération chimique, ruissellement...) qui produirait une sélection dimensionnelle aussi forte. Il semble plus raisonnable, en considérant la forte similitude de dimension des oursins avec les autres perles rondes du gisement, de penser que ces fossiles étaient ramassés de façon sélective par les Magdaléniens pour en faire des objets de parure.

Figure 31 - Oursins fossiles provenant des calcaires à Astéries du Stampien de Noulet, Nérigean. Echelle $=1 \mathrm{~cm}$.

Figure 31 - Fossil urchins from Astéries limestone of the Stampian at Noulet, Nérigean. Scale $=1 \mathrm{~cm}$.

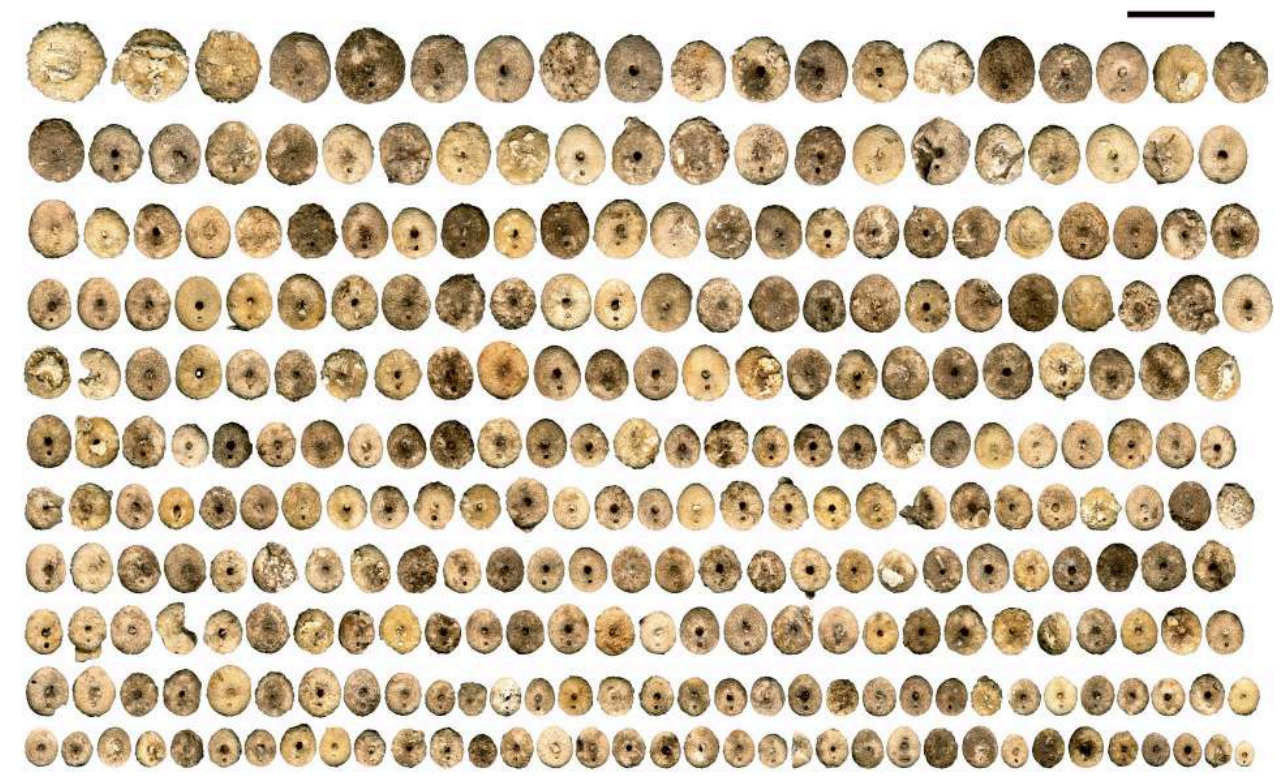


Figure 32 - Diamètre maximal des oursins fossiles de la collection de comparaison oligocène et des pièces archéologiques de Saint-Germain-la-Rivière.

Figure 32 - Maximum diameter of fossil sea urchins from our Oligocene reference collection and of the archaeological specimens from Saint-Germain-la-Rivière.

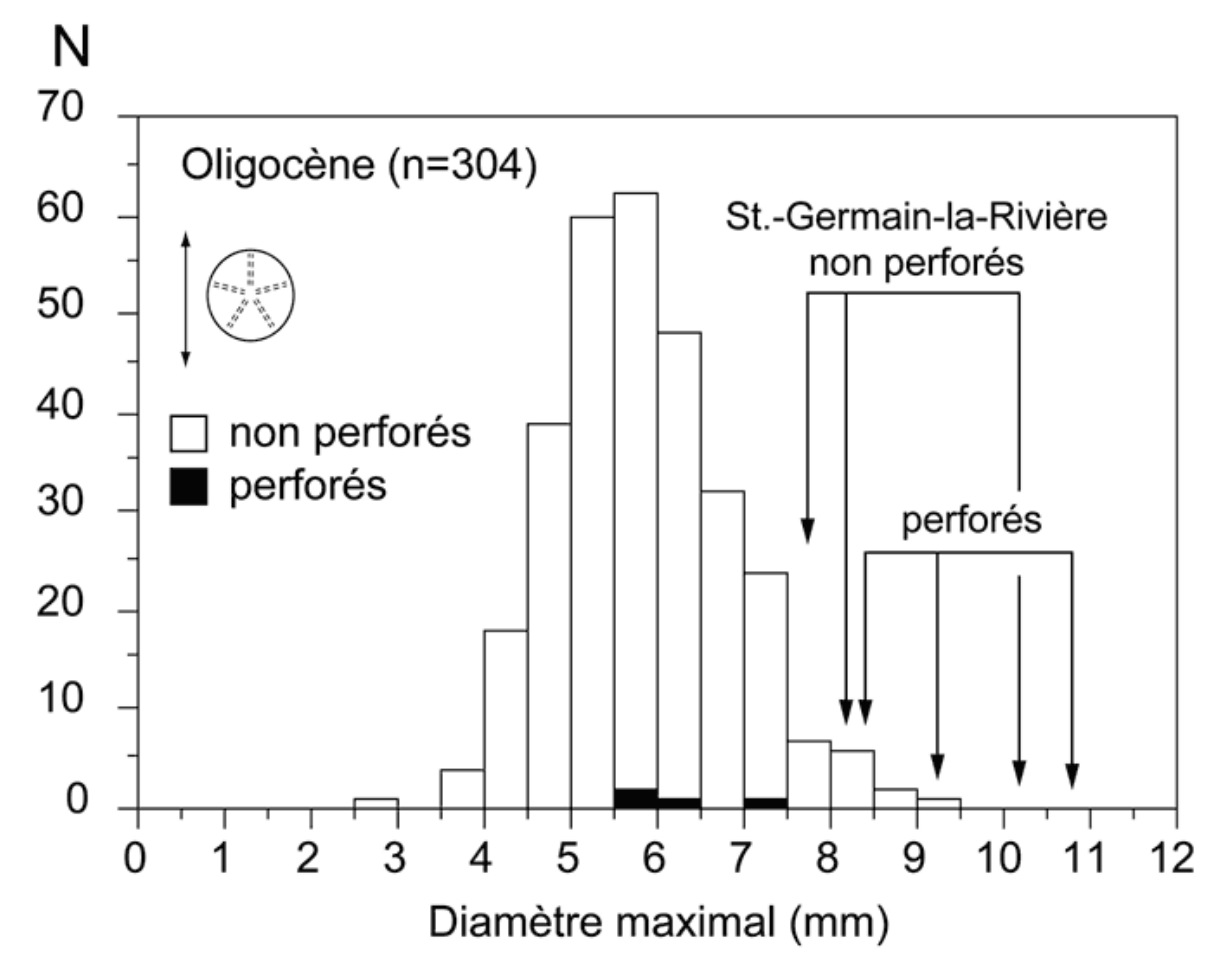

L'analyse microscopique de la perle ronde en stéatite (fig. $28 \mathrm{n}^{\circ} 12$, fig. 33) révèle de rares traces d'une abrasion réalisée en frottant la pièce sur une surface rugueuse. Les stries parallèles engendrées par cette technique sont partiellement effacées par une abrasion postérieure, réalisée par des éléments abrasifs libres (Fig. $33 \mathrm{~d}$ ). Des stries dues au port de la perle se superposent à ces dernières sans que l'on puisse les distinguer aisément. Contrairement à ce que l'on observe généralement la surface de la perforation est couverte de stries parallèles qui la traversent longitudinalement (fig. 33 b-c). Leur largeur et présence sur la totalité de la perforation évoquent plus le glissement d'une tige souple pour régulariser les parois de la perforation que des traces d'utilisation. Une zone avec quelques stries concentriques grossières garde la trace de la rotation de l'outil responsable de perforation. 
Figure 33 - Analyse au MEB des traces de fabrication sur la perle ronde en stéatite provenant des fouilles Trécolle. Les photos $b, c$ et $d$ sont prises au MEB sur des répliques en résine.

Figure 33 - Microscopic analysis of the traces of manufacture on the round steatite bead from the Trécolle excavations. Photos $b, c$ and $d$ are taken by SEM on resin replicas.
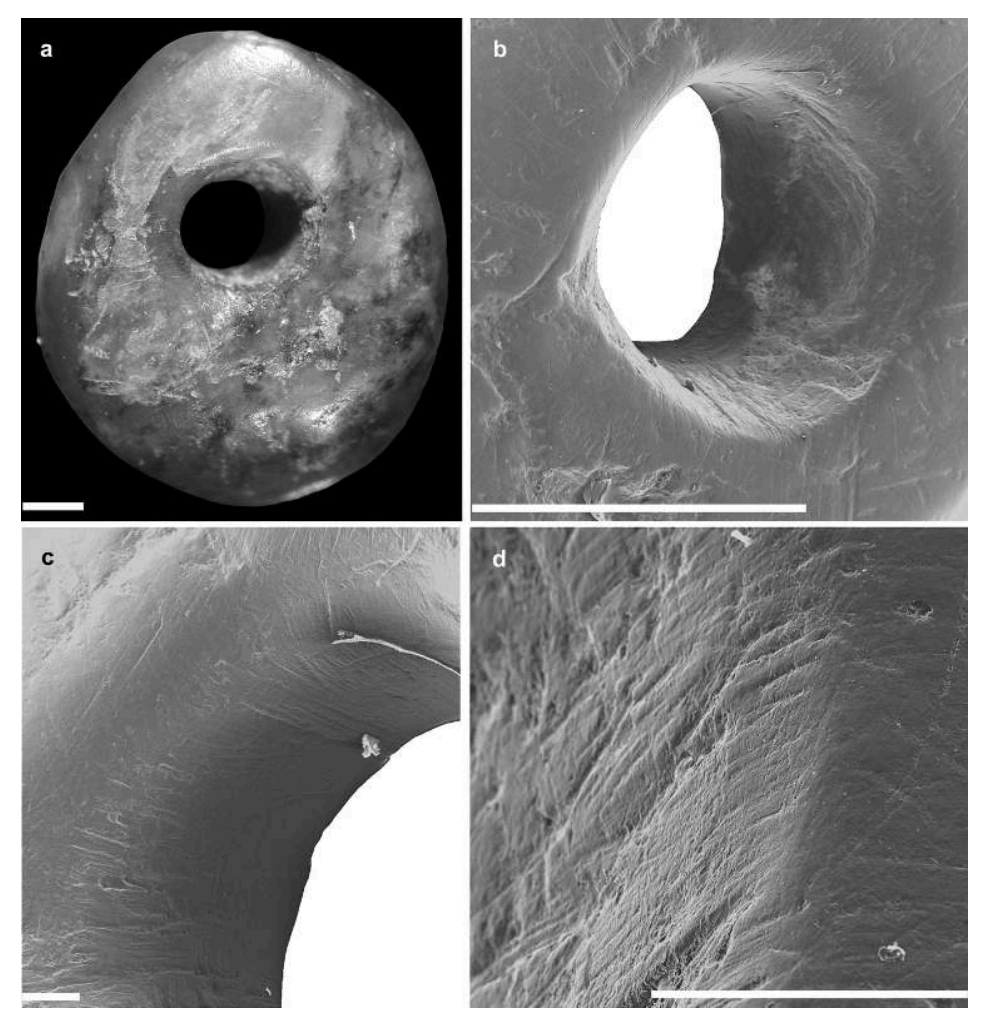

ab : Echelle $=1 \mathrm{~mm}$

$\mathrm{c}:$ Echelle $=100 \mu \mathrm{m}$

$\mathrm{d}:$ : Echelle $=10 \mu \mathrm{m}$

$a b:$ Scale $=7 \mathrm{~mm}$

c: Scale $=100 \mu \mathrm{m}$

d: Scale $=10 \mu \mathrm{m}$

La perle biforée en stéatite de la couche $\mathrm{C} 2\left(\right.$ fig. $29 \mathrm{n}^{\circ} 1$ ) conserve des traces plus claires d'une abrasion sur une meule dormante. L'analyse microscopique des perforations met en évidence une technique de percement originale (fig. 34). Les perforations ont été réalisées par deux forets de taille différente. Le premier avait une pointe cylindrique creuse, comme l'indique le rebord visible près de la perforation. Le deuxième, également cylindrique mais plus fin, a profité de la cupule engendrée par le premier pour achever la perforation. 
Figure 34 - Perle en stéatite imitant une incisive de renne issue des fouilles Trécolle. La flèche en a indique la zone agrandie en $c$ et $d$. Les photos $b$ et $c$ sont prises au MEB sur des répliques en résine.

Figure 34 - Steatite bead from the Trécolle excavation imitating a reindeer incisor. Arrow in a indicates the area enlarged in $b$ and $c$. Photos $b$ and $c$ are taken with a SEM on resin replicas.

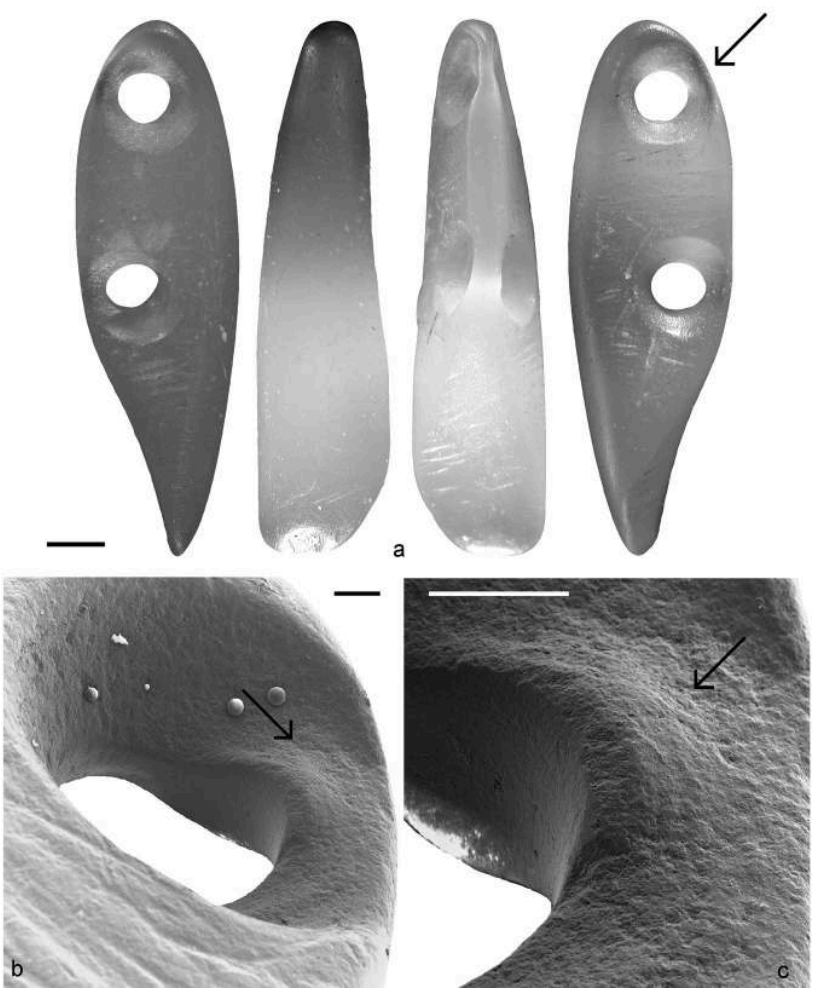
$\mathrm{a}:$ Echelle $=1 \mathrm{~mm}$
b : Echelle $=100 \mu \mathrm{m}$
c: : Echelle $=10 \mu \mathrm{m}$
a: Scale $=1 \mathrm{~mm}$
b: Scale $=100 \mu \mathrm{m}$
c: Scale $=10 \mu \mathrm{m}$

Le support des perles rondes réalisées à partir des épiphyses de métacarpes vestigiaux de renne (fig. $\left.29 \mathrm{n}^{\circ} 10,11\right)$ a pu être obtenu par simple détachement de celle-ci de la diaphyse chez de jeunes animaux ou en sciant l'articulation synostosée chez des adultes. Aucune trace de sciage n'apparaît sur les pièces étudiées, mais celles-ci ont pu être effacées par l'abrasion qui a régularisé cette zone. La perforation a été obtenue en raclant les surfaces mésiales et latérales avec une pointe en silex (fig. 35 a) et en perforant ensuite l'os par rotation avec une pointe lithique (fig. 35 b, c). L'épiphyse de métacarpe vestigiel de renne provenant de l'interface entre les couches $\mathrm{C} 3$ et $\mathrm{C} 4$ ne porte pas de traces anthropiques claires. 
Figure 35 - Détails des perforations sur les métacarpes vestigiels de renne provenant des fouilles Trécolle. Echelle $=1 \mathrm{~mm}$.

Figure 35 - Close-up view of the perforations on reindeer vestigial matacarpals from the Trécolle excavations. Scale $=1 \mathrm{~mm}$.
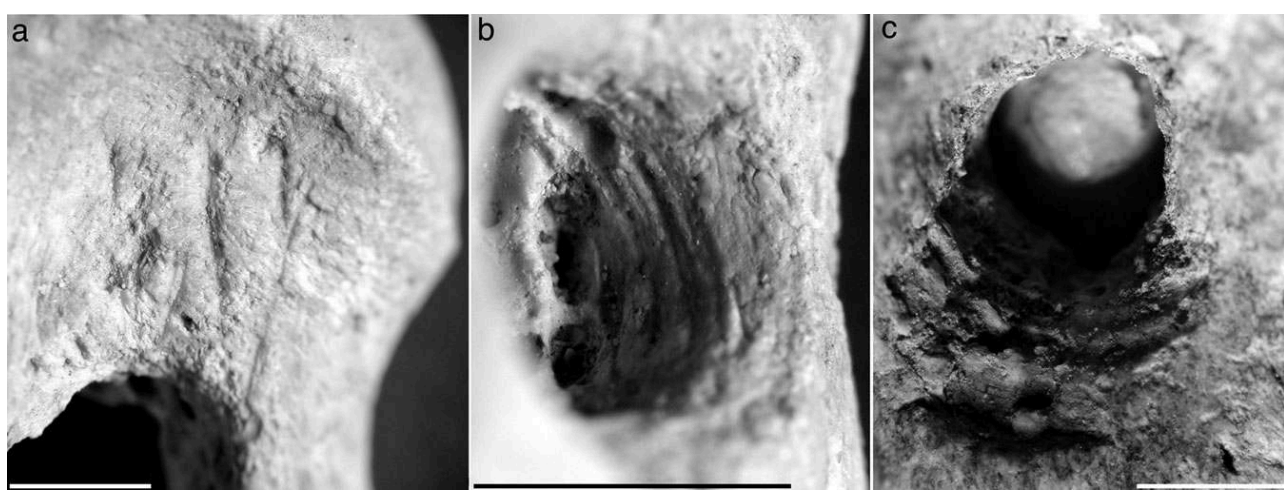

\section{Discussion}

Pouvons-nous interpréter le mobilier funéraire de la Dame de Saint-Germain-la-Rivière et, en particulier, les nombreuses craches percées comme la preuve que les sociétés magdaléniennes possédaient des richesses, c'est-à-dire des accumulations de biens déterminant des inégalités sociales? Dans les sociétés de chasseurs-cueilleurs où de telles richesses existent (Kroeber 1925 ; Ceci 1982 ; Godelier 1996; Ingold et al., 1991 ; Dubin 1999), elles sont composées d'objets présentant une ou plusieurs des caractéristiques suivantes :

- ces objets sont fait dans des matériaux rares soit par nature soit par l'éloignement de leur lieu d'origine ;

- leur fabrication demande un investissement important de temps et de travail ;

- leur production utilise des techniques complexes maittrisées exclusivement par certains membres du groupe;

- ils présentent une standardisation de forme et de couleur. Les trois premiers comportements assurent le contrôle de la production des unités de valeur, le dernier garantit l'interchangeabilité d'objets ayant la même valeur. Dans les sociétés traditionnelles, le port ostentatoire de parures constituées de nombreux objets exotiques acquis par échange caractérise les individus appartenant à un groupe social dominant (Ingold et al., 1991 ; Boone 1998 ; Neiman 1998 ; Smith et Bleige-Bird 2000 ; Testart 2001).

Selon les sociétés, ces richesses sont héritées, distribuées, échangées, détruites ou abandonnées de façon ritualisée, par exemple lors de cérémonies funéraires (Testart 2001, 2003). L'abandon de ces biens dans la tombe s'inscrit généralement dans une stratégie de soustraction délibérée de richesse au réseau d'échange qui empêche la perte graduelle de leur valeur due à l'introduction, par production ou échange, de nouveaux objets dans le système. Dans ces sociétés, les individus ayant accès à ces richesses constituent une minorité. Les autres membres peuvent recevoir en prêt ou en cadeau de petites quantités de ces biens et posséder des biens de moindre prestige car moins élaborés ou d'origine non exotique. Largement diffusés au sein de la société et utilisés par la plus grande partie de ses membres, ces derniers biens devraient avoir plus de chance d'être perdus puis englobés dans le registre archéologique. Les cérémonies funéraires réservées aux " gens communs " peuvent être très différentes de celles destinées aux " honorables" ou simplement constituer une version simplifiée des 
premières (Testart 2003). Des études transculturelles indiquent que l'appartenance à un groupe social privilégié est souvent marquée par la construction de structures mortuaires durables (Tainter 1978 ; Carr 1995). Nous devrions par conséquent pouvoir identifier des sociétés complexes par la présence de sépultures associées à des biens de prestige et à des structures élaborées. Ces sépultures devraient soit s'accompagner d'autres, sans mobilier ou avec un mobilier constitué de biens de moindre prestige pouvant inclure des petites quantités d'objets exotiques, soit apparaître comme les seules témoignages funéraires - indice que les membres des groupes sociaux moins privilégiés étaient soumis à des pratiques funéraires archéologiquement invisibles.

Plusieurs indices font penser que le mobilier funéraire de Saint-Germain-la-Rivière devait représenter une richesse et que son abandon dans la sépulture pourrait témoigner des pratiques que nous venons d'évoquer.

\section{Caractère rare de la parure}

50 Les craches associées avec certitude à la sépulture sont au nombre de 69 et possèdent toutes une seule perforation ${ }^{2}$. Elles proviennent, en considérant les appariements, de 63 individus, 55 mâles et 8 biches. Cet ensemble correspond à une accumulation de dents prélevées sur des animaux abattus au cours d'une période relativement longue et probablement pendant plusieurs années. Mais l'importance prise par cette espèce dans la parure associée à la sépulture contraste avec sa virtuelle absence dans les assemblages fauniques exhumés des couches d'occupation de ce site par les fouilles Trécolle. Ces assemblages (Costamagno 1999) sont dominés par l'Antilope saïga (entre 84 et $66 \%$ du NISP), suivie par le Renne (entre 17 et $8 \%$ du NISP). La présence de restes de Cerf est exceptionnelle dans toutes les couches (moins de 0,1\%). De plus, le Cerf est absent dans les couches ( $\mathrm{C} 1$ et $\mathrm{C} 2$ ) qui ont livré les dates ${ }^{14} \mathrm{C}$ les plus proches de celle obtenue pour la sépulture (fig. 36). A cela s'ajoute le fait que les ensembles fauniques issus de ces couches présentent une forte cohérence écologique (association Saïga, Renne, Cheval) indiquant un environnement steppique sec et froid (Delpech et al., 1983). Des assemblages fauniques comparables se retrouvent dans tous les sites contemporains du Sud-ouest de la France (Delpech 1983 ; Slott-Moller 1988 ; SeronieVivien 1995 ; Costamagno 1999 ; Castel 1999) indiquant que le Cerf, et par conséquent la matière première nécessaire à la production de la parure de la sépulture, devait être très rare voir absent dans la région. 
Figure 36 - Calibration des dates ${ }^{14} \mathrm{C}$ obtenues sur le squelette de la Dame de Saint-Germain-laRivière et sur des fragments de charbon provenant des couches d'habitat du site.

Figure 36 - Calibration of the ${ }^{14} \mathrm{C}$ dates from the Saint-Germain-la-Rivière skeleton and from charcoal collected in the archaeological layers of the site.

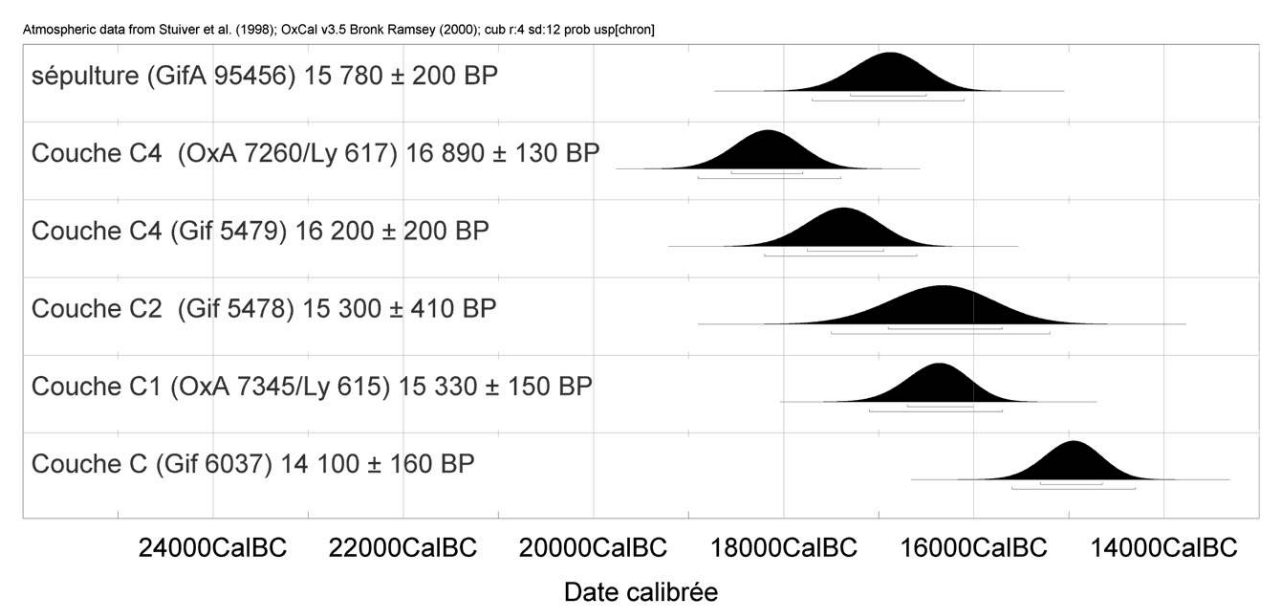

\section{Caractère exotique de la parure}

51 D'où viennent alors toutes ces craches? Elles peuvent provenir de cerfs chassés par les Magdaléniens de Saint-Germain-la-Rivière dans des régions méridionales ou avoir été acquises par échange. La deuxième hypothèse semble la plus probable. En effet, les gisements contemporains les plus proches (fig. 37, tab. 4) avec une présence notable de Cerf se situent à au moins 300 km de Saint-Germain-la-Rivière, au Pays Basque espagnol (Altuna et Merino 1984; Altuna et al., 1985; Utrilla 1982) et dans le Piémont languedocien (Fontana 1999 ; Sacchi 1986). Cette distance est généralement considérée comme le rayon maximal de circulation des groupes de chasseurs-cueilleurs autours de leurs campements de base (Wobst 1976 ; Kelly 1983, 1995 ; Hewlett et al., 1986 ; FéblotAugustins et Perlès 1992). On pourrait avancer que les sites du nord de l'Aquitaine marquaient la limite septentrionale de ce rayon et que les groupes qui les fréquentaient pouvaient chasser le Cerf dans la zone méridionale de leur territoire. Cependant, cette hypothèse est contredite d'une part par les études sur les saisons d'occupation de SaintGermain-la-Rivière et de Moulin-Neuf, qui montrent que les Magdaléniens de Gironde ont occupé annuellement cette région (Costamagno 2001) et, d'autre part, par les datations ${ }^{14} \mathrm{C}$ disponibles qui indiquent qu'aucun site archéologique n'est recensé dans le bassin aquitain au sud de la Garonne entre 16500 et 15000 BP. 
Figure 37 - Carte de distribution des sites (points noirs) et sépultures (points blancs) datés par ${ }^{14} \mathrm{C}$ entre 16500 et $15000 \mathrm{BP}$.

Figure 37 - Distribution map of the sites (black dots) and burials (white dots) dated by ${ }^{14} \mathrm{C}$ between 16500 and $15000 B P$.

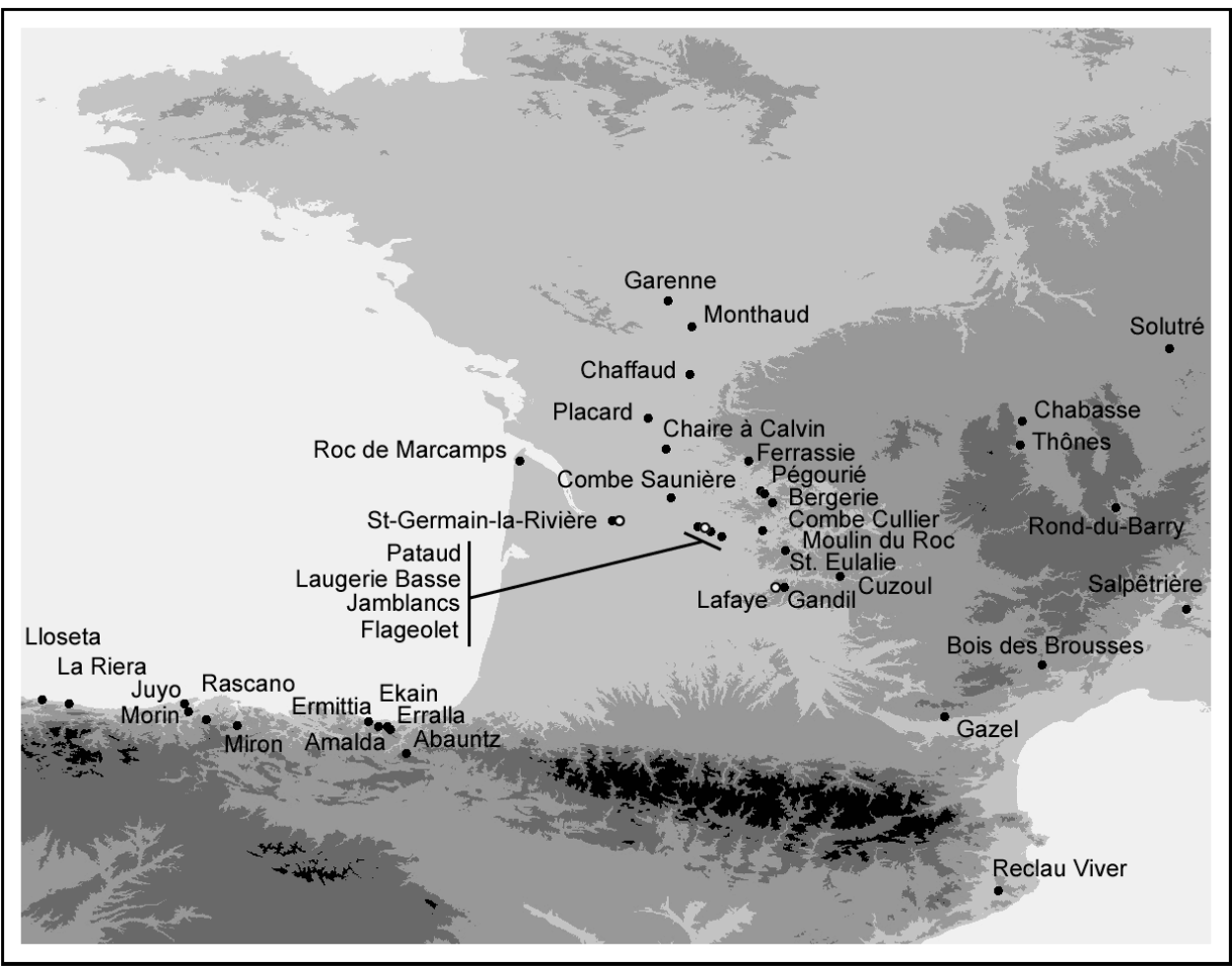

Tableau 4 - Sites d'habitat et sépultures ${ }^{*}$ ) datés par ${ }^{14} \mathrm{C}$ entre 16500 et $15000 \mathrm{BP}$. Table 4 - Living sites and burials (*) dated by ${ }^{14} \mathrm{C}$ between 16500 and 15000 BP.

\begin{tabular}{|c|c|c|c|c|c|c|c|}
\hline Site & Date & Sigma & Code & Site & Date & Sigma & Code \\
\hline Grand Sud-Ouest & & & & Côte Cantabrique & & & \\
\hline Jamblancs & 16490 & 130 & Gif 8668 & Rascano & 16433 & 131 & BM 1455 \\
\hline Placard & 16300 & 190 & Gif 8803 & La Riera & 16420 & 430 & GAK 6448 \\
\hline Combe Saunière & 16300 & 220 & OXA 485 & Erralla & 16400 & 240 & | 12551 \\
\hline St-Germain-la-Riviere & 16200 & 600 & Gif 5479 & Miron & 16370 & 190 & GX 23395 \\
\hline Amalda & 16200 & 380 & | 11428 & Erralla & 16270 & 240 & | 12868 \\
\hline Miron & 16130 & 250 & GX 23396 & Ekain & 16250 & 500 & | 12566 \\
\hline Garenne (Grand Abri) & 15847 & 1220 & C 578 & Amalda & 16090 & 240 & | 11435 \\
\hline St-Germain-la-Riviere * & 15780 & 200 & GifA 95456 & Ekain & 16030 & 240 & | 12224 \\
\hline Combe Saunière & 15750 & 230 & OXA 410 & Rascano & 15988 & 193 & BM 1453 \\
\hline Laugerie Haute & 15730 & 200 & OXA 760 & Ekain & 15970 & 240 & | 12225 \\
\hline Roc de Marcamps & 15700 & 450 & Ly 2681 & La Riera & 15860 & 330 & GAK 6450 \\
\hline La Riera & 15690 & 310 & UCR 1271A & Erralla & 15800 & 230 & 13728 \\
\hline Lloseta & 15655 & 412 & - & Abauntz & 15800 & 350 & Ly 1965 \\
\hline Garenne (Grand Abri) & 15560 & 580 & Ly 1126 & Erralla & 15740 & 240 & 12540 \\
\hline Combe Saunière & 15480 & 210 & OXA 459 & Morin & 15683 & 1800 & WSU 500 \\
\hline Monthaud & 15450 & 290 & Ly 2758 & La Riera & 15600 & 570 & GAK 6449 \\
\hline Chaire à Calvin & 15440 & 440 & Ly 1998 & La Riera & 15520 & 350 & Q 2110 \\
\hline St-Germain-la-Riviere & 15330 & 150 & OXA 7345 & Ermittia & 15420 & 145 & Ua 4244 \\
\hline Garenne (Grand Abri) & 15330 & 950 & Ly 1125 & Ekain & 15400 & 240 & | 12226 \\
\hline St-Germain-la-Riviere & 15300 & 410 & Gif 5478 & Juyo & 15300 & 700 & M 830 \\
\hline Laugerie Basse * & 15290 & 150 & GifA 95047 & La Riera & 15230 & 300 & Q 2116 \\
\hline Flageolet II & 15250 & 320 & Ly 918 & Miron & 15220 & 300 & GX 23393 \\
\hline Pataud & 15215 & 250 & GrN 2254 & Miron & 15220 & 100 & GX 23416 \\
\hline Combe Saunière & 15200 & 200 & OXA 754 & Lloseta & 15200 & 412 & GAK 2549 \\
\hline Combe Saunière & 15190 & 200 & OXA 751 & Miron & 15180 & 100 & GX 23415 \\
\hline Ferrassie & 15180 & 130 & Gif 2428 & Rascano & 15173 & 160 & BM 1452 \\
\hline Chaffaud & 15160 & 150 & - & Miron & 15010 & 260 & GX 23392 \\
\hline Combe Saunière & 15120 & 200 & OXA 756 & & & & \\
\hline Pataud & 15080 & 100 & GrN 2054 & Méditerranée & & & \\
\hline Roc de Marcamps & 15070 & 270 & Ly 4222 & Reclau Viver & 16200 & 500 & M 1020 \\
\hline Pégourié & 16090 & 320 & Ly 5258 & Bois des Brousses & 15800 & 300 & MC 2247 \\
\hline Gandil & 16070 & 160 & Gif A 93238 & Gazel & 15070 & 270 & Gif 2655 \\
\hline Cuzoul & 15980 & 150 & Gif 6638 & Salpêtrière & 15000 & 1000 & Mc 920 \\
\hline Bergerie (Caniac) & 15830 & 400 & Ly 1830 & & & & \\
\hline Lafaye * & 15660 & 130 & GifA 94204 & Centre-Est & & & \\
\hline Moulin du Roc & 15600 & 1200 & Ly 5445 & Chabasse & 15630 & 120 & - \\
\hline Gandil & 15550 & 140 & Gif 9175 & Rond-du-Barry & 15420 & 170 & Ly 3808 \\
\hline Gandil & 15380 & 140 & Gif 9176 & Rond-du-Barry & 15400 & 400 & Gif 2672 \\
\hline Sainte-Eulalie & 15200 & 300 & Gif 2194 & Thônes & 15100 & 60 & \\
\hline Sainte-Eulalie & 15100 & 270 & Gif 1745 & Solutré & 15080 & 130 & OXA 6730 \\
\hline Combe Cullier & 15030 & 330 & Ly 978 & & & & \\
\hline
\end{tabular}


Les premiers indices d'une nouvelle occupation de cette région ne sont attestés qu'à partir de 14800 BP dans des sites comme Dufaure (Landes), Aurensan, Bois du Cantet, Bedeilhac (Pyrénées) et s'accompagnent de faunes froides (Renne, Cheval) avec de rares restes de cerf (Bahn 1983; Altuna et Mariezkurrena 1995). Bien que les raisons de l'absence de sites dans le sud du bassin aquitain soient encore à déterminer, cette absence semble indiquer que les territoires de chasse des Magdaléniens nord aquitains ne s'étendaient pas vers le sud où les cerfs étaient peut être plus répandus. L'hypothèse alternative est que les craches associées à la sépulture soient le résultat d'une longue accumulation de craches acquises par les Magdaléniens nords aquitains au cours de chasses exceptionnelles à cette espèce. Cette hypothèse ne peut être exclue mais le faible nombre d'appariements dans la sépulture et de restes de cerf dans les couches archéologiques de la région rendent une origine exclusivement régionale de craches peu probable. Repérer avec certitude la région de provenance des craches obtenues par échange est pour l'instant problématique. La découverte de cyprées méditerranéens (Luria lurida et Zonaria pyrum) dans la sépulture contemporaine de " l'Homme écrasé " de Laugerie Basse (Massenat et al., 1872, Taborin 1993 : 431) démontre que des objets de parure arrivaient à cette époque en Aquitaine en provenance de la Méditerranée. La présence d'éléments de parure aussi caractéristiques que les perles sur épiphyse distale de métacarpe vestigiel de renne à la Grotte Gazel, dans le couloir de l'Aude (Sacchi 1986) indique des similitudes entre ces deux régions. Quelle que soit la région de provenance, l'origine exotique de la totalité ou de la plupart des craches semble vraisemblable.

\section{Caractère standardisé de la parure}

53 La contradiction entre d'un côté une présence aussi abondante de craches dans la sépulture et d'un autre la composition faunique du site et des sites contemporains de la région est encore plus frappante en considérant les classes d'âges représentées et la proportion de cerfs mâles par rapport aux biches. On pourrait s'attendre, dans un milieu où les cerfs étaient rares, à voir les magdaléniens profiter de toutes les craches disponibles. Or, même si on interprète la courbe de mortalité en forme de "L" (Stiner 1994 ; Klein 1982 ; Klein et Cruz-Uribe 1982 ; d'Errico et Vanhaeren 2002) observée chez les mâles comme le reflet d'une chasse non sélective s'attaquant tout le long de l'année à une population naturelle, il n'en reste pas moins que les craches de vieux mâles sont sous représentées. La proportion de craches de biches correspond quant à elle au plus faible pourcentage observé dans des collections de craches perforées que nous avons pu étudier. A l'Aven des Iboussières (d'Errico et Vanhaeren 2002), où une chasse épargnant les biches en âge de reproduction a été identifiée, le pourcentage des craches de biche (35\%) est trois fois supérieur à celui du " collier " de la sépulture de Saint-Germain-laRiviere (12\%). Ce dernier semble donc se caractériser par un choix délibéré de craches de jeunes mâles adultes. Ces dents, de morphologie semblable, sont celles qui produisent le plus fort impact visuel en raison de la grande taille de leurs couronnes. Un intérêt pour des objets finis de forme standardisée est confirmé par l'analyse technologique des craches. L'étude des perforations sur l'ensemble des craches révèle d'un part que plusieurs artisans et outils ont été impliqués dans leur réalisation et, d'autre part, que tous ces artisans ont fait attention à produire des perforations relativement grandes et localisées au centre de la racine. Cette standardisation indique que les craches ont été perforées de façon à obtenir des objets semblables et 
interchangeables au sein d'une parure. Ce constat s'accorde avec l'hypothèse selon laquelle, pour garder leur valeur, ces dents devaient être conformes à des canons partagés par les " producteurs" et les " acquéreurs". Le fait que les paires semblent avoir été perforées à chaque fois par un seul individu indique que la perforation a été probablement effectuée peu après l'abattage de l'animal et certainement au sein du groupe responsable de sa chasse. Le constat du faible nombre d'appariements s'accorde avec notre interprétation si on conçoit un système de circulation dans lequel le lot de craches disponibles lors de l'échange est significativement supérieur au nombre de craches acquises ou implique un nombre relativement élevé d'intermédiaires. Les craches perforées découvertes dans les sites du Magdalénien ancien de la côte cantabrique et du Languedoc ne contredisent pas cette hypothèse. Elles présentent dans les deux cas et comme chez la Dame de Saint-Germain-la-Rivière des perforations de moyenne à grande taille obtenues par rotation et situées au milieu de la racine. Comme dans la sépulture, certaines craches des deux régions sont décorées d'entailles gravées sur la surface occlusale de la couronne (Corchon 1986; Sacchi 1986). L'ensemble de ces similitudes est difficilement explicable comme le simple résultat d'une convergence technique. Par exemple, aucune des perforations sur les 196 craches associées à la sépulture multiple épipaléolithique de l'Aven des Iboussières (d'Errico et Vanhaeren 2002) porte les traces d'un percement par rotation et leurs dimensions sont significativement plus petites que celles de Saint-Germain-la-Rivière. Contrairement à ce dernier site, les entailles qui décorent les craches de l'Aven des Iboussières sont en grande majorité localisées sur les racines et ne forment jamais de motifs complexes comme ceux présents sur les craches de la sépulture et des sites contemporains du Lot et de la côte cantabrique. Les craches associées à la sépulture gravettienne de Lagar Velho (Vanhaeren et d'Errico 2003) ont des perforations encore plus petites, localisées près du bord proximal de la racine, phénomène absent à Saint-Germain-la-Rivière. En somme, ces différences démontrent que la catégorie des " craches perforées " cache un éventail de choix possibles qui peuvent, une fois identifiés par le croisement d'informations archéozoologiques, techniques, morphométriques et stylistiques, servir pour délimiter des territoires de production et circulation d'objets.

\section{La parure des " autres"}

54 Aucun objet de parure découvert en stratigraphie dans les couches d'occupation contemporaines de la sépulture ne trouve d'analogue dans les objets associés à celle-ci. La parure des couches d'habitat est dominée par les incisives de renne et leurs imitations en stéatite ainsi que par les perles rondes réalisées en stéatite ou en utilisant des oursins fossiles et des métacarpes de renne. A l'exception des pièces en stéatite, dont la source n'est pas établie, tous ces objets sont réalisés dans des matières d'origine locale ou régionale. Ceci et le fait que l'on retrouve en abondance ces mêmes objets dans les autres sites contemporains (Ladier et Welté 1994), s'accordent avec l'hypothèse que les objets abandonnés dans les couches d'habitat représentent des biens d'utilisation plus courante et de valeur moindre que ceux de la Dame de Saint-Germainla-Rivière.

Quant aux sépultures, des quatre inhumations attribuées au Magdalénien ancien/ moyen ou datées par le ${ }^{14} \mathrm{C}$ de cette époque (Gambier et al., 2000), trois (Lafaye, Cap Blanc et Chancelade) ne semblent pas avoir livré d'objets de parure (Hardy 1888; Capitan et Peyrony 1912; May 1986; Binant 1991). La dernière (Laugerie Basse) 
comportait une vingtaine de cyprées dont certaines méditerranéennes (Massenat et al., 1872; Taborin 1993: 431), une catégorie d'objets qui faisait également partie du mobilier funéraire de Saint-Germain-la-Rivière.

Les données archéologiques s'accordent donc avec l'idée que certains groupes du Magdalénien ancien du Sud-Ouest possédaient des objets de parure courants et des objets de prestige d'origine exotique destinés à accompagner certains individus dans la tombe.

\section{La parure hors contexte stratigraphique}

57 Les objets de parure découverts hors stratigraphie ne contredisent pas notre cadre interprétatif. Les objets exotiques y sont rares (craches isolées Mirande et Blanchard) ou découverts sous la forme d'objets finis (collier Mirande) qui ont pu s'inscrire dans une logique de soustraction semblable à celle identifiée pour la sépulture ou même, en considérant le peu d'informations que l'on possède sur ces objets, être associés aux vestiges humains isolés découverts dans la même zone du site.

Les craches du collier Mirande, bien que d'apparence très différentes de celles de la sépulture, pourraient avoir joué un rôle semblable. Comme ces dernières, elles semblent avoir été acquises par échange comme suggéré par l'absence d'appariements. Cette absence est d'autant plus frappante que le collier, clairement construit sur la symétrie, aurait pu gagner en éclat par l'utilisation de craches appariées. Mais, contrairement aux craches de la sépulture à une seule perforation, celles du collier semblent avoir été perforées par les Magdaléniens de la région, à en juger par la similitude de leurs perforations avec celles pratiquées sur les incisives de renne et l'absence de craches biforées dans les régions voisines. A cette différence s'ajoute celle engendrée par leur façonnage. En modifiant les craches par sciage et abrasion, le ou les artisans ont exclu celles-ci du réseau d'échange qui l'approvisionnait avec l'objectif d'intégrer définitivement ces objets dans une parure figée ne pouvant vraisemblablement être échangée qu'en entier. Il est raisonnable de penser que le transfert d'un tel " capital " ne devait pas représenter un fait anodin dans la vie de la communauté. Dans les sociétés traditionnelles possédant des richesses (Testart 1996, 2000 ; Dubin 1999) la transmission de parures de ce type se fait par exemple à l'occasion de l'acquisition d'une femme ou pour payer les services d'un chaman ou le prix du sang.

\section{Conclusion}

Notre étude semble indiquer que certains membres des sociétés du Magdalénien ancien/moyen du Sud-Ouest de la France possédaient des richesses constituées d'objets de parure rares, très probablement exotiques. A l'instar de ce que l'on observe chez certaines populations de chasseurs-cueilleurs et en contradiction avec le caractère supposé égalitaire des groupes humains paléolithiques, ces objets étaient probablement utilisés pour marquer l'appartenance de certains individus à des groupes sociaux privilégiés. 
Figure 38 - Rosy White Thunder, femme indienne Sioux Figure 38 - Rosy White Thunder, Sioux Indian woman

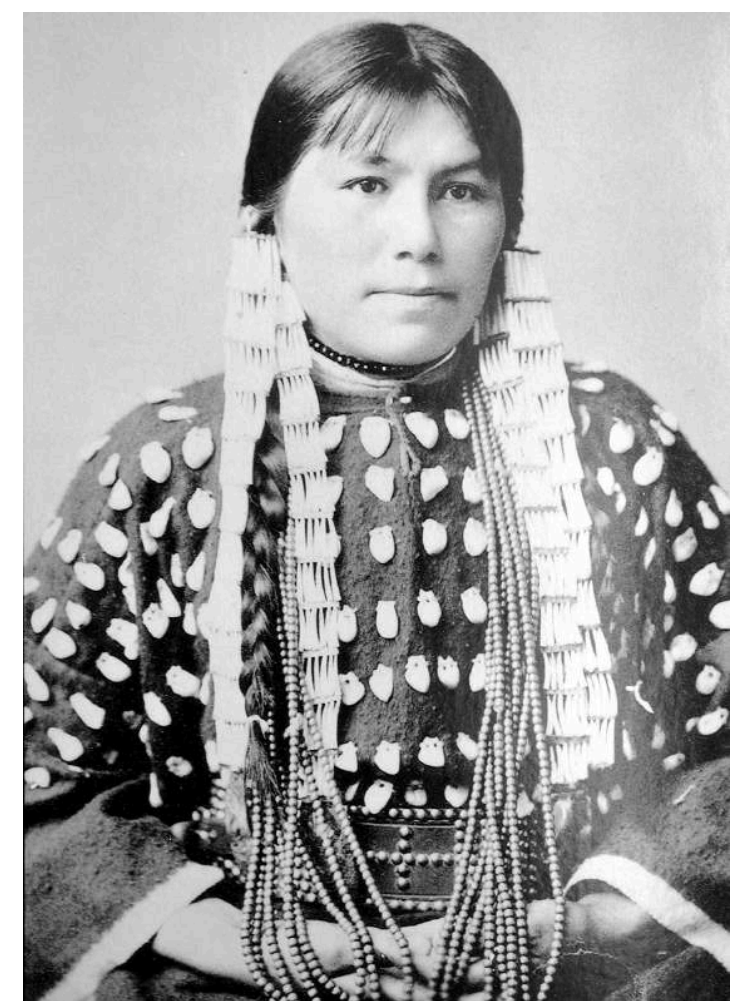

(Photographe anonyme, Indigena Fine Art Publishers Ltd. and Montana Historical Society). (Photographer unknown, Indigena Fine Art Publishers Ltd. and Montana Historical Society).

\section{Remerciements}

Nous remercions l'équipe du Musée National de Préhistoire (Les Eyzies-de-Tayac) et en particulier J.-J. Cleyet-Merle, A. Morala, Ch. Fortin, Ph. Jugie, B. Nicolas, S. Madelaine, P. Jacquement, $C$. Boussat et J. Angot-Westin. Nous sommes également très reconnaissants envers Ch. Martin et M. Rault pour nous avoir permis d'étudier la collection de Saint-Germain-la-Rivière conservée au Musée de la Société Historique et Archéologique de Libourne. L'aide de M. Lenoir nous a également été précieuse. Il nous a autorisé à étudier la parure issue des fouilles $G$. Trécolle, nous a aimablement fourni la collection de référence des oursins, ainsi que des informations indispensables sur certains vestiges et sur l'historique des fouilles. J.-G. Ferrier et $M$. Lenoir ont assuré la relecture critique du manuscrit. V. Laroulandie, S. Costamagno et $F$. Delpech nous ont aidé dans notre " chasse " aux Cerfs magdaléniens. Nous remercions également les trois lecteurs désignés par Paléo, J.-Ph. Brugal, D. Gambier et Y. Taborin, pour la grande attention avec laquelle ils ont relu le manuscrit. Cette recherche a été financée par le programme OHLL/OMLL de l'European Science Foundation, par l'ACI Espaces et Territoires du Ministère délégué de la Recherche et des Nouvelles Technologies et par le programme ECLIPSE du CNRS. 


\section{BIBLIOGRAPHIE}

ALTUNA J et MARIEZKURRENA K. 1995 - Les restes Osseux de Macromammifères. In : STRAUS L.G. 1995 (Ed.) - Les derniers chasseurs de rennes du monde pyrénéen. L'abri Dufaure : un gisement tardiglaciaire en Gascogne. Issoudun : Imprimerie Laboureur, p. 181-211. (Mémoire SPF 22)

ALTUNA J. et MERINO J.M. 1984 - El yacimiento prehistorico de la cueva de Ekain (Deba, Guipuzcoa). San Sebastian : Sociedad de Estudios Vascos, 1984.

ALTUNA J., BALDEON A. et MARIEZKURRENA K. (Eds.) 1985 - Cazadores Magdalenienses en Erralla (Cestona, Pais Vasco). San Sebastian : ARANZADI, 1985. (Munibe 37)

ARNOLD J. 1996 - The archaeology of complex hunter-gatherers. Journal ofArchaeological Method and Theory, 1996, 3, p. 77-126.

BAHN P.G. 1983 - Pyrenean prehistory: a palaeconomic survey of the French sites. Warminster, Wiltshire: Aris et Phillips.

BAHN P.G. 2001 - Save the Last Trance For Me: An Assessment of the Misuse of Shamanism in Rock Art Studies. In: Francfort H.P. et Hamayon R.N. (Eds.), The Concept of Shamanism, Uses and Abuses. Budapest : Akademiai Kiado, 2001, p. 51-94. (Bibliotheca Shamanistica, 10)

BEAUNE S. de 1998 - Chamanisme et préhistoire : un feuilleton à épisodes. L'Homme, 1998,147, p. 203-219.

BINANT P. 1991 - Les sépultures du Paléolithique. Paris : Errance, 1991. (Collection archéologie aujourd'hui)

BLANCHARD R. 1935 - Découverte d'un squelette humain à Saint-Germain-la-Rivière, Bordeaux. Revue Historique et Archéologique du Libournais, 1935, 9, p. 109.

BLANCHARD R. s.d. - Notice sur le fossile humain de Saint-Germain-la-Rivière. Montignac : Imprimerie de la Vézère, s.d.

BLANCHARD R., PEYRONY D. et VALLOIS H.V. 1972 - Le gisement et le squelette de Saint-Germain-laRivière. Paris : Masson, 1972. (Archives de l'Institut de Paléontologie Humaine, Mémoire 34)

BODU P. 1993 - Analyse typo-technologique du matériel lithique de quelques unités du site magdalénien de Pincevent (Seine-et-Marne). Applications spatiales, économiques et sociales. Nanterre : Université de Paris I, 1993. (Thèse de Doctorat)

BOONE J. 1998 - The evolution of magnanimity: when is it better to give than to receive? Human Nature, 1998, 9(1), p. 1-21.

BOSINSKI G., D’ERRICO F. et SCHILLER P. 2002 - Die graviertenFrauendarstellungen von Gönnersdorf. Stuttgart : Steiner, 2002.

BOUVIER J.-M. et TRECOLLE G. 1966 - La frise gravée de Saint-Germain-la-Rivière. L'Anthropologie, 1966, 70, p.: 535-540.

BRAIN R. 1979 - The decorated body. London: Hutchinson, 1979.

CAHEN D. et VAN NOOTEN F. 1980. De Tjongervindplaats Meer IV. Archaeologia Belgica, 1980, 223.

CAPITAN L. et PEYRONY D. 1912 - Trois nouveaux squelettes humains fossiles. Revue anthropologique, 1912, 22(11), p. 439-442.

CAPLAN P. (Ed.) 1987 - The cultural construction of sexuality. London: Tavistock, 1987. 
CAREY M. 1986 - Beads and Beadwork of East and South Africa. Aylesbury: Shrire, 1986.

CAREY M. 1991 - Beads and Beadwork of West and Central Africa. Aylesbury: Shrire, 1991.

CARR, C. 1995 - Mortuary Practices: their social, philosophical-religious, circumstancial, and physical determinants. Journal of Archaeological Methodand Theory, 1995, 2, p. 105-200.

CECI L. 1982 - The Value of wampum among the New York Iroquois: A case study in artefact analysis. Journal of anthropological Research, 1982, 38(1), p. 97-107.

CLOTTES J. et LEWIS-WILLIAMS, D. 1996. Les chamanes de la Préhistoire. Transe et Magie dans les grottes ornées. Paris : Editions du Seuil, 1996.

CONKEY M. 1984 - To find ourselves social geography of prehistoric huntergatherers. In: Schrire

C. (Ed.), Past and Present in Hunter-GathererStudies. New York: Academic Press, 1984, p. 253-276.

CONKEY M. 1987 - New approaches in the search for meaning? A review of research of

"Palaeolithic art". Journal of Field Archaeology, 1987, 14, p. 413-430.

CONKEY M. 1992 - Les sites d'agrégation et la répartition de l'art mobilier, où y a-t-il des sites d'agrégation magdaléniens? In : Le peuplement magdalénien : paléographie physique et humaine. Actes du colloque de Chancelade 10-15 octobre 1988. Paris : CTHS, 1992, p. 19-25.

CORCHON R.S. 1986 - El Arte mueble Paleolitico Cantabrico : contexto yanalisis interno. Madrid : Ministerio de Cultura. (Monografias Centro de investigacion y Museo de Altamira 16)

CORWELL J. et SCHWARZ R.A. (Eds.) 1979 - The fabrics of culture: theanthropology of clothing and adornment. Paris : Mouton, 1979.

COSTAMAGNO S. 1999 - Stratégies de Chasse et Fonction des Sites au Magdalénien dans le Sud de la France. Talence : IPGQ, 1999. (Thèse de Doctorat, Université Bordeaux I)

COSTAMAGNO S. 2001 - Exploitation de l'antilope saïga au Magdalénien en Aquitaine, Paléo, 2001, 13, p. 111-128.

COURTY A. 1957 - Gravures sur rocher à Saint-Germain-la-Rivière. Revue Historique et Archéologique du Libournais, 1957, 30 (83), p. 30.

D'ERRICO F. 1993a - Identification des traces de manipulation, suspension, polissage sur des objets d'art mobilier en os, bois de cervidés, ivoire. In : Traces et fonction : les Gestes Retrouvés. Liège : ULg, 1993, p. 177-188. (ERAUL 50)

D'ERRICO F. 1993b - La vie sociale de l'art mobilier paléolithique. Manipulation, transport, suspension des objets en os, bois de cervidés, ivoire. Oxford Journal of Archaeology, 1993, 12(2), p. $145-174$.

D'ERRICO F. 1998 - Palaeolithic origins of artificial memory systems: an evolutionary perspective. In: Renfrew C. et Scarre C. (Eds.), Cognition andMaterial Culture: the Archaeology of Symbolic Storage. Cambridge : McDonald Institute, 1998, p. 19-50. (McDonald Institute Monographs)

D'ERRICO F. et VANHAEREN M. 1999 - Les méthodes d'analyse de l'art mobilier paléolithique. Anthropologie et Préhistoire, 1999, 110, p. 31-46.

D'ERRICO F. et VANHAEREN M. 2000 - Mes morts et les morts de mes voisins. Le mobilier funéraire de l'Aven des Iboussières et l'identification de marqueurs culturels à l'Epipaléolithique. In : Epipaléolithique et Mésolithique : Les derniers chasseurs-cueilleurs d'Europe occidentale. Actes du colloque international de Besançon, octobre 1998. Besançon : Presses Universitaires FrancComtoises, 2000, p. 325-342. 
D'ERRICO F. et VANHAEREN M. 2002 - Criteria for identifying red deer (Cervus elaphus) age and sex from upper canines. Application to the study of Upper Palaeolithic and Mesolithic ornaments. Journal of Archaeological Science, 2002, 29 : 211-232.

DELPECH F. 1983 - Les faunes du Paléolithique supérieur dans le Sud-Ouest de la France. Paris : CNRS, 1983. (Cahier du Quaternaire, 6)

DELPECH F. et VILLA P. 1993 - Activités de chasse et de boucherie dans la Grotte des Eglises (Ariège). In : Exploitation des animaux sauvages à travers le temps. XIIIe Rencontres Internationales d'Archéologie et d'Histoire d'Antibes. Juan-les-Pins : APDCA, 1993, p. 79-102.

DELPECH F., DONARD E., GILBERT A., GUADELLI J.-L., LE GALL O., MARTINI-JACQUIN A., PAQUEREAU M.-M., PRAT F. et TOURNEPICHE J.-F. 1983 - Contribution à la lecture des paléoclimats quaternaires d'après les données de la paléontologie en milieu continental. Quelques exemples de flore et de faune d'Ongulés pris dans le Pléistocène supérieur. In: Actes du Colloque AGSO, Bordeaux, Mai 1983. Bordeaux : CNRS, 1983. (Cahiers du Quaternaire 34)

DESY P. 1978 - L'Homme-femme (Les berdaches en Amérique du Nord). Libre 3: 57-102.

DONALD L. 1997 - Aboriginal slavery on the Northwest Coast of NorthAmerica. Berkeley: University of California Press, 1997.

DUBIN L.S. 1987 - The History of Beads. From 30,000 B.C. to the Present. London: Thames and Hudson, 1987.

DUBIN L.S. 1999 - North American Indian Jewelry and Adornment. New York: Harry N. Abrams, 2003. DUBOURG C. 1997 - Les expressions du naturalisme dans les arts graphiques du Paléolithique supérieur. Une vision du monde des chasseurs préhistoriques. Talence : IPGQ, 1997. (Thèse de Doctorat, Université Bordeaux I)

FARIS J.C. 1972 - Nuba personal art. London : G. Duckworth, 1972.

FEBLOT-AUGUSTIN J. et PERLES C. 1992 - Perspectives ethnoarchéologiques sur les échanges à longue distance. In : Ethnoarchéologie. Justification, problèmes, limites. XIIe Rencontres Internationales d'Archéologie et d'Histoire d'Antibes. Juan-les-Pins : APDCA, 1992, p. 195-209.

FONTANA L. 1999 - Mobilité et subsistance au Magdalénien dans le Languedoc occidental et le Rousillon. Bulletin de la Société Préhistorique Française, 1999, 96(2), p. 175-190.

FRITZ C. et SIMONNET R. 1996 - Du geste à l'objet : les contours découpés de Labastide : résultats préliminaires. Techne, 1996, 3, p. 63-77.

FRITZ C. 1999 - La gravure dans l'art mobilier magdalénien. Du geste à la représentation. Paris : Maison des sciences de l'Homme, 1999. (DAF 75)

GARDE J.A. 1934 - Inventaire des découvertes préhistoriques faites dans le Libournais (région de Sainte-Foy-la-Grande exceptée). Revue Historique et Archéologique du Libournais, 1934, 6, p. 55-64.

GARDE J.A. 1945 - Notes. Revue Historique et Archéologique du Libournais, 1945, 13, p. 36.

GARDE J.A. 1946 - La Préhistoire régionale au Musée de la Société Historique et Archéologique de Libourne. Revue Historique et Archéologique du Libournais, 1946, 48, p. 47-53.

GARDE J.-A. 1969 - La découverte du gisement de Saint-Germain-la-Rivière. Revue Historique et Archéologique du Libournais, 1969, 37(132), p. 49-51.

GAUTHIER A. 1986 - Une histoire de dents : les soi-disant incisives travaillées du Paléolithique moyen de Sclayn. Helinium, 1986, 26, p. 177-181. 
GODELIER M. 1996. L'Enigme du Don. Paris : Fayard, 1996.

HARDY M. 1888 - Découverte d'une sépulture de l'époque quaternaire à Raymonden, commune de Chancelade. Comptes rendus des séances de l'Académie des Sciences, 1888, p. 1025-1026.

HENRY-GAMBIER D. (Ed.) 2001. La sépulture des Enfants de Grimaldi (Baoussé-Roussé, Italie) : Anthropologie et palethnologie funéraire des populations de la fin du Paléolithique supérieur. CTHS : Paris, 2001. (Documents préhistoriques 14)

HENRY-GAMBIER D. et LENOIR M. 1991. Les vestiges humains du Paléolithique supérieur en Gironde. Bulletin de la Société Anthropologique du Sud-Ouest, 1991, XXVI(1), p. 1-31.

HENRY-GAMBIER D., BRUZEK J., MURAIL P. ET HOUET F. 2002 - Estimation du sexe du squelette magdalénien de Saint-Germain-la-Rivière (Gironde, France). Paléo, 2002, 14, p. 205-212.

HENRY-GAMBIER D., VALLADAS H., TISNERAT-LABORDE N., ARNOLD M. et BESSON F. 2000 -

Datation de vestiges humains présumés du Paléolithique supérieur par la méthode du carbone 14 en spectrométrie de masse par accélérateur. Paléo, 2000, 12, p. 201-212.

HEWLETT B.S., VON DE KOPPEL J. ET CAVALLI-SFORZA L.L. 1986 - Exploration and Mating Range of Aka Pygmies of the Central African Republic. In: Cavalli-Sforza L.L. (Ed.), African Pygmies. New York: Academic Press, 1986, p. 65-79.

HODDER I. 1979 - Economic and social stress and material culture patterning. American Antiquity, 1979,44, p. 446-454.

HODDER I. 1991 - The Meanings of Things. Material Culture and Symbolic Expression. London: Harper Collins, 1991.

INGOLD T., RICHES D. ET WOODBURN J. 1991 - Hunters and gatherers. Property, Power and Ideology. Oxford : Berg, 1988.

JULIEN M. et RIEU J.-L. (Eds.) 1999 - Occupations du Paléolithique supérieur dans le sud-est du Bassin parisien. Paris : MSH, 1999. (Documents d'Archéologie Française 28)

JULIEN M. et al. 1988 - Organisation de l'espace et fonction des habitats magdaléniens du Bassin parisien. In : Otte M. (Ed.), De la Loire à l'Oder. Les civilisations du Paléolithique final dans le nord-ouest européen. Actes du Colloque de Liège. Oxford : BAR International Series, 1988, 444, volume I, p. 81-123.

KELLY R.L. 1983 - Hunter-Gatherer Mobility Strategies. Journal ofAnthropological Research, 1983, 39, p. 277-306.

KELLY R.L. 1995 - The Foraging Spectrum: Diversity in Hunter-GathererLifeways. Washington DC: Smithsonian Institution Press, 1995.

KLEIN R.G. 1982 - Age (mortality) profiles as a means of distinguishing hunted species from scavenged ones in the Stone Age archeological sites. Paleobiology 8 (2): 152-158.

KLEIN R.G. et CRUZ-URIBE K. 1982 - The computation of ungulate age (mortality) profiles from dental crown heights. Paleobiology, 1982, 9(1), p. 70-78.

KOYAMA S. et THOMAS D. (Eds.) 1981 - Affluent Foragers: Pacific CoastsEast and West. Osaka: National Museum of Ethnology, 1981. (Senri Ethnological Studies, 9)

KROEBER A.L. 1925 - Handbook of the Indians of California. Washington: Bureau of American Ethnology, 1925. (bulletin 78)

KUPER H. 1973 - Costume and identity. Comparative studies in society andhistory, 1973, 15, p. 348-367. 
LADIER E. et WELTE A.C. 1994 - Les Bijoux de la Préhistoire. La parure Magdalénienne dans la vallée de l'Aveyron. Montauban, Toulouse : Museum d'Histoire Naturelle, 1994.

LE MORT F. 1985. Un exemple de modification intentionnelle : La dent humaine perforée de Saint-Germain-la-Rivière (Paléolithique supérieur). Bulletin de la Société préhistorique française, 1985, 82(6), p. 190-192.

LEE R.B. et DEVORE I. (Eds.) 1968 - Man the Hunter. Chicago : Aldine Publishing Company, 1968.

LENOIR M. 1983 - Le Paléolithique des Basses Vallées de la Dordogne. Talence : Université Bordeaux I, 1983. (Thèse de Doctorat d'Etat)

LENOIR M. 1997 - Saint-Germain-la-Rivière : Pillebourse. Gallia Information, 1997, 97, p. 68.

LENOIR M., MARMIE F. et TRECOLLE G. 1991 - Données nouvelles sur les industries de SaintGermain-la-Rivière (Gironde). In : 25 Ans d'études technologiques en Préhistoire. XIe Rencontres Internationales d'Archéologie et d'Histoire d'Antibes. Juan-les-Pins : APDCA, 1991, p. 245-254.

LENOIR M., MARMIE F. et TRECOLLE G. 1994 - Le gisement magdalénien de Saint-Germain-laRivière (Gironde) : données anciennes et acquis récents. Revue archéologique de Bordeaux, 1994, 85, p. 39-72.

LENOIR M., MARMIE F. et TRECOLLE G. 1995 - Fouilles préhistoriques de Saint-Germain-la-Rivière. Bulletin de la Société d'Anthropologie du Sud-Ouest (Nouvelles Etudes), 1995, 25(3-4), p. 133-153.

LEPRONT R. et MIRANDE H. 1933 - Le gisement de Saint-Germain-la-Rivière (sa découverte). Revue d'Histoire et d'Archéologie du Libournais, 1933, 36, p. 197-209.

LEROI-GOURHAN A. 1965 - Préhistoire de l'Art Occidental. Paris : Mazenod, 1965.

LEROI-GOURHAN A. et BREZILLON M. 1966 - L'habitation magdalénienne ${ }^{\circ} 1$ de Pincevent, près de Montereau (Seine-et-Marne). Gallia Préhistoire, 1966, 9(2), p. 263-371.

LEROI-GOURHAN A. et BREZILLON M. 1972 - Fouilles de Pincevent : essai d'analyse ethnographique d'un habitat magdalénien (la section 36). Paris: CNRS, 1972. (VIIe suppléments à “ Gallia Préhistoire ")

LEWIS-WILLIAMS D. et DOWSON T. 1988 - The Signs of All Times: Entoptic Phenomena in Upper Palaeolithic Art. Current Anthropology, 1988, 29(2), p. 201-245.

LIPS J.E. 1947 - Naskapi law (Lake St. John and Lake Mistassini bands): law and order in a hunting society. Transactions of the American PhilosophicalSociety N.S., 1947, 37(4), p. 379-492.

LORBLANCHET M. 1995. Les grottes ornées de la préhistoire. Nouveaux regards. Paris : Errance, 1995.

LORBLANCHET M. 1997 - La naissance de l'art. Genèse de l'art préhistorique. Paris : Errance, 1997.

MASSENAT E., LALANDE P. et CARTAILHAC E. 1872 - Découverte d'un squelette humain de l'âge du Renne à Laugerie-Basse (Dordogne). Matériaux pour l'Histoire de l'Homme, 1872, p. 224-228.

MATHIEU N.-C. 1991 - Différentiation des sexes. In : Bonte P. et Izard M. (Eds.), Dictionnaire de l'ethnologie et de l'anthropologie. Paris : PUF, 1991, p. 660-664.

MAY F. 1986 - Les sépultures préhistoriques. Paris : CNRS, 1986.

MCCLORMACK C.P. et STRATHERN M. (Eds.) 1980 - Nature, culture andgender. Cambridge: Cambridge University Press, 1980.

MEAD M. 1948 - Male and female. A study of the sexes in a changing world. New York: William Morrow, 1948. 
MEISCH L. A. 1998 - Why Do they Like Red? Beads, Ethnicity and Gender in Ecuador. In: Sciama L.D. et Eicher J.B. (Eds), Beads and Beadmakers: Gender, Material Culture and Meaning. Oxford : Berg, 1998, p. 147-177.

MUSSI M., FRAYER D.W. et MACCHIARELLI R. 1989. Les vivants et les morts. Les sépultures du Paléolithique supérieur en Italie et leur interprétation. In: Hershkovitz (Ed.), Proceedings of the Second Symposium on UpperPalaeolithic, Mesolithic and Neolithic Populations of Europe and theMediterranean Basin, part II. Oxford: BAR International Series508, 1989, p. 435-458.

NEIMAN F. 1998 - Conspicious consumption as wasteful advertising: a Darwinian perspective on spatial patterns in Classic Maya terminal monument dates. In: BARTON C.M. et CLARK G.A. (Eds.), Rediscovering Darwin: evolutionary theorie and archaeological explanation. Archaeological papers of the AAA no. 7. Washington D.C.: AAA, 1998, p. 267-290.

NOOTER G.W. 1979 - Leadership and headship. Changing authority patterns in an East Greenland hunting community. Mededelingen van het Rijksmuseumvoor Volkenkunde (Leiden), 1979, 20, p. 1-117.

O'HEAR A. 1998 - Lantana Beads: Gender Issues in their Production and Use. In: Sciama L.D. et Eicher J.B. (Eds). Beads and Beadmakers: Gender, MaterialCulture and Meaning. Oxford: Berg, 1998, p. 117-128.

O'SHEA J. 1984 - Mortuary Variability: an archaeological investigation. New-York: Academic Press, 1984.

ORTNER S.B. et WHITEHEAD H. (Eds.) 1981 - Sexual meanings. The cultural construction of gender and sexuality. Cambridge : Cambridge University Press, 1981.

OUZRIT L. 1986 - Recherches sur les faunes du Dryas ancien en Gironde. Le gisement de Saint-Germain-laRivière. Talence : IPGQ, 1986. (Thèse de Doctorat, Université Bordeaux I)

PARKINGTON J. 1989 - Interpreting paintings without a commentary. Antiquity, 1989, 63, p. 13-26.

PIGEOT N., PHILIPPE M., LE LICON G. et MORGENSTERN M. 1991 - Systèmes techniques et essai de technologie culturelle à Etiolles : nouvelles perspectives. In : 25 ans d'études technologiques. Actes des XIe Rencontres Internationales d'Archéologie et d'Histoire d'Antibes. Juan-les-Pins : ACDCA, 1991, p. 159-168

POPLIN F. 1983 - Les dents travaillées de renne et autres anomaux du Petersfels. In : ALBRECHT G., BERKE H. et POPLIN F. (Eds.), Recherches scientifiques sur les inventaires Magdaléniens du Petersfels, fouilles 1974-1976. Tübingen : Universität Tübingen, 1983, p. 133-153. (Tübinger Monographien zur Urgeschichte 8)

PRESTON-WHYTE E. 1994 - Speaking with Beads. London: Thames and Hudson, 1994.

PRICE S. 1991 - Parure. In : Bonte P. et Izard M. (Eds.), Dictionnaire de l'ethnologie et de l'anthropologie. Paris: PUF, 1991, p. 560-561.

PRICE T.D. et BROWN J. (Eds.) 1985 - Prehistoric Hunter-Gatherers: theemergence of Cultural Complexity. New York: Academic Press, 1985.

PRICE T.D. et FEINMAN G.M. (Eds.) 1995 - Foundations of SocialInequality. New York: Plenum Press, 1995.

RAY D. J. 1975 - The Eskimos of Bering Strait 1650-1898. Seattle: University of Washington Press, 1975.

RIQUET R. 1959 - La femme magdalénienne de Saint-Germain-la-Rivière. Revue Historique et Archéologique du Libournais, 1959, 27, p. 65-68. 
ROACH M.E. et EICHER J.B. (Eds.) 1965 - Dress, adornment and social order. New York: J. Wiley, 1965.

ROGERS E.S. 1965 - Leadership among the Indians of eastern and sub-arctic Canada.

Anthropologica, 1965, 7, p. 263-284.

SACCHI D. 1986 - Le Paléolithique supérieur du Languedoc occidental et du Roussillon. Paris : CNRS, 1986. (XXIe supplément à “ Gallia Préhistoire ”)

SCIAMA L.D. et EICHER J.B. (Eds.) 1998 - Beads and Beadmakers: Gender, Material Culture and Meaning. Oxford : Berg, 1998.

SERONIE-VIVIEN M.-R. 1995 - La grotte de Pégourié, Caniac-du-Causse (Lot). Préhistoire quercinoise, 1995, supplément 2.

SERVICE E.R. 1962 - Primitive Social Organisation. An evolutionary Perspective. New York: Random House, 1962.

SERVICE E.R. 1966 - The Hunters. Englewood Cliffs: Prentice Hall Inc, 1966.

SLOBODIN R. 1969 - Leadership and participation in a Kutchin trapping party. In: Damas D. (Ed.), Contributions to Anthropology: Band Societies. Gatineau: Musée canadien des civilisations, 1969, p. 56-89. (National Museums of Canada Bulletin 228)

SLOTT-MOLLER R. 1988 - Contribution à l'étude paléontologique d'un gisement préhistorique : l'exemple du Roc de Marcamps (Gironde). Talence: IPGQ. (Mémoire de DESS de l’Université Bordeaux I)

SMITH E.A. et BLIEGE-BIRD R.L. 2000 - Turtle hunting and tombstone opening: public generosity as costly-signaling. Evolution and Human Behavior, 2000, 14 (1), p. 116-126.

SONNEVILLE-BORDES D. de 1960 - Le Paléolithique supérieur en Périgord. Bordeaux: Delmas, 1960.

STEWARD J.H. 1955 - Theory of Culture Change. Urbana: University of Illinois Press, 1955.

STINER M.C. 1994 - Honor among Thieves: a Zooarchaeologi-cal Study of NeanderthalEcology. Princeton: Princeton University Press, 1994.

STRATHERN A. et STRATHERN M. 1971 - Self-decoration in Mount Hagen. London : G. Duckworth, 1971.

TABORIN Y. 1993 - La parure en coquillage au Paléolithique. Paris : CNRS (XXIXe suppléments à Gallia Préhistoire).

TABORIN Y. (Ed.) 1994 - Environnements et habitats magdaléniens dans le centre du Bassin parisien. Paris: Maison des Sciences de l'Homme, 1994. (daf 43)

TAINTER J.R. 1978 - Mortuary practices and the study of prehistoric social systems. Archaeological Method and Theory, 1978, 1, p. 105-141.

TESTART A. 1981 - Pour une typologie des chasseurs-cueilleurs. Anthropologie et Sociétés, 1981, 5, p. $177-221$.

TESTART A. 1982a - Les chasseurs-cueilleurs ou l'origine des inégalités. Paris: Société d'Ethnographie, 1982.

TESTART A. 1982b - The significance of food storage among hunter-gatherers: residence patterns, population densities, and social inequalities. Current Anthropology, 1982, 23, p. 523-537.

TESTART A. 1996 - Le prix de la fiancée et autres prestations destinées aux parents de l'épouse dans quelques sociétés primitives. Annales de la Faculté de Droit de Clermont-Ferrand, 1996, 32, p. 235-267. 
TESTART A. 2000 - Que peut dire aujourd'hui l'anthropologie sociale des chasseurs-cueilleurs d'hier ? In : In : Epipaléolithique et Mésolithique: Les derniers chasseurs-cueilleurs d'Europe occidentale. Actes du colloque international de Besançon, octobre 1998. Besançon : Presses Universitaires Franc-Comtoises, 2000, p. 343-349.

TESTART A. 2001 - Deux Polithiques funéraires. Texte de Conférence tenue à l'Institut Français de Porto en Janvier 2001.

TESTART A. 2003 - Introduction générale au colloque. Communication présentée au Colloque “ Pratiques funéraires et sociétés", Sens, 12-14 juin 2003.

TURNER T. 1980 - The Social Skin. In: Cherfas J. et Lewin R. (Eds.), Not Work Alone: cross-cultural accounts of activities superfluous to survival. London: Temple Smith, 1980, p. 112-140.

UTRILLA P. 1982 - El yacimiento de la cuava de Abauntz (Arraiz, Navarra). Trabajos de Arqueologia Navarra, 1982, 3, p. 203-345.

VANHAEREN M. 2002 - Les fonctions de la parure au Paléolithique supérieur : de l'individu à l'unité culturelle. Talence : IPGQ, 2002. (Thèse de Doctorat, Université Bordeaux I)

VANHAEREN M. et D'ERRICO F. 2001 - La parure de l'enfant de La Madeleine (fouilles Peyrony). Un nouveau regard sur l'enfance au Paléolithique supérieur. Paléo, 2001, 13, p. 201-237.

VANHAEREN M. et D'ERRICO F. 2003a - Childhood in the Epipaleolithic. What do personal ornaments associated to burials tell us? In: Larsson L. et al. (Eds.), Mesolithic onthe Move. Proceedings of the 6th International Conference on the Mesolithic in Europe (Stockholm, 4-8 Septembre 2000). Oxford: Oxbow Books, 2003, p. 494-505.

VANHAEREN M. et D'ERRICO F. 2003b - The Body Ornaments Associated with the Burial. In: Zilhao J. et Trinkaus E. (Eds.), Portrait of the Artist as a Child. The Gravettian human skeleton from the Abrigo do Lagar Velho and its archaeological context. Lisbonne : Instituto Portugues de Archeologia, 2003, p. 154-186. (Trabalhos de Arqueologia 22)

VIALOU D. 1987 - L'art des cavernes. Paris : Le Rocher, 1987.

WHITE R. 1999. Intégrer la complexité sociale et opérationnelle : la construction matérielle de l'identité sociale à Sungir. In : Préhistoire d'os. Recueil d'études sur l'industrie osseuse préhistorique offert à Henriette Camps-Faber. Aix-en-Provence: Publications de l'Université de Provence, 1999, p. 319-331.

WHITEHEAD H. 1981 - The bow and the burden strap: a new look at institutionalized homosexuality in native North America. In: Ortner S.B. et Whitehead H. (Eds.), Sexual meanings. The cultural construction of gender and sexuality. Cambridge: Cambridge University Press, 1981.

WIESSNER P. 1984 - Reconsidering the Behavioral Basis for Style: A Case Study among the Kalahari San. Journal of Anthropological Archaeology, 1984, 3, p. 190-234.

WILLIAMS B.J. (Ed.) 1974 - A Model of Band Society. Washington D.C.: Society for American Archaeology, 1974. (Memoirs of the Society for American Archaeology 29)

WOBST H.M. 1976. Locational relationships in Palaeolithic society. Journal of HumanEvolution, 1976, 5, p. 49-58.

ZILHÃO J. et TRINKAUS E. 2002. Social Implications. In: Zilhão J. et Trinkaus E. (Eds.), Portrait of the Artist as a Child. The Gravettian Human Skeleton from the Abrigo do LagarVelho and its Archeological Context. IPA : Lisbonne, 2002. (Trabalhos de Arqueologia 22) 


\section{NOTES}

1. Les deux méthodes ont été établies à partir de 300 craches de cerf d'âge et de sexe connus provenant de deux populations de Cerf, celle de l'île de Rhum (Ecosse) et celle du Parc Royal de Richmond (Angleterre). La première méthode se base sur le degré d'usure de la surface occlusale et le croisement de cette information avec celle fournie par quatre autres variables qualitatives. La deuxième méthode estime l'âge en utilisant une équation de régression multiple qui prend en compte six variables morphométriques pour les mâles (longueur et largeur de la couronne, de la racine et de la facette d'usure occlusale) et cinq variables morphométriques pour les biches (longueur, largeur et épaisseur de la couronne, longueur et largeur de la facette d'usure).

2. Il est difficile d'établir si les trois craches biforées appartenaient à la sépulture. Contrairement aux autres, elles ne portent pas de traces d'ocre. De plus, le sédiment marron adhérant à l'une d'elles (fig. 9, $\mathrm{n}^{\circ}$ 9) est fort différent du colorant présent sur les craches avec une seule perforation. Le décompte des craches donné par Blanchard semble également contredire leur association à la sépulture. Cet auteur mentionne 70 craches tandis que nous en avons, avec les biforées et celle figurée par Blanchard mais depuis perdue, 72. Si on enlève les trois craches biforées, on retrouve un nombre (69) proche de celui indiqué par Blanchard auquel s'ajoutait probablement la pendeloque en stéatite, non mentionnée par Blanchard dans son décompte et considérée vraisemblablement par cet auteur comme une crache. Il est possible que les craches biforées proviennent des collections Blanchard ou Mirande et qu'elles aient été incluses dans le mobilier funéraire par erreur. Dans le dernier cas, ce mélange pourrait avoir eu lieu lors de l'exposition conjointe des deux collections à Libourne en 1969. Il n'est peut-être pas anodin que toutes les craches biforées présentes dans la collection du Musée des Eyzies soient cassées, ce qui rend difficile de les distinguer à première vue de celles avec une seule perforation et a pu faciliter le mélange. L'hypothèse que les craches biforées de la sépulture pourraient provenir du collier Mirande semble cependant contredite par le fait que le nombre de craches composant ce collier correspond à celui de son premier inventaire. La différence dans le mode d'aménagement ne peut être invoquée pour soutenir que les craches biforées ne peuvent pas appartenir à la sépulture. Un exemple ethnographique en est fourni par la parure de Rosy White Thunder, une femme Sioux photographiée autour de 1890 (fig. 38), qui comprend à la fois des craches mono- et biforées. Aucun argument ne permet donc à ce jour d'inclure ou d'exclure définitivement les trois craches biforées du mobilier funéraire de Saint-Germain-la-Rivière.

\section{RÉSUMÉS}

L'analyse archéozoologique et technologique du mobilier funéraire de la Dame de Saint-Germainla-Rivière $(15570 \pm 200 \mathrm{BP})$ et sa comparaison avec les objets de parure et la faune découverts dans ce même gisement ainsi que dans les sites et sépultures contemporains révèlent le caractère exceptionnel de cette inhumation. Le grand nombre de craches perforées et la préférence pour des craches de jeunes cerfs mâles qui caractérisent le mobilier de la sépulture contrastent avec l'extrême rareté de cette espèce dans les sites contemporains du Sud-Ouest de la France. La rareté et l'origine probablement exotique des craches, le faible nombre de craches appariées et l'homogénéité technique et morphologique de la collection suggèrent que ces dents ont été acquises par échange sur longue distance et qu'elles devaient représenter des objets de prestige. A l'instar de ce que l'on observe chez certaines populations de chasseurs-cueilleurs et en 
contradiction avec le caractère supposé égalitaire des sociétés paléolithiques, ces objets pourraient avoir été utilisés pour marquer l'appartenance de cette femme à un groupe social privilégié.

Archaeozoological and technological analysis of the grave goods associated to the Saint-Germainla-Rivière burial (15 $570 \pm 200 \mathrm{BP})$ and their comparison with ornaments and faunal assemblages from contemporary Magdalenian sites and burials reveal the exceptional character of this inhumation. The great number of perforated red deer canines and the preference for teeth from young stags contrast with the virtual absence of red deer in south-western France faunal assemblages dated to the same period as the burial. The rarity and probable exotic origin of these teeth, the small number of paired canines, and the technological and morphological homogeneity of the collection suggest that the teeth were obtained through long distance trade and represented prestige items. As observed in a number of hunter-gatherer populations and in disagreement with the supposed egalitarian character of Upper Palaeolithic societies, these items may have materialised the integration of this individual into a privileged social group.

\section{INDEX}

Mots-clés : parure, craches de cerf, sépultures, technologie préhistorique, Magdalénien, objets de prestige, réseaux d'échange, stratification sociale

Keywords : ornaments, red deer canines, burials, prehistoric technology, Magdalenian, prestige items, exchange networks, social ranking

\section{AUTEURS}

\section{MARIAN VANHAEREN}

Université de Bordeaux 1 - Institut de Préhistoire et de Géologie du Quaternaire - UMR 5808 Avenue des Facultés - F-33405 Talence cedex. mel : vanhaere@mae.u-paris10.fr

\section{FRANCESCO D'ERRICO}

Université de Bordeaux 1 - Institut de Préhistoire et de Géologie du Quaternaire - UMR 5808 -

Avenue des Facultés - F-33405 Talence cedex. mel : f.derrico@ipgq.u-bordeaux.fr 